\title{
Growth, development and differentiation: a functional food science approach
}

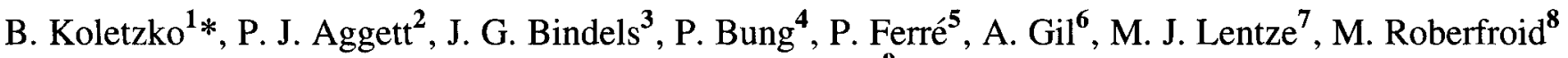 \\ and S. Strobel' \\ ${ }^{1}$ Kinderpoliklinik, Klinikum Innenstadt der Ludwig-Maximilians-Universität, Pettenkoferstr. 8a, D-80336 München, Germany \\ ${ }^{2}$ Institute of Food Research, Norwich Laboratory, Norwich Research Park, Colney, Norwich NR4 7UA, UK \\ ${ }^{3}$ Nutricia Research, Verenigde Bedrijven Nutricia NV, PO Box 1, NL-2700 MA Zoetermeer, The Netherlands \\ ${ }^{4}$ University of Bonn, Women's Hospital, Sigmund-Freud-Strasse 25, D-53105 Bonn, Germany \\ 5 INSERM, Unité 465, Centre Biomédical des Cordeliers, 15, rue de l'Ecole de Médecine, F-75270 Paris, France \\ ${ }^{6}$ University of Granada, School of Pharmacy, Department of Biochemistry and Molecular Biology, Campus of Cartuja, \\ E-18071 Granada, Spain \\ ${ }^{7}$ University of Bonn, Children's Hospital, Adenauerallee 119, D-53113 Bonn, Germany \\ ${ }^{8}$ UCL, Ecole de Pharmacie, Tour Van Helmont, Avenue E. Mounier, B-1200 Brussels, Belgium \\ ${ }^{9}$ Clinical Sub-Dean's Office, Institute of Child Health, 30 Guilford Street, London WCIN 1EH, UK
}

\section{Contents}

1. Introduction

2. Nutrient-gene interaction, genetic regulation

2.1. Introduction

2.2. Modulation of gene expression participates in the adaptations of energy metabolism

2.3. Examples of gene regulation by nutrients

2.3.1. Carbohydrates

2.3.2. Fatty acids

2.3.3. Cholesterol

2.3.4. Amino acids

2.4. Nutrients and cell differentiation

2.4.1. Fatty acids

2.4.2. Retinoic acid

2.5. Concluding remarks

3. An overview of programmed cell death (apoptosis)

4. Supply of food ingredients before and during pregnancy

4.1. Physiological aspects of nutritional requirements in pregnancy

4.1.1. Energy

4.1.2. Protein

4.1.3. Carbohydrates

4.1.4. Lipids

4.1.5. Vitamins, minerals and trace elements

5. Modulation of growth

5.1. Introduction

5.2. Methods for the determination of growth

5.3. Growth factors in human milk and their influence on infant growth

5.4. Potential roles of non-protein nitrogen compounds as growth modulators
S7

S7

S7

$\mathrm{S} 8$

S8

S8

S9

S9

S9

S10

S10

S10

S10

S10

$\mathrm{S} 12$

$\mathrm{S} 12$

S12

S13

S13

S13

S14

S15

S15

S15

S16

S16
5.5. Human milk oligosaccharides and growth

5.6. Free amino acids and tissue growth

5.7. Polyamines and tissue growth

5.8. Dietary nucleotides and tissue growth 5.8.1. Nucleotides and small intestine growth 5.8.2. Nucleotides and liver growth

5.9. Long-chain polyunsaturated fatty acids and cell growth

5.10. Early growth and later obesity

6.1 Introduction gastrointestinal tract

6.2. Development of sugar hydrolases and transporters S18

6.3. Biosynthesis of intestinal brush-border membrane hydrolases

6.4. Intestinal absorption of glucose and fructose

6.5. Oligosaccharides and mucins

6.6 Probiotic substances in milk or milk substitutes S21

6.7. Dietary regulation of xenobiotic metabolism S21

7. Development of the immune system $\quad$ S21

7.1. Introduction

7.1.1. Which constituents of the immune system to investigate?

7.1.2. Special considerations for the immune system of the developing child

7.2. Antioxidants and vitamins

7.2.1. In general

7.2.2. Vitamin $A$

7.2.3. Vitamin $C$

7.2.4. Vitamin $B$ complex

7.2.5. Vitamin $E$

7.2.6. Vitamin $D$
S21

S16

S16

S17

S17

S17

S18

18

18

21

\footnotetext{
Abbreviations: APRT, adenosine phosphoribosyltransferase; cDNA, complementary DNA; DEXA dual-energy X-ray absorptiometry; DHA, docosahexaenoic acid; EFA, essential fatty acids; EGF, epidermal growth factor; GLUT, glucose transporter; hGH, human growth hormone; HGPRT, hypoxanthine phosphoribosyltransferase; HPA, hyperphenylalaninaemia; IDDM, insulin-dependent diabetes mellitus; Ig, immunoglobulin; IGF, insulinlike growth factor; LPH, lactase-phlorizin-hydrolase; MUC1, high-molecular mass glycoprotein; NPN, non-protein nitrogen; PAH, phenylalanine hydroxylase; PCD, programmed cell death; PKU, phenylketonuria; PPAR, peroxisome proliferator activated receptors; PUFA, polyunsaturated fatty acids; SGLT1, sodium-dependent glucose transporter 1; SI, sucrase-isomaltase; SPA, single-photon absorptiometry; SREBP, sterol regulatory element binding protein; XME, xenobiotic-metabolizing enzymes.

*Corresponding author: Professor B. Koletzko, fax +49 895160 3336, email: berthold.koletzko@kk-i.med.uni-muenchen.de
} 
7.3. Multiple micronutrient supplementation studies

7.4. Fatty acids

7.5. Arginine

7.6. Nucleotides

7.7. Maturation of the immune system in formula-fed $v$. breast-fed infants

7.7.1. Effects of antigen transfer via breast milk on the infant's immunity

7.7.2. Maternal diet during pregnancy and effects on the infant's immunity

7.7.3. Maternal diet during pregnancy and lactation

7.8. Role of the gut flora and probiotic bacteria in the infant's immunity and gut defence

7.8.1. Immune exclusion and elimination

7.9. Effects of formulas with protein hydrolysates on the infant's immune responses

7.10. Insulin-dependent type 1 diabetes mellitus and cow's milk exposure in infancy

8. Bone growth and mineralization

8.1. Cell biology of bone growth

8.2. Methodological aspects in bone-mass-related studies

8.3. Peak bone mass and relative risk of osteoporosis
8.4. Bone growth and mineralization in infants and young children

8.5. Calcium supplementation in children and adolescents and bone health

8.6. Nutrients other than calcium and environmental factors involved in bone growth

9. Nutrient effects on development of neural functions and behaviour

9.1. Introduction

9.2. Physiology of neural development

9.3. Nutrition and neural development 9.3.1. Protein

9.3.2. Iodine

9.3.3. Iron

9.3.4. Zinc

9.3.5. Polyunsaturated fatty acids

9.4. Early nutrition and development of taste preferences

10. Production of bioactive factors for inclusion into food products

\section{Abstract}

Few other aspects of food supply and metabolism are of greater biological importance than the feeding of mothers during pregnancy and lactation, and of their infants and young children. Nutritional factors during early development not only have short-term effects on growth, body composition and body functions but also exert long-term effects on health, disease and mortality risks in adulthood, as well as development of neural functions and behaviour, a phenomenon called 'metabolic programming'. The interaction of nutrients and gene expression may form the basis of many of these programming effects and needs to be investigated in more detail. The relation between availability of food ingredients and cell and tissue differentiation and its possible uses for promoting health and development requires further exploration. The course of pregnancy, childbirth and lactation as well as human milk composition and the short- and longterm outcome of the child are influenced by the intake of foods and particularly micronutrients, e.g. polyunsaturated fatty acids, $\mathrm{Fe}, \mathrm{Zn}$ and $\mathrm{I}$. Folic acid supplementation from before conception through the first weeks of pregnancy can markedly reduce the occurrence of severe embryonic malformations; other potential benefits of modulating nutrient supply on maternal and child health should be further evaluated. The evaluation of dietary effects on child growth requires epidemiological and field studies as well as evaluation of specific cell and tissue growth. Novel substrates, growth factors and conditionally essential nutrients (e.g. growth factors, amino acids, polyunsaturated fatty acids) may be potentially useful as ingredients in functional foods and need to be assessed carefully. Intestinal growth, maturation, and adaptation as well as long-term function may be influenced by food ingredients such as oligosaccharides, gangliosides, highmolecular-mass glycoproteins, bile salt-activated lipase, pre- and probiotics. There are indications for some beneficial effects of functional foods on the developing immune response, for example induced by antioxidant vitamins, trace elements, fatty acids, arginine, nucleotides, and altered antigen contents in infant foods. Peak bone mass at the end of adolescence can be increased by dietary means, which is expected to be of long-term importance for the prevention of osteoporosis at older ages. Future studies should be directed to the combined effects of $\mathrm{Ca}$ and other constituents of growing bone, such as $\mathrm{P}, \mathrm{Mg}$ and $\mathrm{Zn}$, as well as vitamins $\mathrm{D}$ and $\mathrm{K}$, and the trace elements $\mathrm{F}$ and $\mathrm{B}$. Pregnancy and the first postnatal months are critical time periods for the growth and development of the human nervous system, processes for which adequate substrate supplies are essential. Early diet seems to have long-term effects on sensory and cognitive abilities as well as behaviour. The potential beneficial effects of a balanced supply of nutrients such as $\mathrm{I}, \mathrm{Fe}, \mathrm{Zn}$ and polyunsaturated fatty acids should be further evaluated. Possible long-term effects of early exposure to tastes and flavours on later food choice preferences may have a major impact on public health and need to be further elucidated. The use of biotechnology and recombinant techniques may offer the opportunity to include various bioactive substances in special dietary products, such as human milk proteins, peptides, growth factors, which may have beneficial physiological effects, particularly in infancy and early childhood. 


\section{Introduction}

There are few other aspects of food supply and the metabolism of food ingredients that are of greater biological importance than the feeding of mothers during pregnancy and lactation, and of their children. The rapid growth of fetuses, infants and children, which double their body weights within only 6 weeks in utero and 4-5 months after birth respectively, depends on the supply of very large amounts of nutrients per $\mathrm{kg}$ body weight through the placenta, human milk and children's diets. Marginal nutrient supplies are usually more critical in a developing and growing organism than in steady-state situations during adulthood. The ability to effectively utilize and compensate for unbalanced supplies is severely limited in the fetus and in young children due to small endogenous stores of a number of relevant substrates, and in many cases also due to immature metabolic pathways (e.g. amino acid metabolism) and physiological functions (e.g. renal conservation of substrates). Nutritional factors during early development have important immediate and short-term effects on growth, body composition and body functions. In addition, accumulating data indicate long-term effects of nutritional and metabolic factors during critical time periods of development on later physiological and metabolic processes, a phenomenon referred to as 'metabolic programming' (Barker, 1994). For example, epidemiological studies have suggested long-term effects of intrauterine and postnatal nutrient supply on the prevalence of obesity in adulthood (Ravelli et al. 1976) and on the risk of developing diabetes, hypertension, hypercholesterolaemia, CHD, and other disorders during adult life (Barker, 1994). The rate of death from all cardiovascular disease and from CHD (Fig. 1) in adulthood was found to be significantly related to body weight at birth (Osmond et al. 1993; Barker, 1994). Standardized mortality from CHD was also closely related to weight at 1 year in males but not in females (Fig. 2). These findings indicate the potential of influencing long-term health and life expectancy by modulations of maternal diet in pregnancy and of postnatal infant feeding. Moreover, the type of postnatal infant feeding has been related to longterm outcomes such as the later incidence of insulin-dependent diabetes mellitus (IDDM) (Virtanen et al. 1991; Gerstein, 1994) and cognitive development (Lucas et al. 1992; Lanting et al. 1994), and a lasting effect of Ca intake during childhood and adolescence on bone mineral density and the risk of fractures in old age has been proposed (Ribot et al. 1995). This programming of permanent effects of the physiology and function of the organism during critical time periods of early development appears to be of major importance in preventive health strategies. Improved knowledge on the cellular and molecular mechanisms of programming and of the complex physiological and nutritional factors relevant to the health and well-being during the periods of reproduction and childhood is required. A better definition of the optimal supply of relevant nutrients and other food ingredients is expected to help optimize dietary intakes during these critical periods of life which should improve the chances that infants and children have to utilize fully their genetic potential, as well as maintain maternal health.

\section{Nutrient-gene interaction, genetic regulation}

\subsection{Introduction}

The perinatal period is attended by important modifications in energy metabolism (Girard et al. 1992). In utero, the fetus receives a continuous intravenous supply of substrates for growth and oxidative metabolism. Immediately after birth, the maternal supply of substrates ceases abruptly and the newborn has to withstand a brief period of starvation before being fed at intervals with milk, a high-fat and low-carbohydrate diet. The sucking-weaning transition is also characterized by profound changes of nutrition (Girard $e t$ al. 1992). Towards the end of the sucking period, the milk is progressively replaced by the solid food diet of the adult, the composition of which is usually lower in fat and higher in carbohydrates. The successful adaptation of neonates to these changes in nutrition requires important modifications

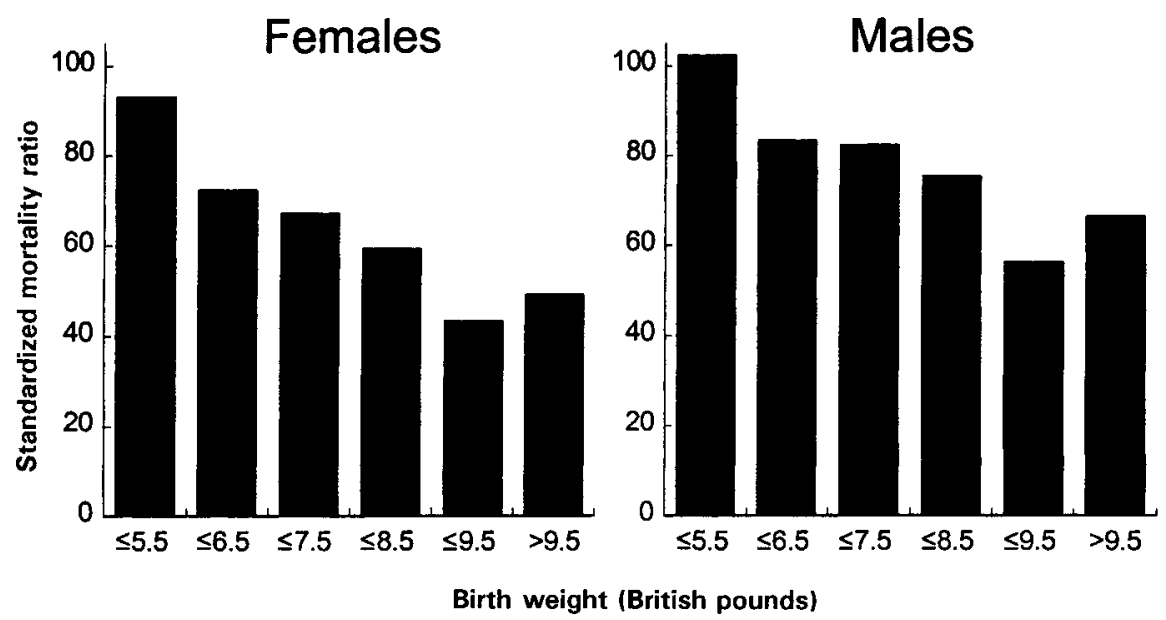

Fig. 1. Standardized mortality ratios for $\mathrm{CHD}$ below age 65 years, showing a statistically significant relationship with birth weight in 5585 women and 10141 men born between 1911 and 1930. (Data from Barker, 1994.) 


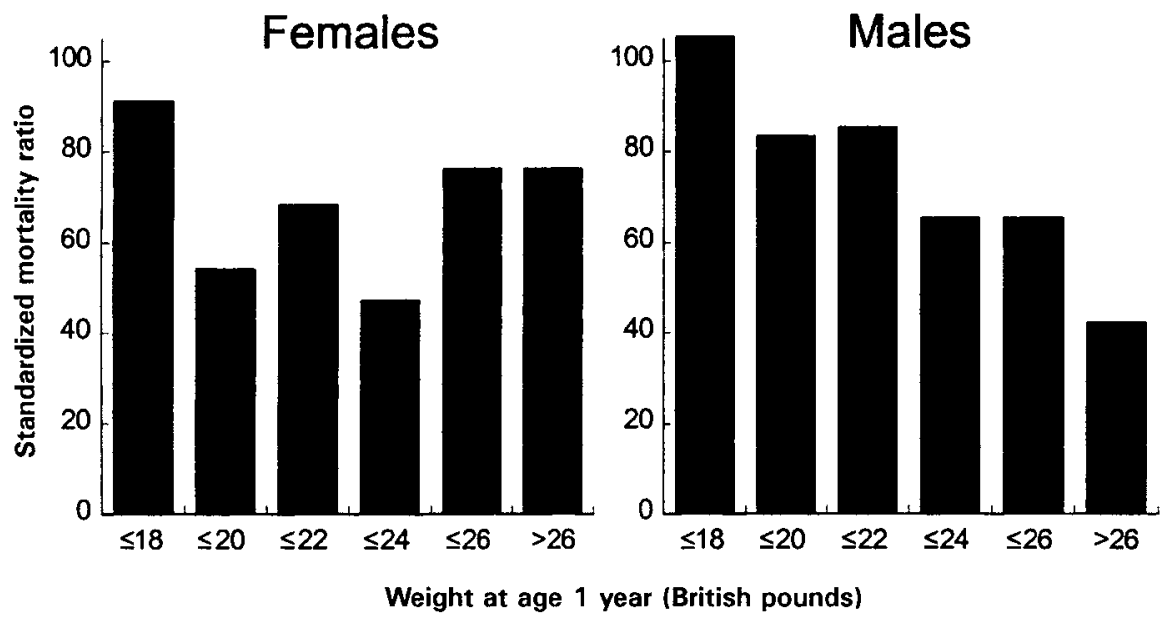

Fig. 2. Standardized mortality ratios for CHD below age 65 years, showing a statistically significant relationship with weight at age 1 year in 10141 men, but not in 5585 women born between 1911 and 1930. (Data from Barker, 1994.)

of energy metabolism in the vast majority of organs, intestine, liver, muscle, adipose tissue and brain. Postnatal development is also associated with differentiation processes and a high growth rate, involving specific requirements of nutrients such as amino acids (protein synthesis) or fatty acids (e.g. brain growth). Thus, nutrients can be considered to cause energy metabolism modifications but also to play a major role in organ growth and/or functional differentiation.

\subsection{Modulation of gene expression participates in the adaptations of energy metabolism}

The adaptations of energy metabolism to the nutritional environment imply the modulation and/or emergence of metabolic pathways. This can be achieved through changes in the efficiency of a given step (specific transporters, enzymes) by allosteric or phosphorylation-dephosphorylation mechanisms, or by translocation of a protein into a different cellular compartment. However, many of these adaptations also imply a change in the amount of a given protein. This phenomenon is usually related to a change of the transcription rate of the corresponding gene.

A good example of such a mechanism is the appearance at birth in mammals of phosphoenolpyruvate carboxykinase (EC 4.1.1.49), an enzyme of the gluconeogenic pathway allowing the de novo production of glucose by the liver (Girard et al. 1992). This pathway is essential for the survival of the newborn mammal, which undergoes a brief period of starvation followed by the ingestion of a diet low in carbohydrates, the milk. The transcription rate of this gene is extremely low during the fetal period and increases abruptly in the first hours after birth, allowing the newborn to maintain glucose homeostasis.

Another example is the lipogenic pathway in the rat species. This pathway allows synthesis of fatty acids from glucose when this substrate is ingested in excess of energy requirements. During the sucking period, the capacity of this pathway is kept very low because the small quantity of glucose ingested is essentially directed towards oxidative processes. When the rat is weaned onto the high-carbohydrate diet, this pathway is switched on and excess glucose will be converted into fatty acids, ultimately stored as triacylglycerols in the adipose tissue. The expression of one of the key enzymes of this pathway, fatty acid synthase ( $E C$ 2.3.1.85) is extremely low during the sucking period but increases when the rat is weaned onto the adult high-carbohydrate diet, but not if weaning occurs onto a high-fat diet, clearly underlining the importance of the nutritional environment in this process. This phenomenon is due to the activation of the gene transcription process at weaning (Foufelle et al. 1996). Thus, modulation of gene expression must be considered as an integral part of the adaptations occurring during development.

Although it has been known for a long time that nutrients can regulate the expression of specific genes in prokaryotes (the lactose operon in Escherichia coli for instance) or in primitive eukaryotes such as yeasts, the demonstration that a similar phenomenon occurs in higher eukaryotes is recent. The regulation of specific gene expression in mammals in response to changes in nutrition has become a major aspect of modern nutrition, due to the emergence of molecular biology that has allowed the cloning of most of the genes involved in the regulation of energy metabolism. Recently, it has been demonstrated that major (glucose, fatty acids, amino acids) or minor ( $\mathrm{Fe}$, vitamins) dietary constituents participate, in concert with hormones, in the regulation of gene expression in response to nutritional changes (see for instance Clarke \& Abraham, 1992).

\subsection{Examples of gene regulation by nutrients}

2.3.1. Carbohydrates. In the liver and adipose tissue, excess glucose, after its metabolism into pyruvate through glycolysis is converted into fatty acids by the lipogenic pathway. The expression of three enzymes of the combined glycolytic-lipogenic pathway has been shown to respond to an increased glucose concentration: L-pyruvate kinase $(E C$ 2.7.1.40; liver), fatty acid synthase and acetyl-coA carboxylase (EC 6.4.1.2; liver and adipose tissue) (Foufelle et al. 1992; Vaulont \& Kahn, 1994). In vivo, it has been shown in rats that high-carbohydrate diets induce the transcription 
of these genes, whereas transcription is inhibited by starvation or a high-fat diet. During the sucking period in rats, the expression of these enzymes is kept low and dramatically increases at weaning on to a high-carbohydrate diet. In vitro studies have shown that glucose is the primary inducer of the gene transcription. This effect requires that glucose is metabolized at least into glucose-6-phosphate which might be the signal metabolite. The response of transcription to high glucose is a very rapid phenomenon (less than $1 \mathrm{~h}$ ). Glucose response elements, which bind specific transcription factors of the USF/MLTF family have been characterized on these genes although the mechanism linking glucose-6-phosphate to transcription factors is presently unknown (Foufelle et al. 1996). In the $\beta$-cells of the islets of Langerhans, glucose induces the transcription of the insulin gene on which glucose response elements have also been characterized (Docherty \& Clark, 1994). This feature is obviously relevant to the diabetic syndrome.

2.3.2. Fatty acids. In vitro studies have shown that the transcription of a number of genes of adipocytes is increased in the presence of fatty acids. This is the case, for instance, for phosphoenolpyruvate carboxykinase, an enzyme involved in this tissue in the provision of $\alpha$-glycerophosphate necessary for the esterification of fatty acids (Antras-Ferry et al. 1995). Similarly, the expression of the fatty acid binding protein ap2, which binds fatty acids into the cell, is strongly stimulated by fatty acids (Grimaldi et al. 1992). Fatty acid response elements have been characterized in the promoter of these genes. They bind a transcription factor called peroxisome proliferator activated receptors (PPAR) which can be activated by the binding of fatty acids or a metabolite of fatty acids (prostaglandin for instance) (Schoonjans et al. 1996).

Fatty acids have also been shown to inhibit gene expression in rats. The addition of a small amount $(20-30 \mathrm{~g} / \mathrm{kg})$ of polyunsaturated fatty acids (PUFA) of the $n-3$ or $n-6$ families to a high-carbohydrate fat-free diet decreases markedly the lipogenic capacity and the activity of lipogenic enzymes (Clarke, 1994). In contrast, monounsaturated and saturated fatty acids have no effects. Interestingly enough, this effect seems to be specific to the liver since lipogenesis is not affected in the adipose tissue. The decrease induced by PUFA of the activity of lipogenic enzymes such as fatty acid synthase, acetyl-CoA carboxylase or glucose-6-phosphate dehydrogenase ( $E C$ 1.1.1.49), is clearly linked to an inhibition of gene transcription as shown in studies using primary cultures of rat hepatocytes (Clarke, 1994). At the present time the cellular and molecular mechanisms involved in the inhibitory effect of PUFA on gene transcription have not been elucidated.

2.2.3. Cholesterol. A very interesting series of studies has been performed by the group of Brown and Goldstein on the effect of cholesterol on gene expression (Wang et al. 1994). Cholesterol represses the expression of genes involved either in the synthesis of cholesterol (cytoplasmic hydroxymethylglutaryl-CoA synthase, $E C$ 4.1.3.5) or in its uptake from external sources, the LDL receptor (LDL are lipoproteins rich in cholesterol). In the absence of cholesterol, the transcription of these genes is activated by a transcription factor called sterol regulatory element binding protein (SREBP). SREBP is usually hooked onto the endoplasmic reticulum where it can be cleaved by a protease. SREBP can then be transferred into the nucleus and activates the transcription of relevant genes. In the presence of cholesterol, the protease is inhibited and SREBP can no longer enter into the nucleus and stimulate gene transcription (see Fig. 3).

2.3.4. Amino acids. In yeast, amino acid starvation results in the activation of several genes involved in $\mathrm{N}$ metabolism and the mechanisms involved are now known (Kilberg et al. 1994). In mammalian cells, amino acid availability also modulates the expression of some genes as shown, for instance, for asparagine synthetase (EC 6.3.5.4) which is responsible for the biosynthesis of asparagine from aspartate and glutamine. When cultured cells are transferred to a medium lacking asparagine, the concentration of asparagine synthetase mRNA increases. It must be underlined, however, that the signalling mechanism exhibits a broad substrate specificity since availability of other amino acids controls the asparagine synthetase mRNA

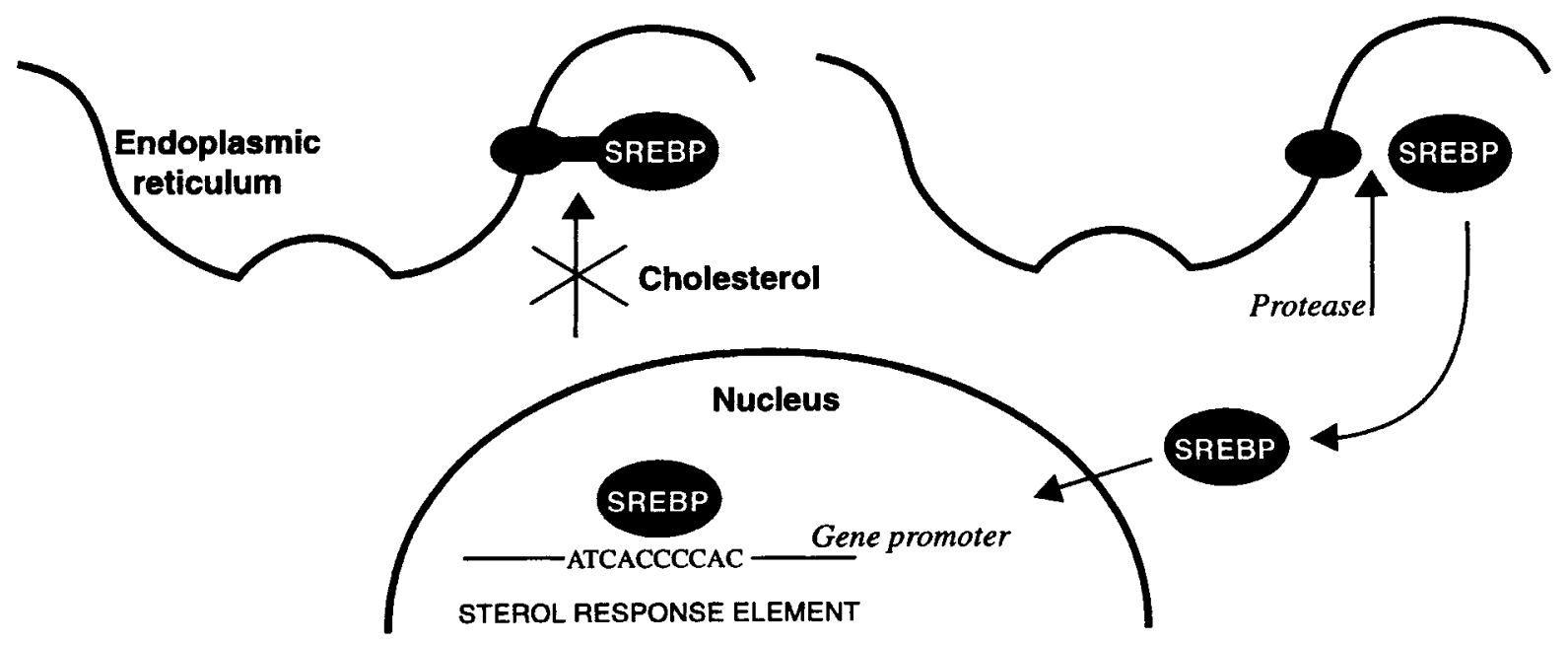

Fig. 3. Model for the cholesterol-dependent control of gene transcription. SREBP, sterol regulatory element binding protein. 
concentration as well. The mechanisms for the increase in asparagine synthetase mRNA concentration could involve both cis-acting elements contained in the mRNA itself and affecting its stability, as well as in the genomic promoter sequence (Kilberg et al. 1994). The signal metabolite could be, in fact, the degree of occupancy of the transfer RNA as in yeast, although evidence is clearly lacking.

\subsection{Nutrients and cell differentiation}

The fetal-neonatal period is also characterized by the differentiation of a number of organs. One important question, which is presently totally unaddressed, is whether nutrients could affect differentiation per se and thus modulate physiological functions on a long-term basis. Two examples are listed here.

2.4.1. Fatty acids. One example of such a mechanism stems from in vitro studies on pre-adipocyte cell lines. It has been shown that fatty acids are not only able to modulate the transcription rate of specific genes in differentiated adipocytes, but are also able to induce preadipocyte differentiation into adipocytes through their action on a specific isoform of a PPAR transcription factor (Schoonjans et al. 1996). Obviously, if this happens also in vivo, it would imply that perinatal nutrition could modulate the number of adipocytes and, thus, be a crucial determinant of a possible expansion of this tissue, in relation to the obesity syndrome.

2.4.2. Retinoic acid. Vitamin $\mathrm{A}$ or retinol can be oxidized to retinoic acid in cells. In addition to retinol, $\beta$-carotene may also be a source of retinoic acid. Retinoic acid and retinoid $X$ receptors which belong to the family of steroid-thyroid hormone receptors have been cloned (De Luca, 1991). They are, in fact, ligand-activated transcription factors (of the same family as the PPAR, see p.S9). It has been shown in numerous studies that retinoic acid is a potent morphogen and that it can affect fetal development (De Luca, 1991). Thus, vitamin A or $\beta$-carotene deficiency or overload might have major consequences on tissue differentiation and fetal development.

\subsection{Concluding remarks}

These examples underline the idea that gene regulation by nutrients, a process we induce each time we eat a food of specific composition, includes a very wide range of mechanisms involved in the regulation of crucial pathways as well as in cell differentiation. Since the fetal-neonatal period is concomitant with marked changes in the nutritional environment, it represents a period in which these mechanisms are particularly important.

As for other components of cell functions, it is very likely that gene regulation by nutrients is subject to variations linked to genetic polymorphisms among individuals, of which some could ultimately lead to pathologies. This obviously opens new fields for genetic studies on nutrientrelated pathologies (obesity, for instance).

\section{An overview of programmed cell death (apoptosis)}

A type of cell death which does not involve primary cell membrane disintegration and tissue inflammatory responses was identified some 70 years ago, and the term apoptosis was applied by analogy with the deciduous loss of leaves by trees. The process was identified by characteristic histomorphological changes in the cell nuclei (Kroemer et al. 1995). Although apoptosis is sometimes used as a synonym for programmed cell death (PCD), it has become apparent that apoptosis can be caused by noxious or toxic events which might affect several cell components and not just primarily the nucleus. PCD applies to the entire process and phenomenology of this form of cell death and thus embraces the intrinsic mechanisms and regulatory processes involved. PCD might not necessarily be induced by external toxic stimuli, but rather by signals which are a fundamental component of cellular and tissue physiology. The distinction between the two terms PCD and apoptosis is subtle, and not invariably respected. Clearly it is misleading to characterize PCD on the basis of nuclear morphological changes since these are not always the primary events in PCD (Kroemer et al. 1995; Hale et al. 1996; Vaux \& Strasser, 1996; Nagata, 1997) but one should not be distracted overmuch by the distinction: rather interest should focus on the processes involved in the induction, mediation, regulation and process of the cellular events, and the ways in which dietary components might affect these mechanisms which are fundamental to tissue differentiation, development and function.

PCD is a more appropriate description of a variety of intrinsic cellular events, involving cytoplasmic as well as nuclear processes which precede loss of intracellular and cellular membrane integrity, should these occur at all. However, non-physiological stimuli can effect mechanisms involved with PCD, and the process or its dysfunction can be an integral part of oncogenesis and autoimmune disorders (Hale et al. 1996).

All multicellular organisms use PCD to remove superfluous and damaged cells in tissues and organs, particularly, but not exclusively, in proliferating tissues. There is a strong evolutionary conservation of the mechanisms of PCD and the nematode Caenorhabditis elegans is a valuable model for the system in higher species, including man, in whom several genes and effectors of PCD are homologous to cell death genes and products in $C$. elegans (e.g. proto-oncogene bcl-2 is homologous to the nematode 'cell-suicide gene' ced3) (Kroemer et al. 1995; Vaux \& Strasser, 1996).

The induction mechanisms of PCD are more complex in higher animals in whom co-operativity between the different tissues of organs plays an important part in determining PCD. For example, the extracellular matrix exerts some control over differentiation and morphogenesis of organs by specific effects on constituent cells, tissue-specific gene expression, and cell death (Roskelley et al. 1995). This is important for the differentiation of tissues and organs (e.g. the gastrointestinal tract) throughout life as well as during embryogenesis.

PCD can be envisaged to comprise three stages: induction, the effector stage, and degradation (Fig. 4) (Kroemer et al. 1995). There are at least two principal routes of inducing PCD. One involves genotoxic events damaging DNA; the other involves receptor-mediated stimuli such as specific death signals, the absence of rescue signals such as growth factors, and contradictory or conflicting signals (Kroemer $e t$ al. 1995; Nagata, 1997). 


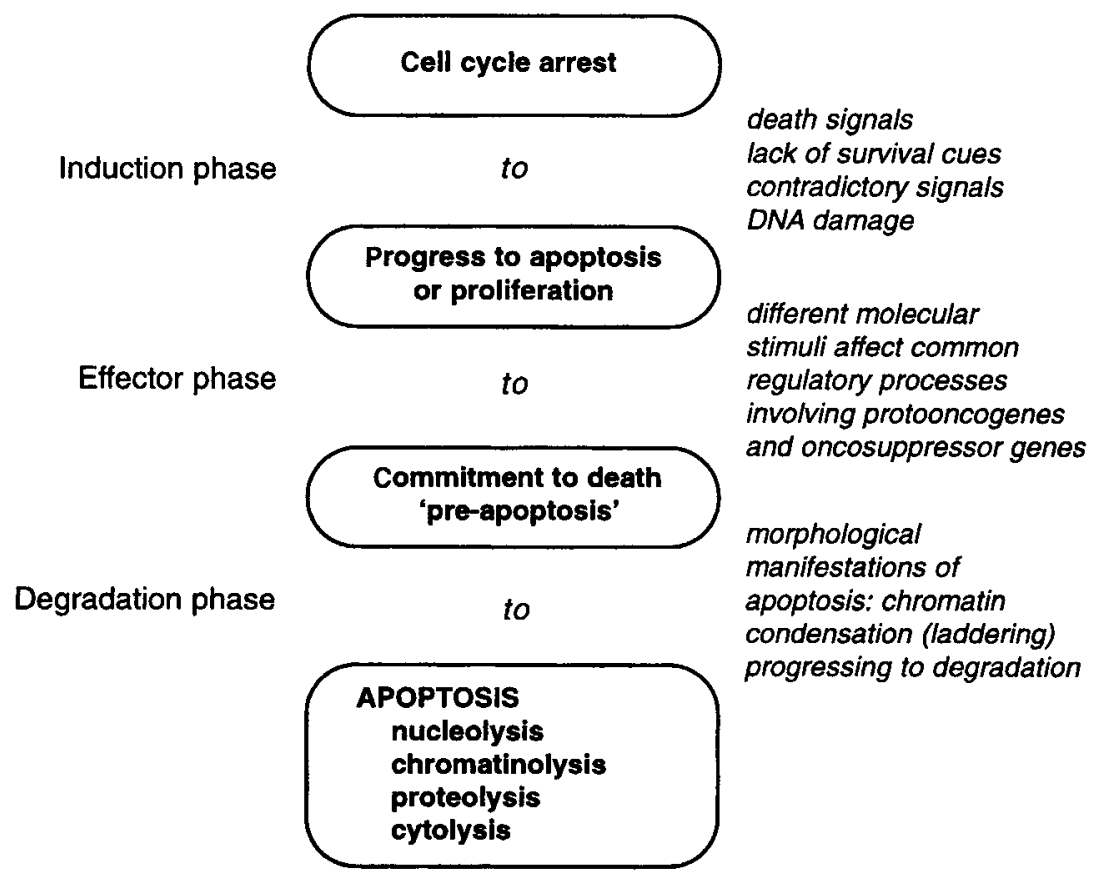

Fig. 4. The stages of programmed cell death and apoptosis. (From Kroemer et al. 1995.)

The origin of signals can be systemic or local (e.g. extracellular matrix) (Hakomori \& Igarashi, 1995) humoral cytokines (Nagata, 1997), or cellular such as cytotoxic $T$ cells. The signal and transduction systems stimulating PCD include steroids (Evans-Storms \& Cidlowski, 1995), cytokines such as tumour necrosis factor and nerve growth factor and interleukins, all of which operate through their cognate receptors (Cosman, 1994; Nagata, 1997).

The responsiveness to such stimuli may also be determined by the nature of the cell surface receptors which might change during ontogenesis (and, for that matter, oncogenesis). The surface receptors include glycosphingolipids, lectins and sphingosines and their respective roles have not been totally clarified. It is noteworthy that inherited defects of cell-surface CD40 cause a human X-linked immunodeficiency syndrome associated with defective PCD, and analogous syndromes in mice are associated with congenital abnormalities of Fas receptors and ligands (Cosman, 1994; Nagata, 1997). Changes in structural components of cellular membranes (e.g. ceramide formation) can induce signal transduction cascades (Ballou et al. 1996) leading to cell death.

The heterogeneity of signals is matched by the variety of effector mechanisms which are stimulated. These involve tyrosine kinase, protein kinase $\mathrm{C}$, and other kinases, $\mathrm{Ca}$ permeability routes and intracellular proteases. These initiate an amplification cascade affecting a number of genes, several of which are known proto-oncogenes (e.g. c-myc) or tumour suppressors (e.g. p53) and which are common both to PCD and to the regulation of normal cell differentiation, function and intermediate metabolism (Kroemer et al. 1995; Hale et al. 1996; Nagata, 1997). This highlights the central conundrum of $\mathrm{PCD}$, namely what is the ultimate determinant of whether a cell undergoes PCD or not? Is there a threshold event? It has been suggested that one basic determinant is the stage of the cell cycle when the cell receives the relevant signals (Meikrantz \& Schlegel, 1995) or the availability of an appropriate nutrient supply (that is, do some stressors such as a specific nutrient excess or deficiency induce cell death by more direct means than, say, oxidant damage or simple starvation?).

Intrinsic effector systems for cell death programmes involve cytoplasmic and nuclear metabolic and functional disintegration with ultimate morphological damage. Within the mitochondria there is a decrease in transmembrane potential, energy uncoupling of the respiratory chain, and increased production of reactive $O$ species. These increase oxidative damage and increase leakage of mitochondrial $\mathrm{Ca}$. In the cytoplasm there is a loss of anabolic activities with a corresponding activation of proteases, disruption of the cytoskeleton and of the endoplasmic reticulum: similarly in the nucleus the endonucleases are activated and there is nucleolysis with some activation of enzymes usually associated with repair activity.

The mechanisms and regulation of PCD and apoptosis in abnormal cell proliferation have focused on their role in cancer and the possibility that external events or compounds might induce, suppress, regress, or protect against cancer by affecting these processes. The potential role of dietary components influencing these processes is being investigated actively in relation to functional food science. In other physiological areas there might exist other opportunities to explore and exploit a better understanding of these processes in cellular proliferation and differentiation. These are outlined in the following paragraphs.

PCD of uterine cells enables blastocyst implantation and placentation (Welsh, 1993). Prostaglandins, leukotrienes, platelet-activating factor, and transforming growth factor are thought to induce this process. In embryogenesis there is extensive mesodermal PCD to eliminate undifferentiated 
cells (Sanders \& Wride, 1995; Wride \& Sanders, 1995). The extracellular matrix and the regulation of cell adhesion molecules and integrins, perhaps involving tumour necrosis factor- $\alpha$ as a cellular growth and differentiation factor, have been shown in the regulatory processes in the morphogenesis of the limb bud (Hurle et al. 1995).

Again extracellular matrix and specified cell adhesion molecules control endothelial cell position and behaviour and enable the definition of mechanisms directing endothelial cell differentiation, commitment, migration and organization into a tube as the fundamental components of vasculogenesis (Baldwin, 1996). PCD has also been shown to be integral to the development of the conduction processes and to be involved in the pathogenesis of congenital cardiac structural and electrical conduction abnormalities as well as acquired cardiovascular disease (James, 1993). The role of PCD in intestinal mucosal development and differentiation is discussed elsewhere: a similar dependence on PCD has been demonstrated in renal organogenesis (Igarashi, 1994).

It is in haematopoiesis and in the development of the immune system that there might be some particular aspects of relevance to functional food science. Haematopoiesis and PCD involve an extensive multigene cytokine network which has positive regulators such as colony-stimulating factors and interleukins and negative regulators such as transforming growth factor- $\beta$ and tumour necrosis factor (Krammer et al. 1994; Cidlowski et al. 1996; Sachs, 1996). Apoptosis in $\mathrm{T}$ and $\mathrm{B}$ lymphocytes is involved in all fundamental processes in the immune system and $\mathrm{PCD}$ appears to be vital in selecting or favouring development of specific lymphocytes and eliminating cells which are sensitized to autoantigens. Factors which would interfere with this process would be undesirable and there exists a possibility that similar selective processes might underlie the acquisition of immunotolerance to ingested antigens in foods or the development of adverse immune reactions to food constituents.

In the central nervous system neurones and glia synthesize and secrete cytokines which affect the differentiation and function of nerve cells (Dragunow \& Preston, 1995; Kawata, 1995; Sei et al. 1995). Disturbance of these cytokinemediated interactions may lead to neuronal dysfunction and/or cell death and contribute to the pathogenesis of central nervous system diseases. The functional and cellular differentiation underlying sexual dimorphism in the central nervous system might depend on the effects of steroids on PCD in the relevant regions of the brain.

Many of the phenomena regarded as inevitable consequences of ageing, including nerve cell death, involve processes of PCD and apoptosis, and a better understanding of these events might in due course lead to a more sophisticated and rational scientific basis on which to base functional food science and its application to avoid the depredations of ageing (Zakeri \& Lockshin, 1994).

\section{Supply of food ingredients before and during pregnancy}

The nutritional status of the mother before and during pregnancy may influence fertility, the course of pregnancy and the incidence and severity of complications during gestation and birth, lactation (Rasmussen 1992), and the short- and long-term health and development of the baby. During recent years scientific understanding of the physiology of energy metabolism, weight gain and particularly the effects of micronutrient status and their clinical consequences have considerably improved. The dietary supply of certain nutrients may have beneficial or preventive aspects both for the course of gestation and for the offspring.

\subsection{Physiological aspects of nutritional requirements in pregnancy}

The range of weight changes that occurs in pregnant women is wide and ranges from a loss of weight to a gain of $25 \mathrm{~kg}$ or more. A normal weight gain during pregnancy for most women with normal prepregnancy weight is in the order of $11-15 \mathrm{~kg}$ (Institute of Medicine, 1990). In addition to food intake, weight gain is also influenced by medical disorders such as development of oedema associated with preeclampsia. The weight increase and substrate deposition in maternal and fetal tissues is not only due to increased dietary intake during pregnancy, but also supported by a variety of complex adaptations of gastrointestinal, endocrine and metabolic functions. The effects of food ingredients on these adaptations as well as on placental function and the efficacy of materno-fetal substrate transfer are not well understood and require further exploration. Substrate needs during pregnancy are not only met by the food consumed during this period of time, but food intake before or between pregnancies may be of major importance for providing adequate availability of a number of nutrients, e.g. $\mathrm{Ca}$ and Fe. Also, it is increasingly appreciated that substrate needs during pregnancy may show marked interindividual variability, partly due to genetic heterogeneity in a population as is the case for metabolic pathways involving folic acid.

4.1.1. Energy. Based on a factorial approach calculating the additional energy requirements for the deposition of protein and fat as well as the energetic cost of tissue synthesis and enhanced maintenance metabolism, the total energy cost of pregnancy is assumed to be in the order of $334.72 \mathrm{MJ}(80000 \mathrm{kcal})$ (Food and Agriculture Organization/World Health Organization/United Nations University (FAO/WHO/UNU), 1985). In women who maintain their previous physical activity, this results in an additional energy allowance of about $837 \mathrm{~kJ} / \mathrm{d}(200 \mathrm{kcal} / \mathrm{d})$ equivalent to an increase of $9 \%$ over the energy needs of $9.2 \mathrm{MJ}$ ( 2200 $\mathrm{kcal}$ ) of a non-pregnant, moderately active woman, or if adapted to an estimated increase of energy needs during the course of pregnancy, about $628 \mathrm{~kJ} / \mathrm{d}(150 \mathrm{kcal} / \mathrm{d})$ during the first and about $1464 \mathrm{~kJ} / \mathrm{d}(350 \mathrm{kcal} / \mathrm{d})$ during the second and third trimesters of pregnancy (FAO/WHO/UNU, 1985). However, energy needs may be lower with reduced physical activity, particularly towards the end of pregnancy.

While moderately reduced energy intakes have little effect on pregnancy outcomes, severe energy deprivation during pregnancy results in reduced infantile birth weight. During the 6-month period of the Dutch famine with an available energy supply below $4184 \mathrm{~kJ} / \mathrm{d}(1000 \mathrm{kcal} / \mathrm{d})$ and a protein intake of no more than $30-40 \mathrm{~g} / \mathrm{d}$, average birth 
weight fell by $200 \mathrm{~g}$ (Ravelli et al. 1976). The effect was most marked if the hunger period coincided with the latter part of pregnancy. Later studies have confirmed these observations. In underweight women, a close relationship between maternal and neonatal body weights has been observed, while the correlation is much less close in pregnant women with a normal body weight (Luke \& Petrie, 1980). Not only total body weight, but also the organ weights of liver, spleen, heart, adrenal gland, kidneys, skeleton and thymus are reduced in newborn infants of mothers who are underweight (Naeye et al. 1969), and placental size and number of cells by 15-20\% in pregnancy with intrauterine infantile growth failure or even up to $50 \%$ in severe maternal malnutrition (Winnick, 1970). In malnourished South American women, average placental weights were reduced by about $15 \%$, and there was a marked reduction of the placental peripheral villi surface, the site of materno-fetal nutrient transfer, which may aggravate the restricted nutrient supply to the fetus in malnourished mothers. These findings are of concern, since neonatal birth weight is the strongest predictor of infant morbidity and mortality, and epidemiological studies have found strong associations of low birth weights with increased risks for cardiovascular disease and total mortality rates in adulthood (Barker, 1994).

Several studies on energy supplementation during pregnancy in malnourished women found an increase in average birth weight and a reduction of the rate of low-birth-weight infants (Lechtig et al. 1975; Prentice et al. 1987), while intervention studies with an increased energy intake in apparently healthy women in Europe did not have significant effects on neonatal weight. However, dietary supplementation in Canadian women with twin pregnancies resulted in an increase of average birth weight by $80 \mathrm{~g}$, and reductions of preterm deliveries and the rate of verylow-birth-weight infants by 30 and $50 \%$ respectively (Dubois et al. 1991). In conclusion, energy supplements during pregnancy appear to be beneficial in selected populations at risk of very low intakes or increased demands.

4.1.2. Protein. With a factorial approach again based on calculated materno-fetal accretion, the additional protein requirements for the four successive 10-week periods of a normal pregnancy have been estimated as $0 \cdot 6$, $1 \cdot 8,4 \cdot 8$ and $6 \cdot 1 \mathrm{~g} / \mathrm{d}$, respectively (Hytten \& Leitch, 1971), and an increase of recommended protein intakes by about $6 \mathrm{~g} / \mathrm{d}$ (expressed as milk or egg protein) over non-pregnancy values has been recommended (FAO/WHO/UNU, 1985). Even though this represents an increase of about $30 \%$ over recommended intakes in non-pregnant women, and hence the recommended relative increment of protein intake is clearly higher than that of energy, the protein intakes of most pregnant women in Europe tend to exceed minimal requirements by far, with the possible exception of small subgroups consuming low-protein diets. It has been proposed that protein-enriched diets during pregnancy may be beneficial for the prevention of pregnancy-induced hypertension and pre-eclampsia, but conclusive evidence to support these hypotheses is missing (Roberts et al. 1974; Williams et al. 1981).

4.1.3. Carbohydrates. Glucose serves as the major energy source for the fetus, comprising about $90 \%$ of the energy supply. Hence, maternal carbohydrate metabolism during gestation is of potential relevance to the optimal supply for the fetus. Little is known about the effects of dietary habits, particularly the total amount and relative composition of sugars and starches on gestation, and potential implications for clinically relevant outcome variables such as macrosomia, postpartal hypoglycaemia, or increased risk of developing glucose intolerance later in life.

4.1.4. Lipids. Although there is a tendency in some pregnant women to aim at a low consumption of dietary fat (Hachey, 1994), there are no conclusive data to demonstrate the safety of maternal low-fat diets or immediate benefits for pregnant women and the fetus and infant. On the other hand, pregnant women appear to have high requirements for lipidsoluble vitamins and PUFA. During pregnancy, the concentrations of blood lipids and their constituent fatty acids increase considerably. Amounts (mg/l) of plasma phospholipid-associated essential fatty acids (EFA) were reported to increase during the course of pregnancy by about $40 \%$ and those of the long-chain PUFA arachidonic acid $(20: 4 n-6)$ and docosahexaenoic acid (DHA, 22:6n-3) by about 23 and $52 \%$ respectively (Al et al. 1995). It has been proposed that a high supply of long-chain $n-3$ fatty acids may be beneficial for fetal development because of the importance of these compounds for neural tissue development (Koletzko, 1992), and that they may improve some obstetric complications, particularly lessen the severity of pregnancy-induced hypertension (Secher \& Olsen, 1990). Moreover, observations in the population of the Faroe islands which consumes a diet rich in fish suggested that this high intake of $n-3$ fatty acids may increase average birth weight by prolonging gestation (Olsen et al. 1986). However, in this population there were also apparent adverse effects of $n-3$ fatty acids, including higher rates of blood loss on delivery, which may be explained by fish-oilinduced suppression of platelet aggregation, and a higher perinatal mortality. An intervention with supplementation of $n$-3 long-chain PUFA was reported to prolong pregnancy without any detrimental effects on growth of the fetus or the course of delivery (Olsen et al. 1992). Supplementation of fish oil with vitamins and minerals has been considered to reduce the frequency of pre-eclampsia, but a double-blind placebo-controlled trial did not find any effect of fish-oil supplementation on the occurrence of pregnancy-induced hypertension (Onwude et al. 1995).

Pregnancy may be associated with DHA mobilization from maternal stores. Under the present dietary conditions, pregnancy is associated with a reduction of the EFA status and particularly of the DHA status. After delivery normalization takes place, but recovery of the DHA status appears to be still incomplete after 6 months (Al et al. 1995). Throughout pregnancy, the DHA content of plasma phospholipids of primigravida is significantly higher than that of multigravida, and a negative relationship was observed between DHA content and gravida number, which is reflected in neonatal DHA status and may have functional consequences for infant growth and development. Since increased supplies of selected PUFA during pregnancy may well have some benefits, the possible benefits as well as the potential risks of such strategies should be carefully evaluated. 
4.1.5. Vitamins, minerals and trace elements. Relative to the increased energy needs (about 10\%), the recommended relative increase of some other nutrients is markedly higher, for example, for folate the reference intake increases by $100 \%$ in pregnancy (Scientific Committee for Food, 1993). Based on these considerations, the potential for an inadequate intake of one or more of these specific nutrients during pregnancy is greater than for total energy.

Calcium. During the latter part of pregnancy, the fetus has a high rate of $\mathrm{Ca}$ accretion in the order of $250-300 \mathrm{mg} /$ d. This appears to be partly accounted for by extensive adjustments in $\mathrm{Ca}$ metabolism during pregnancy, particularly the inhibitory effects of placental oestrogen on maternal bone resorption that result in an enhanced release of parathyroid hormone and, hence, increased maternal $\mathrm{Ca}$ absorption, decreased urinary excretion and enhanced $\mathrm{Ca}$ retention (Cole et al. 1987). Although low dietary Ca intakes of malnourished pregnant women have been associated with reduced bone mineral densities of the newborn infants (Ramam et al. 1978), in well-nourished mothers no enhancement of neonatal $\mathrm{Ca}$ accretion by increased maternal intakes has been demonstrated. However, at relatively low intakes, maternal body stores of $\mathrm{Ca}$ may be utilized and depleted to meet fetal needs (Duggin et al. 1974). In women with multiple pregnancies, in particular, low $\mathrm{Ca}$ intakes may increase the risk of osteomalacia at a later age.

Although dental caries is relatively common during pregnancy, there is no evidence for a causal link of its rate of occurrence with dietary $\mathrm{Ca}$ intakes.

Low $\mathrm{Ca}$ intakes during pregnancy have also been associated with the occurrence of EPH-gestosis (oedema, proteinuria and hypertension) as well as eclampsia (Burke et al. 1943). In a controlled study, supplementation of the diets of pregnant women with $\mathrm{Ca}$ was associated with a reduced systolic blood pressure at term and a lower incidence of pregnancy-induced hypertension (Villar et al. 1987). In contrast, another study found no effect of a $\mathrm{Ca}$ supply on the incidence of pregnancy-induced hypertension, although mean blood pressure was lowered.

Magnesium. $\mathrm{Mg}$ status is related to neuromuscular excitability, and it has been proposed that an additional $\mathrm{Mg}$ supply may contribute to prevention of eclampsia and other complications of pregnancy. However, controlled trials have not provided conclusive evidence for an improved course of pregnancy or delivery (Spatling \& Spatling, 1988; Sibai et al. 1989).

Iron. The total $\mathrm{Fe}$ needs for pregnancy have been estimated to be in the order of $300-850 \mathrm{mg}$ (Bothwell et al. 1979; Hallberg, 1988). Although the efficacy of $\mathrm{Fe}$ absorption is markedly enhanced in pregnancy, the incidence of $\mathrm{Fe}$ deficiency and Fe-deficient anaemia during pregnancy remains a sizeable problem that may increase maternal and fetal morbidity and mortality (Llewellyn-Jones, 1965), cardiovascular stress associated with increased complication rates before and at birth (Banks \& Beutler, 1988) and an elevated risk of delivering lowbirth-weight and premature infants (Scholl \& Hediger, 1994). At particular risk of poor Fe status in pregnancy are women with vegetarian or predominantly vegetarian diets, because of the relatively low absorption of non-haem Fe.
Thus, foods that promote net $\mathrm{Fe}$ absorption may be beneficial for some pregnant women.

Zinc. Maternal $\mathrm{Zn}$ deficiency is highly teratogenic in rodents, and in monkeys it induces abnormal fetal brain development (Worthington-Roberts 1985). Studies in human pregnancies found that maternal leucocyte $\mathrm{Zn}$ levels during pregnancy were correlated with later infantile birth weight (Wells et al. 1987) and inversely related to the rate of low-birth-weight infants (Neggers et al. 1991). Moreover, a better maternal $\mathrm{Zn}$ status was associated with lower rates of pregnancy-induced hypertension, protracted delivery and maternal complications at birth and the rate of premature rupture of membranes (Sikorski et al. 1990). In contrast, another controlled study evaluating $\mathrm{Zn}$ supplementation in the second and third trimesters of pregnancy in Europe did not find any effect. To what extent these differing results were influenced by variations in $\mathrm{Zn}$ status of the respective populations studied, and may be reproduced in other populations, remains to be clarified.

lodine. In parts of Europe, the I status of many pregnant women is inadequate with a sizeable prevalence of increased thyroid size in mothers and newborn infants (World Health Organization, 1993). Poor I status is associated with an increased risk of miscarriage in early gestation and preterm delivery as well as compromised mental development of the infant (Xue-Yi et al. 1994).

Fluoride. Since postnatal $\mathrm{F}^{-}$supply has a strong preventive effect on the incidence of dental caries, the question was raised whether an increased $\mathrm{F}^{-}$supply to pregnant women may contribute to protecting pre-eruptive teeth of the unborn child, but conclusive evidence to answer this question is not available.

Folic acid. Folic acid is essential for the synthesis of pyrimidines, purines and hence of DNA and RNA, as well as amino acids and neurotransmitters; thus, an adequate folate status is of importance to allow undisturbed cell multiplication and growth during pregnancy. Following observations of a relation between folic acid status and the occurrence of neural tube defects in the offspring, several controlled clinical trials have demonstrated that folic acid supplied before conception and during the first weeks of pregnancy can markedly reduce the incidence of neural tube defects, such as spina bifida and anencephaly, by $40-70 \%$ (Butterworth \& Bendich, 1996). This important preventive effect is apparently associated with a folic acid-responsive derangement in homocysteine metabolism in a genetically determined subgroup of the population (SteegersTheunissen et al. 1991). Poor folic acid status of pregnant women has also been associated with miscarriages, repeated abortions, pregnancy length and neonatal outcome as well as unexplained sterility (Pietrzik et al. 1992; Bung et al. 1993, 1995). It has been recommended that all pregnant women should be supplemented with a daily dose of $0.4 \mathrm{mg}$ folic acid from before conception to at least four completed weeks after conception (Scientific Committee for Food, 1993). In view of the postulated key role of folic acid status in the aetiology of atherosclerosis by means of modulating homocysteine metabolism, the question of a potential programming effect of intrauterine folic acid supply on the later risk of cardiovascular diseases has been raised (Pietrzik et al. 1992). 


\section{Modulation of growth}

\subsection{Introduction}

The term 'growth' expresses the increase in number and size of cells of a particular species and it refers to changes in body dimensions. Growth is a phenomenon usually associated with increase in length and weight whereas the term 'development' is a physiological concept indicating the progressive differentiation of tissues and organs with acquisition of their specific functions. All mammals start life as a single cell; during the early part of the gestation the fertilized ovum divides many times and different kinds of cells develop during the process of differentiation and arrange themselves to form part of the various organs of the body. The general principles of growth apply to all species but the rate of cell division is genetically determined and depends on nutrient supply and utilization. Regardless of the exact time that differentiation occurs it always results in the transformation of the parental cell into a large number of morphologically different progeny cell types. The rapidity of physical growth is regulated during the life cycle and is modulated by genetics, a variety of growth factors that interact with target cells, as well as environment and diet (Hernández \& Argente, 1992; Philips, 1995).

Human growth hormone (hGH) or somatotropin is essential for normal postnatal growth. It is released from the anterior pituitary gland on stimulation by growth hormonereleasing hormone or somatocrinin, a factor produced by the hypothalamic region of the brain. Like other pituitary hormones, hGH acts on target tissues, primarily the liver, to cause synthesis and release of a second hormone mediator, insulin-like growth factor (IGF)-I, also called somatomedin $\mathrm{C}$, into the systemic circulation. IGF-I is a growth-accelerating peptide that acts directly on cartilage to promote bone growth. Deficiency of hGH production causes metabolic alteration and growth failure (Philips, 1995).

Different requirements for growth of different cell types have been established (Sato et al. 1982) but despite considerable progress in tissue culture systems we are still a long way from identifying all the stimulatory and inhibitory macromolecules that regulate the growth of all the human cell types in vivo. Most growth factors are polypeptides or small proteins with molecular masses that vary from 1 to $40 \mathrm{kDa}$ and bind to specific cell surface receptors, with pleiotropic effects on cells including changes in gene expression (Watson et al. 1987). By binding to their receptors, growth factors modify the activity of the membrane-bound enzyme adenylate cyclase ( $E C$ 4.6.1.1), using the GTP-binding protein as an intermediate so that the level of cAMP in the cell is altered. This, in turn affects the activity of cAMP-dependent protein kinases which phosphorylate specific target proteins, regulating their activity. Other possible second messengers to carry signals from growth receptors to the cell include $\mathrm{Ca}$, inositol triphosphate and diacylglycerol (Lodish et al. 1995).

In addition to genetic factors, neurohormonal and tissuespecific growth factors, growth is also affected by a number of metabolic and environmental factors which include the availability of nutrients. Recommended daily nutrient intakes have been established for all periods of life and both sexes to support an adequate growth of the human being (National Research Council, 1989). However, there is a lack of information about how semi-essential nutrients can affect growth in specific periods of life and in particular situations including disease states.

The rapidity of physical growth in the normal infant during the first months of life is remarkable and unmatched during later times of life. Moreover, physiological and developmental changes during infancy are as notable as the speed of physical growth. Changes in the rates of physical growth and in the allocation of dietary intake of energy and protein for growth and maintenance occur as a continuum rather than in discrete stages, but the progression of changes during the early months of life is very rapid.

Human milk provides all nutrients necessary to support adequate growth of the term infant during the first 4-6 months of life. Furthermore, in addition to universally recognized nutrients, human milk contains a number of semi-essential nutrients, enzymes, hormones and growth factors which appear to have a role in supporting infantile growth (Koldovsky \& Strbak, 1995). However, there is a lack of information about how those nutrients and factors interact with the growth process and how they affect specific tissue growth.

\subsection{Methods for the determination of growth}

Anthropometric measurements such as weight, length, head circumference, skinfold thickness, limb circumference, mid-arm cross-sectional area, BMI etc. at various ages during infancy have been published in many developed countries and are useful in evaluating the size of an infant in relation to the size of his or her peers (Fomon \& Nelson, 1994). In the infant the Quetelet index is difficult to interpret since the body mass increases rapidly from birth to 4 months of age and the percentage of body weight contributed by body fat also increases rapidly during that period. Reference data for increments in size and other indices of nutritional status are more sensitive in children beyond infancy, particularly in alerting to the possibility of illness or nutritional inadequacy (Fomon, 1991).

Data on body composition at various ages are one of the bases for the factorial approach in estimating the requirements for various nutrients for growth. Chemical composition of animals is determined by direct whole-body analysis. The most extensive data on the composition of the term infant are those published by Widdowson (1982), but data beyond infancy are scanty. The most useful indirect methods of estimating various aspects of body composition in the infant are determination of total body water from the concentration of a suitable tracer in body fluid, i.e. heavy water, extracellular water, and determination of natural abundance of ${ }^{40} \mathrm{~K}$ in the whole body (Forbes, 1987). Measurements of both bioelectric impedance and of total body electrical conductivity can estimate non-invasively the fat-free body mass of infants and children (Mayfield $e t a l$. 1991; Houtkooper et al. 1992). Many new techniques are available for measurement of total body fat, although only a few can be used in general practice or in epidemiological research (Deurenberg, 1992).

The urinary excretion rates of endogenous creatinine and 3-methyl-histidine have been proposed as indices of muscle 
mass, and the urinary excretion rates of endogenous hydroxyproline and type I and type III procollagen propeptides as indices of growth rates (Trivedi et al. 1991). Measuring cell kinetics represents a new approach in evaluating cell and tissue growth. Cell kinetics can be used to measure the proliferation rate of cells, the phases of the cell cycle and the percentage of cells in cycle, to plot the position of dividing cells and determine the size of the proliferation compartment and to follow the movements of labelled cells. Cell kinetic studies received a boost when $\left[{ }^{3} \mathrm{H}\right]$ thymidine was introduced in the 1950s. Recently, several new techniques have been used in cell kinetics, i.e. incorporation of bromodesoxyuridine and labelling of cell antibodies (Kember, 1993). There is a need for new methods to evaluate the specific organ and tissue growth applicable in a wide range of conditions.

\subsection{Growth factors in human milk and their influence on infant growth}

A large number of hormones and growth factors are present in human and bovine milks (Koldovsky \& Thornburg, 1987; Strbak, 1991). Non-peptide hormones (thyroid hormones, cortisol, progesterone, pregnanediol, oestrogens and artificial contraceptives) and peptide hormones and growth factors (erythropoietin, hGH, growth hormone releasing factor, gonadotropin-releasing hormone, epidermal growth factor (EGF), insulin, IGF-I, nerve growth factor, gastrointestinal regulatory peptides and thyroid-parathyroid hormones) have been isolated and quantitated in human milk (Koldovsky \& Strbak, 1995). The orogastric effects of hormones and growth factors on infant growth require further elucidation. However, there is some evidence that a number of hormones in human milk may contribute to the intestinal maturation of sucking infants. For example, oral administration of EGF to 10-d-old sucking rats resulted in changes in protein and DNA content of colonic mucosa (Koldovsky \& Thornburg, 1987).

\subsection{Potential roles of non-protein nitrogen compounds as growth modulators}

Non-protein N (NPN) compounds are present in most foods mainly as nucleic acids, free amino acids, small peptides and other minor compounds. The concentration of nucleic acids in foods depends on the number of cells of the original biological tissue. Thus, meat, fish and vegetal seeds are rich in nucleic acids whereas fruits have a low content (Gil \& Uauy, 1995b). NPN accounts for $18-30 \%$ of the total N in human milk. Some of this $\mathrm{N}$, namely urea, contributes to the pool available for synthesis of non-essential amino acids in infants. Other NPN components may have particular roles in tissue growth. Among the NPN known to have specialized roles in the ontogeny of the human newborn are the growth factors, namely EGF, amino sugar oligosaccharides, free amino acids like taurine, arginine and glutamine, amino alcohols of phospholipids i.e. choline, nucleotides and nucleic acids and polyamines.

\subsection{Human milk oligosaccharides and growth}

In addition to lactose, the carbohydrates of human milk include nucleotide sugars, glycolipids, glycoproteins, and oligosaccharides. Viverge et al. (1990) have isolated three oligosaccharide fractions representing $13-18 \mathrm{~g} / \mathrm{l}$; the concentration varied with the mother's genetic ability to synthesize specific fucosyl linkages. Approximately eighty neutral and sialic acidic oligosaccharides have been isolated and identified (Newburg \& Neubauer, 1995).

Human milk oligosaccharides appear to be synthesized by some of the same glycosyltransferases that participate in the synthesis of glycoprotein and glycolipid cell surface components. Thus, it is reasonable to postulate that some of those compounds can act as analogues to host cell surface receptors for pathogens. Anderson et al. (1986) reported that specific oligosaccharides can inhibit binding of Streptococcus pneumoniae and Hemophilus influenzae to their receptors and Cravioto et al. (1991) described an oligosaccharide that inhibits adherence of enteropathogenic $E$. coli to their receptors. Other authors have reported that specific fucosylated oligosaccharides inhibit binding of invasive strains of Campylobacter jejuni (Ruiz-Palacios et al. 1992) and the toxicity of E.coli in vivo (Newburg et al. 1990).

Gangliosides are glycosphingolipids that contain sialic acid ( $N$-acetylneuraminic acid) as part of their carbohydrate moiety. $\mathrm{GM}_{1}$, a milk ganglioside present in human milk, binds to E. coli and Vibrio cholerae toxins and may contribute to infant protection against infection by those enteropathogens (Laegrid et al. 1986).

Since lactating mothers differ genetically in their ability to produce various oligosaccharides, this variability might influence the susceptibility of breast-fed infants to enteric disease. The influence of supplementing infant milk formulas with oligosaccharides on the susceptibility of infants to gastrointestinal diseases, namely acute diarrhoea, is one of the current fields of intense investigation.

\subsection{Free amino acids and tissue growth}

The free amino acid pool of human milk is small compared with the total amount of milk amino acids in protein. Free amino acids contribute only $10 \%$ of the total NPN in human milk. Glutamine and taurine are the free amino acids found in higher concentrations in human milk. While clinical effects of low dietary intakes of taurine have not been demonstrated, there is a concern about the possibility of subclinical deficiency, particularly in the premature infant since its ability to synthestize taurine may be limited (Gaull et al. 1977).

Free glutamine accounts for about $20 \%$ of the total glutamine pool in human milk. Glutamine is currently extensively investigated because of its importance in cell and tissue culture and because it serves as a preferred respiratory fuel for rapidly proliferating and growing cells, such as enterocytes and lymphocytes. Moreover, it is a regulator of acid-base balance through the production of urinary $\mathrm{NH}_{3}$, a carrier of $\mathrm{N}$ between tissues and an important precursor of nucleotides, amino sugars and proteins (Lacey $\&$ Wilmore, 1990). There is increasing evidence that glutamine may become a conditionally essential amino acid in critically ill patients, and glutamine appears to be important for the maintenance of small-intestinal structure and functionality (Newsholme \& Carrié, 1994).

Arginine and ornithine are also present in human milk as free amino acids, although the first is found in higher 
concentrations in milk proteins. Arginine has multiple biological properties, including the ability to stimulate anabolic hormone secretion: intravenous and enteral administration of arginine increases both insulin and hGH secretion (Cynober, 1994). Several studies show that arginine given to patients, as well as in various experimental stress models, acts by improving $\mathrm{N}$ balance, accelerating wound healing, and restoring depressed immunity. Dietary supplements of arginine have been shown to inhibit tumour growth in animals, probably by activating the immune system. However, in cancer patients arginine stimulates tumour protein synthesis, suggesting that arginine might have separate stimulatory effects on the tumour and on the immune system, the outcome depending on which effect predominates (Garlick \& McNurlan, 1994). Arginine has also been shown to enhance the growth-hormone-releasinghormone-induced hGH rise in patients with anorexia nervosa (Ghigo et al. 1994). Moreover, oral administration of arginine enhances the hGH response to growth hormone releasing hormone in short children (Loche et al. 1993).

Ornithine shares with arginine the ability to stimulate hGH secretion. In addition, ornithine as its $\alpha$-ketoglutarate salt generates various molecules, i.e. glutamine. Ornithine ketoglutarate has been shown to improve $\mathrm{N}$ balance in various acute and chronic malnutrition states. It increases muscle protein anabolism in moderate catabolic states and reduces protein catabolism in hypercatabolic states (Cynober, 1994).

Arginine and ornithine are precursors of NO and polyamines respectively. These metabolites participate intimately in permeability and adaptive responses of the gut. Recent animal studies showed improved morphology after ornithine ketoglutarate administration, acting perhaps through increased polyamine synthesis (Cynober, 1994). It is controversial whether exogenous arginine can be a relevant precursor of polyamines.

\subsection{Polyamines and tissue growth}

Polyamines are detectable in relatively high quantities in human and rat milk. Artificial infant formulas do not contain appreciable amounts of polyamines, specifically putrescine and spermidine, and spermine is undetectable. Thus, formula-fed infants are not exposed to polyamines nor to any potential effects that these compounds may have on the developing intestine. It is noteworthy that food contains polyamines and that polyamines are produced by the gastrointestinal microflora. Thus, the direct uptake by enterocytes of preformed polyamines could contribute to the polyamine cellular pool. Indeed, putrescine and spermidine uptake has been shown in isolated rat enterocytes (Cynober, 1994).

\subsection{Dietary nucleotides and tissue growth}

Human milk is the exclusive source of dietary nucleotides for infants during the first months of life, and its nucleotide profile (Gil \& Sánchez-Medina, 1982; Gil \& Uauy, 1995a) differs markedly from that of cow's milk and most infant formulas (Gil \& Sánchez-Medina, 1981; Gil \& Uauy, 1989, 1995a). Preformed nucleotides may be of importance for the growth of tissues with a rapid turnover (Van Buren et al. 1985; Nuñez et al. 1990; Uauy et al. 1990; Gil \& Uauy, $1995 b$ ), particularly bone marrow, leucocytes and the intestinal mucosa which preferentially use the nucleotide salvage pathway to fulfil their purine and pyrimidine nucleotide requirements (Mackinnon \& Deller, 1973; Savaiano \& Clifford, 1981; LeLeiko et al. 1983; Cohen et al. 1984).

Dietary nucleotides may modulate lipoprotein and fatty acid metabolism in human early life (Gil et al. 1986b, 1988; De-Lucchi et al. 1987; Pita et al. 1988; Morillas et al. 1994; Sánchez-Pozo et al. 1994), and they may enhance the growth of bifidobacteria and limit that of enterobacteria in the gut of newborn infants (Gil et al. 1986a; Gil \& Uauy, 1995). Dietary nucleotides may affect small-intestinal growth in experimental animals (Gil \& Uauy, 1995) and may have a role in the maintenance of the immune response both in animals (Van Buren et al. 1983, 1985; Pizzini et al. 1990; Kulkarni et al. 1992) and in human subjects (Carver $e t$ al. 1991; Gil \& Uauy, 1995).

5.8.1. Nucleotides and small intestine growth. A number of factors are involved in the regulation of the renewal of the absorptive epithelium and in the repair of the epithelium under pathological conditions (Shiner et al. 1990). N-containing nutrients appear to be important for gut growth. At weaning, protein modulates the ontogenic changes in tissue DNA synthesis and plays a role in completing the growth of the rat's gastrointestinal tract (Buts \& Nyakabasa, 1985). Dietary nucleotides have been shown to influence gut development and repair after injury. Uauy et al. (1990) reported that intestinal disaccharidase activities are increased in rats during development by dietary nucleotides, and DNA, lactase ( $E C$ 3.2.1.23), sucrase ( $E C$ 3.2.1.48) and maltase $(E C$ 3.2.1.20) activities increase with a nucleotide-supplemented diet in animals after chronic diarrhoea (Nuñez et al. 1990; Bueno et al. 1994). Dietary nucleotides promote the enterocyte growth in tissue culture (He et al. 1993; Sanderson \& He, 1994) and improve the intestinal repair in an animal model of radiation injury (Uauy et al. 1994). Recent studies on the potential roles of exogenous nucleotides on proliferation, differentiation and apoptosis of human small-intestinal epithelium have shown that AMP may have an important role in controlling the dynamic balance of cellular turnover in the developing human small intestine (Tanaka et al. 1996). Moreover, dietary nucleotides influence the gene transcription in the intestine (LeLeiko et al. 1995). Animals receiving a purine and/or pyrimidine-free diet have a decreased protein synthesis and RNA throughout the intestine and specific mRNA for the enzymes hypoxanthine phosphoribosyltransferase (HGPRT) and adenosine phosphoribosyltransferase (APRT) (LeLeiko et al. 1987). A 35-base pair region identified in the HGPRT promoter is necessary to confer sensitivity to exogenous purines as a site for binding to trans-acting regulatory proteins (Walsh et al. 1990, 1992).

5.8.2. Nucleotides and liver growth. Extracellular nucleotides and nucleosides have been reported to modulate hepatocyte growth (Ohyanagi, 1989; Gil \& Uauy, 1995b) and regeneration and to play an important role in the synthesis of glycogen (Buxton et al. 1986). Ogoshi et al. $(1985,1988)$ reported that parenterally administered 
nucleotides improved the hepatic function and promoted earlier restoration of the $\mathrm{N}$ balance after liver injury or partial hepatectomy. Moreover, it has been observed that adenosine administration partially prevents cirrhosis induced by $\mathrm{CCl}_{4}$ in rats due to a stimulation of total hepatic collagenase activity and is able to counteract the drastic decrease in adenine nucleotides (Hernández-Muñoz et al. 1990).

Deprivation of dietary nucleotides results in a transient decrease in acid-soluble nucleotides and RNA content in rat liver as well as in a decreased protein synthesis rate (LópezNavarro et al. 1995). Dietary nucleotides have improved liver structural recovery and binuclearity in experimental cirrhosis induced by thioacetamide (Torres et al. 1996). In that model dietary nucleotides led to a lower number of stellate cells and to a lower collagen deposition.

\subsection{Long-chain polyunsaturated fatty acids and cell growth}

Despite recent advances in neonatal care, low-birth-weight infants do not achieve first year growth equivalent to that of infants born at term. It has not been clarified how the administration of long-chain fatty acids to infants may affect growth and specific tissue growth and differentiation. Direct evidence that normalized growth might relate to arachidonic acid status came from the observation that formula supplemented with marine oil but no arachidonic acid decreased the concentrations of plasma phosphatidylcholine arachidonic acid (Carlson et al. 1991) and reduced weights compared with standard formula without marine oil (Carlson et al. 1992). Phosphatidylcholine arachidonic acid declined in preterm infants fed on non-supplemented formulas, and weight fell progressively beginning at 2 months of age. The nadir of plasma phosphatidylcholine arachidonic acid and growth was further reduced by formula containing marine oil compared with the non-supplemented formulas (Carlson et al. 1993).

Koletzko \& Braun (1991) have investigated whether birth weight correlates with the postnatal EFA status in premature infants. A significant and positive correlation between body weight and plasma triacylglycerol content of arachidonic acid and total $n-6$ long-chain-PUFA was found as well as a negative correlation with $\alpha$-linolenic acid.

There is only limited information about how intakes of $n-6$ and $n-3$ long-chain-PUFA may affect specific tissue growth. Animal studies using diets supplemented with both types of fatty acids have shown that in addition to plasma and erythrocyte cell membranes, small intestine, liver, kidney, lung and heart are affected in their fatty acid composition. Depending on the composition of the diet, susceptibility to oxidation may be affected, which might influence tissue growth and function (Suarez et al. 1996a,b).

\subsection{Early growth and later obesity}

In animal studies, early overfeeding may have lasting effects on nutrient utilization and body composition (Davis et al. 1973; Lewis et al. 1986). In male infants of pregnant women who suffered from starvation, obesity in young adulthood was more prevalent if the mothers were exposed to the famine during the first half of gestation, while the incidence of later obesity was reduced if starvation occurred during late gestation and the early postnatal period (Ravelli et al. 1976). Also, food composition, and particularly protein intake, in early childhood has been suggested as a predictor of later risk of obesity. In view of the high prevalence of obesity in Europe and its major importance for public health and health-care costs, the potential modulation of later obesity by early food choice needs to be further explored.

\section{Maturation of the gastrointestinal tract}

\subsection{Introduction}

Digestion and hydrolysis of macro- and micronutrients by the gastrointestinal tract are essential prerequisites for longterm survival of mammals including man. Proteins, fats and carbohydrates are digested and hydrolysed by a variety of potent excretory glands and by the brush-border enzymes of the small intestine as well as by bacterial breakdown within the large intestine. As for carbohydrates, a cascade of hydrolytic events finally leads to the presence of monosaccharides within the lumen of the gastrointestinal tract which are transported across the microvillus membrane by highly specialized transporters. Carbohydrates with high molecular mass in the form of amylose and amylopectin are hydrolysed by $\alpha$-amylase (EC 3.2.1.1) of the saliva and the pancreas. $\alpha$-Amylase can hydrolyse 1-4- $\alpha$-glycosidic bonds which are present in both amylose and amylopectins. The branches of 1-6- $\alpha$-glycosidic side chains in amylopectins remain after the action of $\alpha$-amylase as $\alpha$-limitdextrins, and are further hydrolysed by sucrase-isomaltase (SI) (Gray, 1967). Hydrolysis of starches is dependent on the age of the infant. In the first 6 months of life, activity of $\alpha$-amylase is low and reaches full activity at the end of the first year of life (Lentze, 1986). Defects in sugar digestion occur because of disturbances within the combined action of pancreatic $\alpha$-amylase and that of intestinal brush-border enzymes. Decreased digestion and hydrolysis of carbohydrates will induce either osmotic diarrhoea and/or bacterial overgrowth within the small intestine as well as bacterial breakdown of carbohydrates within the colon.

Malnutrition is very often combined with chronic diarrhoea and damage of the gastrointestinal mucosa as a consequence of lack of protein and energy. Key factors in this devastating cascade are the brush-border membrane of the small intestine and its hydrolysing and absorptive capacity. Important observations with regard to the hydrolytic capacity of intestinal disaccharidases, which are responsible for sugar hydrolysis, have come through the study of their intracellular pathways and processing of enzyme molecules in normal and altered human as well as animal mucosa using various techniques of molecular biology. The knowledge of these investigations has considerably increased our understanding as to how carbohydrates are hydrolysed and absorbed from the intestinal epithelial cell.

\subsection{Development of sugar hydrolases and transporters}

The morphological development of the small intestine starts in the 9th week of gestation from the proximal to the distal part of the gut (Hauri, 1986). Small villi develop over a 
stratified epithelium of several layers. The first crypts are seen at the age of 10-11 weeks gestation within the duodenum and jejunum, and at 11-12 weeks in the ileum and colon. The changes into a columnar epithelium occur together with the appearance of secondary lumina visible by electronmicroscopy and parallel invagination of mesenchymal cells and extrusion of surface cells (Naim et al. 1988). The development of a brush-border membrane is seen together with crypt development in the 10-12th week of gestation. At the same time brush-border membrane hydrolases start to appear. Lactase-phlorizin-hydrolase (LPH), SI and maltase-glucoamylase are first detectable at the 10th week of gestation (Dahlqvist \& Lindberg, 1965). Their enzymic activities increase during gestation. As SI and maltase-glucoamylase reach their full activities by the 25th week of gestation (Jirsova et al. 1965-6), the activity of LPH remains low until the 28th week of gestation and increases slowly between the 32nd and 34th weeks of gestation (Dahlqvist \& Lindberg, 1966). For the nutrition of very immature premature babies with very low birth weight between the 26th and 28th weeks of gestation this could play a role in the digestion and hydrolysis of lactose given in breast milk or infant formula. After introduction of lactose-containing milk the activity of LPH matures quickly to normal enzymic activities. The glucose transporters in the small intestine develop during gestation at about the same time as the sugar hydrolases. Sodium-dependent glucose transporter 1 (SGLT 1), glucose transporter (GLUT) 5 and GLUT 2 appear at the 11th week of gestation as seen by the expression of specific mRNA in human fetal intestine (Davidson et al. 1992).

\subsection{Biosynthesis of intestinal brush-border membrane hydrolases}

Mature intestinal epithelial cells are highly polarized and are composed of two main membranous regions: the apical cell membrane, with its unique feature of a brush border, and the basolateral membrane. The microvillar membrane is characterized by a network of microvilli which contain the important glycoproteins responsible for the hydrolysis and absorption of micronutrients and minerals. For the degradation of various sugar and peptide molecules of different composition and chain length, the intestinal disaccharidases SI, maltase-glucoamylase, LPH, trehalase and a variety of peptide hydrolases are present within the microvillar region of the columnar epithelia in order to digest carbohydrate molecules and oligopeptides from nutritional intakes. The disaccharidases are the best studied brush-border hydrolases. Their enzymic activities and their distribution throughout the gastrointestinal tract as well as their age dependency have been investigated by many groups of researchers. The biogenesis of the disaccharidases produced and processed by the mature enterocyte has been elucidated in mammals as well as in man, demonstrating common pathways within the translational and post-translational routes.

SI and LPH are the best studied brush-border membrane hydrolases in all species including man. The data accumulated from these studies have led to a general understanding as to how these hydrolases are synthesized and processed within the small-intestinal enterocyte. After transcription a single-chain precursor (pro-SIh) rich in mannose (high mannose precursor) is produced in the rough endoplasmic reticulum. This contains carbohydrate residues which are $\mathrm{N}$-glycosylated and has an apparent molecular mass of $210 \mathrm{kDa}$ in human subjects (Hauri et al. 1980; Ghersa et al. 1986). From the rough endoplasmic reticulum the proSIh is transported to the Golgi apparatus where trimming of the mannose residues and addition of complex carbohydrates occur to yield pro-SIc (molecular mass $245 \mathrm{kDa}$ ) (Hauri et al. 1982). The complete primary structure of the pro-SI from rabbit is composed of 1827 amino acid residues containing the two active catalytic subunits isomaltase $(140 \mathrm{kDa})$ and sucrase $(120 \mathrm{kDa})$ which are associated by oncovalent, ionic interactions (Sjöström et al. 1980). After complex glycosylation in the Golgi the pro-SIc is translocated and inserted into the microvillus membrane by vesicular transport directly into the apical microvillus membrane. The exact route for the transportation of glycoproteins from the Golgi to the microvillar membrane remains to be established. The time course of transport of the pro-SIc from the Golgi into the brush-border membrane in a human colon carcinoma cell line ( $\mathrm{CaCo}-2$ cells) is rather slow (Herskovics et al. 1981). Similar transport kinetics were also obtained when the biosynthesis of SI was investigated in the organ culture of human intestinal explants (Naim et al. 1988). Insertion of pro-SIc into the microvillus membranes is obtained by anchoring a single hydrophobic segment of the molecule which is located at the $\mathrm{N}$-terminus of isomaltase (Hauri et al. 1986). After insertion into the microvillar membrane pro-SIc is cleaved into sucrase and isomaltase by pancreatic proteases (Naim et al. 1988). The mature catalytic enzymes sucrase and isomaltase cleave various substrates including sucrose, isomaltose, maltose, maltotriose and amylose as well as $\alpha$-limit dextrins which are derived from the hydrolysis of amylopectins. SI, together with maltase-glucoamylase, plays a major role in starch digestion during the first month of life as $\alpha$-amylase in human infants is not developed during the first 6 months of life (Danielsen et al. 1981). Striking structural and functional similarities suggest that intestinal SI, human lysosomal $\alpha$-glucosidase and Schwanniomyces occidentalis glucoamylase are derived from a common ancestral gene (Naim et al. 1991).

$\mathrm{LPH}$, as the only $\beta$-glycosidase of the brush-border membrane, has been reported in earlier work to be synthesized also as a single-chain precursor with a molecular mass of $150 \mathrm{kDa}$ (Sjöström et al. 1983). However, conflicting results were obtained on the structure and identification of the precursor molecules. In the pig a precursor protein of $200 \mathrm{kDa}$ was observed (Danielsen et al. 1984). The same group reported in a more recent publication that the precursor molecule of LPH in the pig small intestine is a membrane-bound polypeptide of $225 \mathrm{kDa}$ which is intracellularly cleaved after complex glycosylation (Mantei et al. 1988). Similar data were obtained in $\mathrm{CaCo}-2$ cells (Herskovics et al. 1981). In human intestinal epithelial cells a high-mannose precursor of $215 \mathrm{kDa}$ was demonstrated in intestinal explants maintained in organ culture (Hauri, 1986). Here the intracellular cleavage of the highmannose precursor occurs during the translocation of the 
molecule across the Golgi before complex glycosylation takes place. The mature form of LPH is then inserted into the membrane with a molecular mass of $160 \mathrm{kDa}$. The primary structure of the human lactase molecule is known and comprises 1927 amino acids in man and 1926 amino acids in the rabbit (Messer \& Kerry 1967). The place at which the mature form of lactase is cleaved from its precursor is position 866 of the whole molecule. In contrast to most other brush-border membrane hydrolases the mature lactase is anchored within the lipid bilayer from its carboxyl end of the protein chain (Messer \& Kerry, 1967).

Maltase-glucoamylase hydrolyses 1-4- $\alpha$-glycosidiclinked glucose polymers including maltose and maltotriose (Naim et al. 1989). The enzyme is developed early in gestation and contributes to the digestion of starch after birth. The biosynthesis of maltase-glucoamylase is similar to that of SI as a precursor molecule of 225 and $245 \mathrm{kDa}$. The former represents the high mannose and the latter the complex glycosylated precursor of maltase-glucoamylase in the pig small intestine (Danielsen et al. 1984). The biosynthesis and processing of maltase-glucoamylase in human intestinal biopsy specimens does not involve intracellular or extracellular proteolytic modifications, in contrast to SI and LPH (Pfeffer \& Rothman, 1987).

\subsection{Intestinal absorption of glucose and fructose}

Our current understanding of glucose (galactose) and fructose is that the monosaccharides are transported by different methods into the intestinal absorptive epithelial cells. Whereas SGLT 1 is responsible for the active transport of glucose or galactose with equimolar amounts of $\mathrm{Na}$ against a concentration gradient into the cytoplasm of the enterocyte (Crane 1975), fructose undergoes facilitated transport by the GLUT 5 transporter which is also located on the brush-border membrane (Davidson et al. 1992). Once taken up into the enterocyte, $\mathrm{Na}^{+}$is exchanged with $\mathrm{K}^{+}$by the $\mathrm{Na}^{+}, \mathrm{K}^{+}$-ATPase (EC 3.6.1.3) which is located in the basolateral membrane and glucose is pumped into the intracellular space by another glucose transporter protein, GLUT 2. GLUT 2 has also been shown to be localized within the basolateral membrane. The function of SGLT 1 is essential for survival of a given species such as man. When absent or deficient, as in congenital glucose-galactose malabsorption, the malfunction of SGLT 1 is a lethal factor.

The absorption of these simple monosaccharides when present in the intestinal lumen is dependent on a variety of factors contributing to the rate of absorption. It is dependent on age, composition of food and species. In mice a relationship between the type of diet and sugar uptake was demonstrated. When fed on a high-carbohydrate, low-protein chow, the uptake of glucose remained high, and dropped considerably when the mice were put on a low-carbohydrate, high-protein diet (Karasov et al. 1983). Moreover, it was shown that a strong correlation exists between glucose uptake and the type of natural diet within various vertebrate species. The more herbivore the species is, the more glucose is absorbed; the more carnivore the species is, the less glucose is taken up (Riby et al. 1993). Fructose absorption depends strongly on the presence of other carbohydrates within the intestinal lumen. Fructose given together with glucose, galactose, sucrose or starch is better absorbed than fructose alone (Fujisawa et al. 1991) whereas the presence of sorbitol or dextrin leads to fructose absorption as with fructose alone. Species differences have a considerable influence on fructose absorption which depends entirely on the composition of the natural diet. Whereas the carnivores (cats) have a low fructose absorption after weaning, the rat and the rabbit increase their fructose absorption considerably after weaning (Buddington \& Diamond, 1989).

The complete mechanism for fructose absorption from the human intestine remains to be elucidated. A model of fructose absorption can be deduced from animal studies as well as from human studies. The rate of fructose absorption is influenced by glucose, but also by the amino acid glycine. Two mechanisms have been proposed to explain this effect. Fujisawa et al. (1991) speculate that a mechanism in the brush-border membrane exists which they call the disaccharidase-related transport system. This speculation is based on their findings that the specific inhibitor of SI, acarbazone, decreases fructose absorption when given with sucrose, whereas absorption increases without the inhibitor. Another explanation could well account for this effect: glucose absorption as well as glycine absorption increases the water flow from the lumen into the intercellular space by osmosis. Therefore, a solvent drag occurs leading to an enhanced uptake of fructose. The same mechanism applies when starches or sucrose are present at the same time as fructose because of the rapid hydrolysis of these carbohydrates to glucose and/or fructose by the action of maltaseglucoamylase and SI. In order to elucidate this effect fructose absorption should be studied in individuals with SI deficiency which would be the equivalent model to the rat intestinal fructose uptake studies with acarbazone. Except for LPH, the activities of other sugar hydrolases as well as SGLT 1 can be influenced by substrates (Buddington $e t$ al. 1991; Quan \& Gray, 1993). The close presence of sugar hydrolases and sugar transporters within the microvillar membrane of the small-intestinal enterocyte as well as the transporters for amino acids is the guarantee of a steady uptake of sugars derived from various sources.

\subsection{Oligosaccharides and mucins}

Besides the most abundant sugar lactose, human milk contains more than 130 different oligosaccharides and is unique among all mammalian species for its content of higher oligosaccharides, i.e. larger than lactose. For a long time the oligosaccharide fraction in human milk has been overlooked although it is the third largest solute (up to 18.5 $\mathrm{g} / \mathrm{l}$ ) and present in higher amounts than protein (Egge et al. 1983). As oligosaccharides escape the hydrolysis in the small intestine, two possible functions are discussed. One function would be the intact absorption of these components serving as substrates for organ maturation such as the brain, where rapid synthesis of sialoglycoproteins and gangliosides occurs (Sabharwal et al. 1991). Their role in the large bowel as 'dietary fibre' and their fermentation would be of significant value in nutrition. The oligosaccharides in human milk are based on five monosaccharide residues: sialic acid, $N$-acetylglucosamine, fucose, glucose 
and galactose. All oligosaccharides possess a lactose moiety at their reducing end, with sialic acid (when present) and fucose at the non-reducing end. The chain length varies between three and eleven units. The oligosaccharide composition of human milk shows temporal and individual variations (Miller et al. 1994). At the same stage of lactation the variation in oligosaccharide content was shown to be fourfold.

Recent findings on the chemical structure of oligosaccharides in milk have demonstrated structural homologies to carbohydrates carried by glycoproteins and glycolipids on cell surfaces. Such oligosaccharides are very antigenic and were targets of monoclonal antibodies in the search for specific binding to human cancer cells. Similar novel oligosaccharides which can inhibit antigenantibody reactions have been detected in human milk (Fievre et al. 1991; Kitagawa et al. 1991). They are useful hapten inhibitors to study the binding specificities of anticarbohydrate antibodies produced as mucins on cancer cells. This observation has great clinical implications with respect to breast cancer. High-molecular-mass glycoproteins (MUC1) in milk and lactating tissue have been found to contain up to $80 \%$ of carbohydrates. The low level of expression of MUC1 in healthy, undifferentiated (nonlactating) breast tissue, and its presence in many, particularly metastasizing, breast tumours has established a very useful marker in breast cancer screening. The exact nature of MUC1, its biological role and expression, has been studied in milk and mammary tissue (Patton et al. 1995). MUC1 as expressed in tumours activates B- and T-lymphocytes. These epitopes represent underglycosylated forms of MUC1 characteristic of breast and pancreatic cancer. It is also responsible for keeping ducts and lumens, such as the mammary ducts, open. Here it binds also to L-selectin which is expressed on the surface of leucocytes. By this action leucocytes are bound to the lumen and excreted into the milk (Welply et al. 1994). It also escapes digestion and is excreted in the stools of breast-fed infants. In the colon it binds to micro-organisms, particularly to the fimbrins of $E$. coli, contributing to the host defence of the breast-fed infant (Cravioto et al. 1991; Schroten et al. 1993).

\subsection{Probiotic substances in milk or milk substitutes}

There are indications that certain ingested micro-organisms added to milk or milk products may exert some physiological effects and promote health in human infants. Such an example is the use of Lactobacillus GG added to the milk formula for premature infants. After administration of these bacteria to premature infants it was noted that the bowel was colonized by Lactobacillus GG, and no clinical side-effects were seen. However, no clinical benefit was noted either (Millar et al. 1993). As far as potential effects on fermentation are concerned, Lactobacillus GG given to premature infants had no effect on production of short-chain fatty acids in stools. The observed small increase in ethanol excretion is unlikely to have any clinical significance (Stansbridge $e t$ al. 1993). Whether or not pre- and probiotics modulate gut maturation and have relevant health benefits in infancy remains to be elucidated.

\subsection{Dietary regulation of xenobiotic metabolism}

The nutritional status or specific nutrients may influence the metabolic capacity of the liver, but also of other organs (intestinal mucosa). The exact mechanism of drug-nutrient interaction remains unknown. Moreover, the health effects of such interactions have to be explored.

Diet could modulate the metabolism either through an action on substrate availability or by modifying key enzymes of metabolism. The influence of starvation on conjugation and glucuronidation illustrates this point (Mandl et al. 1995)

One important discovery of recent years is that some components of food (antioxidants like butylated hydroxytoluene) are able to modulate the activity of key enzymes of phase 1 or 2 metabolism, by modifying gene expression (Kashfi et al. 1994). This is a promising area that requires further work. In fact the modulation of gene expression by nutrients is well described in the context of the influence of food on carbohydrate or lipid metabolism but the effect of macro- or micronutrients on xenobiotic-metabolizing enzymes (XME) remains unelucidated.

Diet may also influence XME by inducing specific pathology e.g. steatosis. The part played by nutrients and morphological alteration in the modification of XME has to be established (Leclercq et al. 1996).

Specific components of food ( $n$-3 PUFA), even at very low concentrations (piperine from black pepper, naringenine from grapefruit) may modify the activity of specific isoforms of XME (e.g. glucuronosyltransferases) (Speck $e t$ al. 1991). This could lead to interesting developments in several fields. (1) Fundamental research: it will help in studying this metabolic reaction in detail by using those nutrients as activators or specific inhibitors. (2) Those nutrients which can be used at low dose could, thus, be considered as 'toxico-modulators'. (3) Such compounds have been proposed as therapeutic adjuvants, allowing reduction of the dose of expensive drugs, or drugs with a low safety-therapeutic index. The discovery of new nutrients with new targets could constitute a very promising area. Finally, the validation of experimental models (and particularly in vitro models) allowing the study of drug-nutrient interactions would give a new input in this area.

\section{Development of the immune system}

\subsection{Introduction}

Positive effects of particular foods or food ingredients on the human immune system (e.g. inhibition of CHD and cancer development etc.) could conceivably be related to early nutritional events or may only be seen after decades of intake or lifestyle changes. An important unresolved issue is whether there are critical time periods during which a provision may be especially beneficial to the immune system. In view of these difficulties, in vitro surrogate markers for study end-points are frequently used. A surrogate end-point can be defined as a laboratory measurement or a physical sign used as a substitute for a meaningful endpoint that measures directly how a patient feels, functions or survives. Changes to a surrogate end-point induced by a dietary intervention are expected to reflect changes in a 
biologically meaningful end-point. However, surrogate endpoints do not always reflect the true clinical outcome and can be misleading or even meaningless (Fleming \& DeMets, 1996). Other important limitations of studies reporting effects on the development of immunity are:

short duration;

lack of standardized tests;

lack of correlation of in vitro and/or in vivo findings with immune protection or immune suppression;

lack of demonstration of health-enhancing effects in a developing normal, presumably non-deficient population of infants, but with changing nutritional requirements.

7.1.1. Which constituents of the immune system to investigate? The immune system is a highly complex regulatory cellular and humoral system of protection and stimulation directed to avoid danger to the host. On this basis a possible role of diet in cancer prevention could be taken as summary evidence for beneficial effects of the diet on the immune system. This extrapolation, however, seems highly conjectural since it would argue that a number of cancers are due to deficient immune surveillance mechanisms. This may or may not be the case and a number of other protective mechanisms could be equally plausible.

The present report focuses separately on published evidence mostly in infants and children and, where appropriate, in normal individuals and animals. Parenteral micronutrient supplementation in disease states or after surgery, low level toxicity and multiple chemical sensitivities will not be addressed.

7.1.2. Special considerations for the immune system of the developing child. There is a dearth of reliable information of the effects of vitamins, saturated and unsaturated fatty acids, trace minerals and other normal food constituents on the infant's developing immune system. The majority of reports examine the effects of corrections of severe or moderate deficiencies on the immune responses in infants and children (or animals). Very little is known of the effects of supplementations, either in line with recommendations or above, in a non-deficient population. As indicated earlier, most measurements have been related to surrogate endpoints and the relationships between administration of test substances and their effects on the immune system are not strongly causal.

\subsection{Antioxidants and vitamins}

7.2.1. In general. Antioxidant vitamins generally enhance different aspects of cellular and non-cellular immunity. The antioxidant function of these micronutrients could, at least in part, enhance immunity by maintaining the functional and structural integrity of important immune cells. Multiple effects attributed to antioxidants include risk reduction of a variety of chronic diseases (Messina \& Messina, 1996), anti-(retro)-viral activity (Formica \& Regelson, 1995), immune enhancement in animals (Forni et al. 1986; Gebhard et al. 1990, ), in man (Chavance et al. 1989; Penn et al. 1991; Rall \& Meydani, 1993), and evidence that certain vitamins alone or in combination and other micronutrients given in levels above the current recommendations have critical, beneficial effects on human immune responses (Bendich, 1995).

7.2.2. Vitamin A. The effects of vitamin A supplementation on measles in deficient and non-deficient children have been the subject of several recent reports (Coutsoudis et al. 1992, 1995; Rosales \& Kjolhede, 1994; Semba et al. 1995; Stabell et al. 1995; Keusch, 1996). In general, in the last decade epidemiological, immunological, and molecular studies have yielded substantial evidence for a central role. The recent discovery of retinoic acid and retinoid $\mathrm{X}$ receptors has provided a molecular basis for the action of vitamin $\mathrm{A}$ and its metabolites at the level of gene activation. $\beta$-Carotene supplementation enhances the expression of functionally associated molecules on human monocytes (Hughes et al. 1996) and also enhances immune responses to poor immunogens, which may be relevant to infants receiving vaccines which are characterized by low seroconversion rates (Semba, 1996), however under certain conditions seroconversion rates may be negatively affected too (Semba et al. 1995). No difference was found (using whole-blood culture techniques) in the in vitro proliferative responsiveness of $\mathrm{T}$-cells to concanavalin- $\mathrm{A}$ and tetanus toxoid of children with normal or low-normal concentrations of vitamin A or $\mathrm{Zn}$ (Kramer, 1996).

7.2.3. Vitamin C. Vitamin $\mathrm{C}$ has gained great scientific and media attention through the promotions of its effects on the common cold. Early reports of systemic conditioning of infants following an increased intake of vitamin $\mathrm{C}$ during development seem to have been unfounded (Gerster \& Moser, 1988). Studies which failed to identify a positive effect on the symptoms of the common cold have recently been critically reviewed and it now seems likely that there is a reduction in clinical symptoms associated with intake of 2-3 g ascorbic acid/d at the onset of the cold (Hemila, 1996).

7.2.4. Vitamin $B$ complex. Few studies have addressed the effects of supplementation with individual B vitamins and/or the coenzyme CQ10. When studied, positive enhancing effects on cell-mediated immunity, CD4:CD8 ratios, delayed type hypersensitivity and antibody production have been reported (Gebhard et al. 1990; Miller \& Kerkvliet, 1990; Folkers et al. 1993). Tumour inhibition by high dietary pyridoxine may be mediated by immunological mechanisms that are lacking in the genetically immunodeficient (athymic) mice in which these studies have been carried out (Gebhard et al. 1990).

7.2.5. Vitamin E. Vitamin $\mathrm{E}$, in its role as a potent antioxidant and immunostimulant, has received a great deal of attention (Tengerdy, 1990; Shor Posner et al. 1995; Liang et al. 1995; Finch \& Turner, 1996; Liang \& Watson, 1996). Vitamin E supplementation enhances humoral and cellmediated immunity, and augments the efficiency of phagocytosis in laboratory animals and human subjects. Vitamin E deficiency has been suggested to contribute to alterations of the neonatal neutrophil function, and supplementation with $120 \mathrm{mg} / \mathrm{kg}$ over the first $14 \mathrm{~d}$ of life of healthy premature infants has been shown to increase phagocytosis (Chirico et al. 1983).

7.2.6. Vitamin $D$. There is now increasing evidence that the hormonal form of vitamin D, 1,25-dihydroxycholecalciferol $\left(1,25(\mathrm{OH})_{2} \mathrm{D}_{3}\right)$, is involved in the regulation of the 
immune system. $1,25(\mathrm{OH})_{2} \mathrm{D}_{3}$ exerts most of its actions after it has bound to its specific receptors which are present in monocytes and activated lymphocytes. The hormone inhibits lymphocyte proliferation and immunoglobulin production in a dose-dependent fashion. It interferes with $\mathrm{T}$-helper cell function, reducing T-helper cell-induction of immunoglobulin production by B-cells and inhibits the passive transfer of cellular immunity by T-helper cells in vivo. Expression of Class II antigen by lymphocytes and monocytes is also affected. In experimental in vivo studies $1,25(\mathrm{OH})_{2} \mathrm{D}_{3}$ is particularly effective in preventing autoimmune diseases (Schwartz, 1992; Mathieu et al. 1994; Thomasset, 1994). There is no information on the effects of vitamin $\mathrm{D}$ or its metabolites on the developing human immune system.

\subsection{Multiple micronutrient supplementation studies}

Trace elements perform important functions in growth and development. However, little information exists about dietary requirements of them during the demanding period of infancy. Although several factors influence the dietary needs of these essential elements, the basis for establishing dietary needs in infants is hindered by the dearth of studies that have assessed their bioavailability and effects on the immunity in this age group. Thus, until it has been conclusively shown otherwise, the physiological response to human milk is used as the standard for infant feeding practices (Milner, 1990).

Key questions such as the risks to human health of altered environmental distribution of $\mathrm{Zn}$, assessment of $\mathrm{Zn}$ status in man, effects of $\mathrm{Zn}$ status in relation to other essential metals on immune function, reproduction, neurological function and others remain (Sherman, 1992; Walsh et al. 1994; Prasad, 1995; Ripa \& Ripa, 1995; Sazawal et al. 1996). $\mathrm{Zn}$ supplementation has recently been shown to reduce persistent diarrhoea in children (Sazawal et al. 1996).

In vitro and in vivo studies show that antioxidants generally enhance different aspects of cellular and non-cellular immunity. The antioxidant function of these micronutrients could, at least in part, enhance immunity by maintaining the functional and structural integrity of important immune cells (Chew, 1995).

Effects of trace minerals on the outcome of pregnancy have been reviewed. About $30 \%$ of pregnant women suffer from $\mathrm{Fe}$ deficiency worldwide, and while its effects on neonatal $\mathrm{Fe}$ status are not severe, adverse sequelae include impaired neonatal immune status (Allen, 1986; for review, see Bryan \& Stone, 1993). Low maternal intakes of $\mathrm{Cu}, \mathrm{Mn}$, and Se have not been associated with adverse outcomes of pregnancy. Se deficiency, however, appears to result in immunosuppression affecting neutrophil function, antibody production, cytotoxicity and lymphocyte proliferation (Kiremidjian Schumacher \& Stotzky, 1987).

\subsection{Fatty acids}

Several lines of evidence support the role of dietary lipids as regulators of the immune system. This is demonstrated by studies examining lipid alteration of the immune response to allergens, malignancy, autoimmune disease, sepsis, trauma, and transplantation. Both the quantity and quality of lipid are important in immunoregulation. Both cell-mediated and humoral immunity are affected by dietary lipids. Multiple mechanisms probably contribute to the overall effects of lipids, including alteration of arachidonic acid metabolism, changes in cell membranes, production of inflammatory cytokines, and impairment of the reticuloendothelial system (Perez \& Alexander, 1988; Yetiv, 1988; Fernandes et al. 1990; Melnik et al. 1991; Watanabe et al. 1994; Endres, 1996; Hellerstein et al. 1996).

\subsection{Arginine}

Many of the known roles of arginine (e.g. in immune function, wound healing, and protection against $\mathrm{NH}_{3}$ intoxication) are mediated by a metabolic pathway synthesizing NO in the liver. Both stimulatory and suppressive functions have been identified with a prominent role of the macrophage (Barbul, 1990; Rodeberg et al. 1995; Suzuki et al. 1995; Krenger et al. 1996; Marcinkiewicz et al. 1996). Particular effects on the developing human immune system are uncertain. Oral administration may be less effective than parenteral administration (Torre $e t$ al. 1993). A number of reports investigate the potential benefits of arginine supplementation during surgical and other periods of stress in human subjects and in experimental models. Beneficial effects on wound healing, reduction of postoperative septicaemias etc. cannot always be attributed entirely to arginine, since it was often given with other dietary modulations (Daly et al. 1990; Cerra et al. 1991; Seidman et al. 1991; Kemen et al. 1995; Senkal et al. 1995; Braga et al. 1996; Kudsk et al. 1996; Marcinkiewicz et al. 1996).

\subsection{Nucleotides}

Dietary sources of preformed purines and pyrimidines seem to be important for optimal function of the cellular immune response. It was previously assumed that nucleotides were not needed for normal growth and development, but the results described in the present review demonstrate a need for nucleotides in the response to immunological challenges. The need for sources of preformed nucleotides in defined formulas such as parenteral and enteral formulas and infant formulas is suggested in some studies (Carver, 1994; Kulkarni et al. 1994; Rudolph, 1994). An exogenous source of nucleotides from the diet may optimize the function of rapidly dividing tissues when growth is rapid and the diet is low in nucleotides. Studies performed in human infants are, at most, inconclusive (Carver, 1994; Kulkarni et al. 1994) and further studies are required to assess in infants the interesting findings about dietary nucleotides reported in experimental models (Gil \& Uauy, 1989; Sanchez Pozo et al. 1994, 1995; Ortega et al. 1995; Lopez-Navarro et al. 1996; Navarro et al. 1996).

\subsection{Maturation of the immune system in formula-fed $\mathbf{v}$. breast-fed infants}

In a small study of systemic and secretory immunity of breast-milk-fed $v$. formula-fed infants it was shown that 
there is a general stimulation of responsiveness by cytokines in milk and a reduction of specific responses by antigen exclusion. Bottle-fed infants reached a similar level of immunological maturity by 3 months of age, exhibiting raised levels of serum antibodies against gut organisms and milk proteins and demonstrating increased non-specific activation of lymphoid cells (Stephens, 1986; Stephens et al. $1986 a, b)$

7.7.1. Effects of antigen transfer via breast milk on the infant's immunity. Dietary antigen excretion into breast milk seems to be a general phenomenon and has been reported for milk, egg, wheat proteins and parasite antigens (Kilshaw \& Cant, 1984; Troncone et al. 1987; Petralanda et al. 1988). Excreted amounts are in the range of $\mu \mathrm{g} / \mathrm{l}$. The immunological significance of transfer of dietary antigens during breast-feeding is still unclear. It is generally accepted that breast-feeding reduces the risk of food allergic reactions and also of atopy in a population at risk (uni- or biparental history of atopy) but sensitizing effects in infants have also been described (Warner, 1980; Gerrard \& Shenassa, 1983; Savilahti et al. 1987; Lindfors \& Enocksson, 1988). Studies by Chandra et al. (1986, 1989a), Zeiger et al. (1992) and others (Halken et al. 1993a; Vandenplas et al. 1995) suggest that elimination of (significant) dietary antigen transfer via breast milk for 6 months (amongst other preventive measures) in a population at risk reduces the probability of a food-specific sensitization (and possibly atopic symptoms) for up to 48 months, an effect which persists even after the diet of the infant has been liberalized. The following points merit special consideration.

7.7.2. Maternal diet during pregnancy and effects on the infant's immunity. There are no reports which demonstrate any preventive (or sensitization) effects in infants with a parental history of atopy (Fälth-Magnusson et al. 1987; Lilja et al. 1989; Fälth-Magnusson \& Kjellman, 1992).

7.7.3. Maternal diet during pregnancy and lactation. In view of the complexity of the studies and the number of confounding variables, it is not entirely surprising that a number of studies have come to different conclusions. Maternal diet, while continuing breast-feeding, has been shown to be of moderate benefit in the reduction of atopic manifestations (mainly eczema) and milk allergy in infants or children (Chandra et al. 1989a,b; Sigurs et al. 1992; Zeiger et al. 1992; Zeiger \& Heller, 1995). Other studies have failed to show this effect (Lilja et al. 1989).

\subsection{Role of the gut flora and probiotic bacteria in the infant's immunity and gut defence}

Little is known about the immunomodulating capacity of the first bacteria colonizing the gut. Breast-fed infants develop a typical intestinal flora and this has been linked to a certain resistance to enteric infections. However, breast milk contains a host of other immunomodulating factors and it is difficult to claim any causality in these studies. Infants given breast-milk substitutes with various strains of lactic acid-producing bacteria may also exhibit some resistance to infections. In a small clinical study of thirty-nine children, protective effects of the supplementation of an infant formula with oligosaccharides, fermented milk or lactic acidproducing bacteria on the reduction of the incidence of acute diarrhoea were reported. A randomized controlled feeding trial with Bifidobacterium breve in ninety-one very-lowbirth-weight infants demonstrated effective colonization, fewer abdominal signs and better weight gain (Kitajima et al. 1997). An enhancement of the circulating antibodysecreting cell response was observed in infants with rotavirus diarrhoea supplemented with a strain of Lactobacillus casei, compared with a placebo group (Kaila et al. 1992). The duration of this response and other protective or longerterm effects are unknown. Other small studies reported an enhancement in the phagocytic activity of granulocyte populations in the blood of human volunteers after consumption of fermented milk with Lactobacillus acidophilus and B. bifidum (Schiffrin et al. 1995). It is unresolved whether studies in a larger number of unselected infants under different conditions in different countries would yield similar encouraging results.

The gut microflora is an important constituent in the intestine's defence barrier. Probiotic bacteria have been suggested to affect different aspects of gut defence: immune exclusion, immune elimination and immune regulation.

7.8.1. Immune exclusion and elimination. Although many clinical benefits have been ascribed to consumption of candidate probiotic strains in gastrointestinal disease (Isolauri et al. 1991; Saavedra et al. 1994), only a few human studies have assessed the effects of these bacteria on gut defence mechanisms. Early reports associated clinical observations with the effects on the intestinal microflora (Niv et al. 1963). Oral bacteriotherapy affected microbial imbalances shown during rotavirus infections in infants (Isolauri et al. 1994). Oral introduction of probiotic microorganisms has been associated specifically with reduction of intestinal inflammation (Majamaa \& Isolauri, 1997) and an increase in circulating antibody-secreting cells in the serum as an indicator of the intestine's immunological barrier function (Kaila et al. 1992). In children with rotavirus diarrhoea, probiotic bacteria administered during the diarrhoeal phase of the infection promoted clinical recovery and enhanced intestinal immunoglobulin $\mathrm{A}(\operatorname{Ig} \mathrm{A})$ responses (Kaila et al. 1992).

\subsection{Effects of formulas with protein hydrolysates on the infant's immune responses}

Extensively hydrolysed casein formula has been used in the treatment of children with cow's milk protein allergy and/or intolerance. Recently, ultrafiltrated whey hydrolysates have been also been used therapeutically (Halken et al. 1993b). In an attempt to prevent and/or modulate the risk of developing food-allergic and atopic manifestations in infants and children, less extensive (partial whey hydrolysates) (Chandra, 1991; Vandenplas et al. 1992, 1995) and extensively hydrolysed formulas (Chandra et al. 1989a; Zeiger et al. 1989; Halken et al. 1993a; Zeiger \& Heller, 1995; Oldaeus et al. 1997) have been used. Although these studies have been performed in infants of different (atopic) family and ethnic background, with different nutritional habits and different measures of control for confounding variables and a lack of standardized diagnostic protocols, they could be summarized as follows. (1) Infants with a high-risk family 
background of atopic disease are likely to benefit from exclusive breast-feeding for 4-6 months with some added benefit if the mother avoids certain foods such as milk, eggs, fish and possibly nuts (including peanuts) during lactation. The benefits include a reduction in the incidence of cow's milk and food allergies and atopic eczema for up to 4 years. (2) If exclusive breast-feeding for 4-6 months cannot be sustained, the use of a hydrolysed infant formula may help reduce the overall incidence of atopic manifestations in the child at risk. (3) Preventive effects of hydrolysed formulas in infants with a normal risk of developing atopic manifestations and the respective benefits of extensively $v$. less extensively hydrolysed infant formulas need to be further evaluated.

\subsection{Insulin-dependent type 1 diabetes mellitus and cow's milk exposure in infancy}

Insulin-dependent diabetes mellitus (IDDM) is considered to be a chronic autoimmune disease characterized by gradual $\beta$-cell destruction mediated by autoreactive T-lymphocytes during an asymptomatic prediabetic phase of varying duration (Knip, 1992). In a Finnish study, associations of infant feeding patterns and milk consumption with cow's milk protein antibody titres were studied in newlydiagnosed diabetic children, sibling-control children and birth-date- and sex-matched population-based control children. Inverse correlations were observed between the duration of breast-feeding, or age at introduction of dairy products, and antibody titres. High $\operatorname{IgA}$ antibody titres to cow's-milk formula were associated with a greater risk of IDDM both among diabetic-population-control and diabetic-sibling-control pairs. The results suggested that young age at introduction of dairy products and high milk consumption during childhood increase the levels of cow's milk antibodies and that high IgA antibodies to cow's milk formula are independently associated with increased risk of IDDM (Vaarala et al. 1996). Similar associations between bovine serum albumin antibodies and onset of IDDM have also been found in a low-incidence French population (Levy Marchal et al. 1995). Human T-lymphocyte cultures of cells taken from affected children allowed the detection of bovine serum albumin-specific $T$-cells which were mapped to the ABBOS peptide (pre-bovine serum albumin position 152-169) previously identified as a possible immunological mimicry epitope which could explain the cross-reactivity with pancreatic islet cell antigens (Cheung et al. 1994). A currently ongoing prospective dietary intervention trial in children genetically at risk will be able to address the causality of this highly intriguing association and, it is hoped, open the way for a primary nutritional prevention strategy.

\section{Bone growth and mineralization}

\subsection{Cell biology of bone growth}

Bone growth and mineralization is an ongoing process during human fetal and postnatal development, stabilizing at about 21 years of age. Skeletal Ca content increases from $30 \mathrm{~g}$ in the neonate to $1200 \mathrm{~g}$ in the adult, and skeletal $\mathrm{P}$ from 17 to $700 \mathrm{~g}$. Bone tissue possesses a series of enzymic mechanisms that permit mineralization of its extracellular matrix. This matrix is composed of collagen, proteoglycans and other non-collagen proteins in which insoluble mineral salts of hydroxyapatite and small amounts of other salts of $\mathrm{Mg}$, sodium carbonate and citrate are deposited, converting it into a structure capable of supporting the organism. The two most important bone cell types are osteoblasts and osteoclasts. Osteoblasts are responsible for the formation and organization of the extracellular matrix and its subsequent mineralization. Osteoclasts are large motile multinucleated cells, located on bone surfaces, responsible for the resorption of bone matrix. Bone growth or bone modelling is the result of two processes: first formation of new bone and then resorption to maintain the same structural form with, as a net result, acquisition of bone mass. At the age of about 18 years, both male and female adolescents have reached $95-99 \%$ of their individual peak bone mass. After adolescence the processes of bone resorption and formation become quantitatively in balance and this situation is referred to as bone remodelling. After 35-40 years of age the processes of bone resorption and formation become uncoupled and net bone loss will occur, eventually leading to osteoporosis (Price et al. 1994; Anderson, 1996a,b). The obvious strategies to prevent, or at least delay, the onset of osteoporosis include: (a) optimizing the attainment of peak bone mass in adolescents, and (b) preventing bone loss in later life.

\subsection{Methodological aspects in bone-mass-related studies}

In the interpretation of the bone-mass-related results of the various studies one needs to be aware of the actual technique used. The first non-invasive methods for measuring bone mass were based on quantitative evaluation of standard radiographs. During the last decade gamma- or X-ray techniques were developed based on the variable effect of matter on the passage of radiation. Most studies were performed using either single photon absorptiometry (SPA) or dual-energy X-ray absorptiometry (DEXA). SPA is a relatively simple technique using ${ }^{125} \mathrm{I}$ as the radioactive source. Its application is limited to the peripheral skeleton, particularly the radius. DEXA is becoming more and more the preferred technique to assess bone density at various sites of the skeleton with only minimal radiation exposure. Although calibration of DEXA instruments seems to be a rather trivial exercise, it relies strongly on highly specific software, with the results that measurements on one patient made with instruments of different brands do not necessarily result in similar bone mineral density data (Slosman et al. 1995). An additional feature of DEXA is its ability to measure whole-body mineral content as well as body composition. Appropriate DEXA software for infants has been developed recently and reference values from the first studies are now beginning to become available in the literature (Rigo et al. 1996). The fact that SPA and DEXA data cannot be compared with each other is illustrated by the fact that SPA produces a measurement of bone mineral content $(\mathrm{g} / \mathrm{cm})$ and assumes that the site of measurement is a small cylinder of constant width, whereas DEXA produces a measurement of bone mineral density $\left(\mathrm{g} / \mathrm{cm}^{2}\right)$ by correcting 
Table 1. Additional increment in bone mineral density (BMD) (as a percentage) following supplementation of the diet with calcium or dairy products, in children and adolescents from five different studies (From Kerstetter, 1995)

\begin{tabular}{|c|c|c|c|c|c|c|}
\hline & \multicolumn{2}{|c|}{ Johnston et al. (1992)* } & \multirow[b]{2}{*}{ Lloyd et al. (1993) } & \multirow[b]{2}{*}{ Lee et al. (1994) } & \multirow[b]{2}{*}{ Andon et al. 1994)† } & \multirow[b]{2}{*}{ Chan et al. (1995) } \\
\hline & Prepubertal & Pubertal & & & & \\
\hline $\begin{array}{l}\text { Subject no., total } \\
\text { Sex }\end{array}$ & $\begin{array}{l}22 \text { twin pairs } \\
\text { Boys and } \\
\text { girls }\end{array}$ & $\begin{array}{c}23 \text { twin pairs } \\
\text { Boys and } \\
\text { girls }\end{array}$ & $\begin{array}{c}94 \\
\text { Girls }\end{array}$ & $\begin{array}{l}162 \\
\text { Boys and } \\
\text { girls }\end{array}$ & $\begin{array}{l}248 \\
\text { Girls }\end{array}$ & $\begin{array}{c}48 \\
\text { Girls }\end{array}$ \\
\hline $\begin{array}{l}\text { Entry age (years) } \\
\text { Intervention duration (months) }\end{array}$ & $6.9(S D 1.4)$ & $36^{10 \cdot 6(\operatorname{SD} 2 \cdot 0)}$ & $\begin{array}{c}11.9(\operatorname{SD~} 0.5) \\
18\end{array}$ & $\begin{array}{c}7 \cdot 2(\operatorname{SD~} 0 \cdot 2) \\
18\end{array}$ & \multirow{2}{*}{$\begin{array}{c}11.4(\text { SD } 0.8) \\
6 \\
888\end{array}$} & $\begin{array}{c}11 \cdot 1(\text { SD 1·0) } \\
12\end{array}$ \\
\hline $\begin{array}{l}\text { Baseline Ca intake }(\mathrm{mg} / \mathrm{d}) \\
\quad \text { (placebo) }\end{array}$ & \multicolumn{2}{|r|}{908} & 935 & 280 & & 728 \\
\hline $\begin{array}{l}\text { Total Ca intake }(\mathrm{mg} / \mathrm{d}) \\
\quad \text { (diet + supplement) }\end{array}$ & \multicolumn{2}{|r|}{1612} & 1370 & 580 & $1315 \quad 1618$ & 1437 \\
\hline $\begin{array}{l}\text { Supplemental Ca source } \\
\text { BMD determination }\end{array}$ & \multicolumn{2}{|c|}{$\begin{array}{c}\text { Ca citrate malate } \\
\text { DEXA }\end{array}$} & $\begin{array}{c}\text { Ca citrate malate } \\
\text { DEXA }\end{array}$ & $\begin{array}{c}\mathrm{CaCO}_{3} \\
\mathrm{SPA}\end{array}$ & $\begin{array}{c}\text { Ca citrate malate } \\
\text { DEXA }\end{array}$ & $\begin{array}{l}\text { Dairy foods } \\
\text { DEXA }\end{array}$ \\
\hline Change in BMD $\ddagger$ & & & & & & \\
\hline Midshaft radius & $+5 \cdot 1$ & -0.1 & & & & \\
\hline Distal radius & $+3 \cdot 8$ & $+2 \cdot 9$ & & $+3 \cdot 1$ & & NS \\
\hline Lumbar spine & $+2 \cdot 8$ & $-1 \cdot 0$ & $+2 \cdot 9$ & & & $+9 \cdot 9$ \\
\hline Femoral neck & $+1 \cdot 2$ & -0.4 & & & & NS \\
\hline Ward's triangle & $+2 \cdot 9$ & -0.4 & & & & \\
\hline Greater trochanter & $+3 \cdot 5$ & $+0 \cdot 2$ & & & & \\
\hline Total body & & & $+1 \cdot 3$ & & $+1 \cdot 0$ & $+6 \cdot 6$ \\
\hline
\end{tabular}

DEXA, dual-energy X-ray absorptiometry; SPA, single photon absorptiometry.

* Two age groups were studied: prepubescent $(6.9(\mathrm{SD} 1 \cdot 4)$ years) and pubescent $(10.6$ (SD2-0) years).

$\dagger$ Two levels of dietary $\mathrm{Ca}(1315$ and $1618 \mathrm{mg} / \mathrm{d})$ were studied.

$\ddagger$ Change in $B M D=$ percentage increase in supplemented group minus increase in unsupplemented group.

the bone mineral content for the projected area of bone (Slosman et al. 1995). A shortcoming of the usual expression of bone mineral density obtained by DEXA $\left(\mathrm{g} / \mathrm{cm}^{2}\right)$ is that this areal bone mineral density does not take the agerelated increase in bone thickness into account. Therefore Cowell et al. (1995) have developed a measure of true bone mineral density, volumetric bone mineral density $\left(\mathrm{g} / \mathrm{cm}^{3}\right)$, and demonstrated its usefulness in assesssing patients with phenylketonurea (PKU), chronic renal failure and chronic asthma.

\subsection{Peak bone mass and relative risk of osteoporosis}

The relative importance of peak bone mass on the subsequent risk of osteoporosis has recently been reviewed by Ribot et al. (1995). They started with the available in vitro evidence on the relationship between low bone mass and the risk of osteoporosis relating to the mechanical properties of bone. The relevant in vivo studies include both crosssectional surveys and at least eleven prospective studies. From these studies it can be deduced that the relative risk of osteoporosis for each $1 \mathrm{SD}$ decrease in bone mineral density is increased by a factor of between $1 \cdot 7$ and $2 \cdot 7$. On comparing this value with the relative risk of $\mathrm{CHD}$ for a 1 $\mathrm{SD}$ rise in serum cholesterol or that of stroke for $1 \mathrm{SD}$ increase in blood pressure being $2 \cdot 1$ and $1 \cdot 3$ respectively, it is clear that low peak bone mass is a very strong risk factor for later osteoporosis. Another appealing value relating to the relevance of optimizing or increasing peak bone mass can be deduced from the study by Gilsanz et al. (1991) on comparing the development in peak bone mass in white and black girls. They found a 10-20\% higher bone density in black girls relative to white girls which is likely to correspond to an additional 10-20 years of protection against the decline in skeletal mass, and might explain the relatively low prevalence of osteoporosis in black women. About $80 \%$ of the variance in bone mineral density is accounted for by genetic factors (Pocock et al. 1987), thus leaving only $20 \%$ of the variance to be influenced by environmental factors such as diet. For this reason the investigation of twin pairs is very attractive because the genetic bias may thus be minimized (Johnston et al. 1992). From a study with postmenopausal twins in Britain, Spencer et al. (1995) reported a genetic linkage between the vitamin $\mathrm{D}$ receptor genotypes and bone mineral density. The degree to which this might explain the genetic factors is as yet unclear and a recent study from Denmark failed to find any significant association between common allelic variations at the vitamin $\mathrm{D}$ receptor locus and bone mineral density (Jørgensen et al. 1996).

\subsection{Bone growth and mineralization in infants and young children}

The literature on the effects of different diets during infancy on bone mineral content at 2 or 5 years of age is not yet consistent. Exclusive feeding of breast milk during the first 6 months of life supports a bone growth considered adequate even though breast milk contents of $\mathrm{Ca}$ and vitamin $\mathrm{D}$ are relatively low. Infant formulas in general, and formulas for premature infants in particular, contain higher levels of these nutrients to meet the dietary requirements and to provide a safety margin to correct for a likely lower bioavailability. Surprisingly, Bishop et al. (1995) reported a strong positive association between the amount of human milk consumed and bone mineral content at the age of 5 years in their multi-centre cohort of prematurely born infants. The authors raised two possible hypotheses to interpret their finding. Bone mineral depletion in preterm infants fed on unsupplemented human milk might 'programme' these infants to be conservative with bone mineral and to reduce the overall rate of growth so that 
'over-mineralization' occurs at a later stage when the intake of bone mineral substrates is normal. A second possibility is that one or more of the human milk growth factors might survive breast milk pasteurization and the immature digestion system and end up via the circulation at the target organ. Until one of these hypothetical mechanisms is further substantiated, the general goal in the nutrition of premature infants remains to provide enough mineral supplementation to allow attainment of bone mineral content comparable to that accrued in utero and to support catch-up growth in the first year of life. Several studies comparing bone mineralization in term-born breast-fed infants with that in infants fed on formulas containing moderate or high $\mathrm{Ca}$ content conclude that the bone mineral content of formula-fed infants is higher at the ages of 2 and 5 years (Demirini \& Tsang, 1995). Whether this effect of cumulative Ca intake during the first 2 years of life will be retained until adolescence is still unclear. A negative impact on bone growth and mineralization has been reported for a number of chronic conditions during infancy and early childhood like cystic fibrosis, IDDM, cerebral palsy, leukaemia, renal disease, growth hormone deficiency and anorexia nervosa (Shaw \& Bishop, 1995). In a group of fifty-five children with milk allergy showing a broad distribution of daily $\mathrm{Ca}$ intake (quartiles: 409, 663, 950 and $1437 \mathrm{mg} \mathrm{Ca} / \mathrm{d}$ ), a clear correlation was found between $\mathrm{Ca}$ intake and bone mineral density, thus underlining the vulnerability of this group and illustrating the efficacy of dietary measures or supplementation of $\mathrm{Ca}$ to achieve normal bone growth (Henderson \& Hayes, 1994).

\subsection{Calcium supplementation in children and adolescents and bone health}

Despite the relatively poor contribution diet is supposed to make to the variance of peak bone density, a substantial number of studies have been published in recent years to address the effects of nutrition, particularly of $\mathrm{Ca}$, on bone density in children and adolescents. These studies have been reviewed by Kerstetter (1995) who concluded that the cross-sectional and correlation studies have yielded rather mixed results. Surprisingly, more consistent findings were obtained from the five recent prospective $\mathrm{Ca}$ or dairy supplementation studies in children and adolescents published between 1992 and 1995. In Table 1 the basic data from these studies (Johnston et al. 1992; Lloyd et al. 1993; Andon et al. 1994; Lee et al. 1994; Chan et al. 1995) are compared. In all studies the baseline $\mathrm{Ca}$ intake was less than $1000 \mathrm{mg} / \mathrm{d}$ and the amount of supplemented Ca ranged from 300 to $700 \mathrm{mg} / \mathrm{d}$. The percentage increase in bone mineral density in all the supplemented groups amounted to $1-10 \%$ and was significant in all studies. Of those intervention studies, the one by Chan et al. (1995) is most appealing because in this study a near doubling of the Ca intake (from 728 to $1437 \mathrm{mg} / \mathrm{d}$ ) was reached only by supplementation with dairy products and the increase in total body bone mineral density amounted to $7 \%$. However, the conclusion which one might draw on superficial reading of the review by Kerstetter (1995) that dairy products outperform other $\mathrm{Ca}$ supplements cannot be substantiated yet. Nevertheless, it is remarkable that in the study by Chan et al. (1995) the supplemented dairy products also contained some vitamin D and extra $P$, which can at least be interpreted as showing that $P$ has no negative effect on peak bone mass accretion in adolescents under these conditions. In conclusion, the results from the $\mathrm{Ca}$ and dairy-product supplementation studies summarized have clearly demonstrate that it is possible to increase peak bone mass at the end of adolescence simply by dietary means.

\subsection{Nutrients other than calcium and environmental factors involved in bone growth}

The crystal salt of bone resembles hydroxyapatite $\left(\mathrm{Ca}_{10}\left(\mathrm{PO}_{4}\right)_{6}(\mathrm{OH})_{2}\right)$ which contains $\mathrm{Ca}$ and $\mathrm{P}$ in the proportion $2.15: 1(\mathrm{w} / \mathrm{w})$; in addition approximately $60 \%$ of the body $\mathrm{Mg}$ and $30 \%$ of the body $\mathrm{Zn}$ are present in the skeleton. It is, therefore, obvious that $\mathrm{P}, \mathrm{Mg}$ and $\mathrm{Zn}$ are also important nutrients in the process of bone mineralization. Although there is little information about conditions in developed countries where $\mathrm{Mg}$ or $\mathrm{Zn}$ would represent single limiting factors causing impaired bone growth, it seems reasonable and prudent to include these elements proportionally in supplements, possibly also taking their different rates of absorption into account. The case for $\mathrm{P}$ is more delicate and, except for premature infants where $P$ intake can be a limiting factor for bone growth, much more concern has been shown about excessive dietary intakes of $P$ (Calvo \& Park, 1996). High $P$ intake results in an increased serum $P$ concentration which initiates several hormonal respones, of which an increase in parathyroid hormone level effects the balance between bone mineralization and bone resorption (Anderson, 1996a,b). It is for this reason that in several supplementation studies no phosphate was given in order to shift the $\mathrm{Ca}: \mathrm{P}$ ratio as much as possible in the direction of $\mathrm{Ca}$. As already mentioned, the results from the study by Chan et al. (1995) give support to a concept where the absolute amount of $\mathrm{Ca}$ is more important than the $\mathrm{Ca}: \mathrm{P}$ ratio.

A nutrient which is most important in bone metabolism is vitamin $\mathrm{D}$. The major role of dietary vitamin $\mathrm{D}$ is to function as precursor for 25-hydroxy- and 1,25-dihydroxycholecalciferol which maintain the plasma $\mathrm{Ca}$ concentration within very narrow limits. This is accomplished by varying the proportion of dietary $\mathrm{Ca}$ absorbed and excreted. As the body becomes vitamin $\mathrm{D}$ depleted, the efficiency of $\mathrm{Ca}$ absorption decreases from $30-50 \%$ to no more than $15 \%$. In addition, 1,25-dihydroxycholecalciferol has a direct effect on osteoblast production and thus on bone formation and mineralization (Anderson, 1996a,b). The major source for vitamin $\mathrm{D}$ in human subjects is exposure to sunlight which enables cutaneous synthesis of vitamin D. However, several groups ranging from premature infants to institutionalized elderly people may not be able to receive sufficient exposure to sunlight and thus require dietary vitamin D.

The involvement of vitamin $\mathrm{K}$ in bone metabolism is through its action on maturation of osteoblastic bone proteins by carboxylation of their glutamate residues (Vermeer et al. 1996). Vitamin $\mathrm{K}$ may be generated by the intestinal microflora or obtained from dietary sources such as green vegetables and meat. Except for the fact that it depends on the quantity of fluoride ingested and the time of exposure, 
the role of $\mathrm{F}$ in bone health is still poorly understood. It has been used as a therapeutic agent in bone pathology including osteoporosis, but also cases of skeletal fluorosis are reported with radiologically demonstrable abnormal bone densification (Boivin et al. 1993). Of the minerals for which a role and/or essentiality in man is still unclear, $B$ has been connected with the mechanical properties of bone (Mastrmatteo \& Sullivan, 1994). Because the effects of B supplementation are not striking, and plausible mechanistic explanations still need to be presented, it is uncertain whether B will become an important issue in bone health research. In a cross-sectional study in about 500 children and adolescents (aged 8-17 years) bone mineral density was found to be related to diet, weight-bearing exercise and daylight hours spent outdoors (Gunnes \& Lehman, 1995). Next to an effect in accordance with the literature with respect to dietary $\mathrm{Ca}$ it is surprising that the authors found a positive correlation between bone mineral density and saturated fat, fibre and vitamin C. Any interpretation of these correlations can only be speculative. The positive association between fat intake and bone mineral density might be attributed to an increased intake of vitamin $D$ with the fat or might possibly be mediated by a higher cholesterol level. The positive association between bone mineral density and fibre intake is even more puzzling because one might expect exactly the opposite based on impairment of Ca absorption by dietary fibre. As a possible explanation for the association between vitamin $\mathrm{C}$ and bone mineral density, the authors indicate the fact that vitamin $C$ is a cofactor in collagen synthesis. Moreover, they point to a possible link between high intakes of $\mathrm{Ca}$, fibre and vitamin $\mathrm{C}$ as constituents of a more wholesome diet. Considering the importance of a high $\mathrm{Ca}$ intake in achieving maximal bone growth and peak bone mass, it seems logical to prevent any negative dietary interactions which might interfere with maximal $\mathrm{Ca}$ absorption. Of the dietary interactions affecting $\mathrm{Ca}$ absorption reviewed by Licata (1993), the possible negative effect of caffeine is mentioned because it increases urinary $\mathrm{Ca}$ excretion. However, this effect is considered to be fairly unimportant relative to other factors and is also not consistently found in all the studies. A clear negative effect on $\mathrm{Ca}$ absorption is represented by dietary oxalate-exemplified by the poor $\mathrm{Ca}$ absorption (only $5 \%$ ) from oxalaterich spinach. Although some authors report a stimulating effect of lactose on Ca absorption in humans, others fail to find any significant effect. Essentially the same holds true for the effect of protein on $\mathrm{Ca}$ absorption: if there is any stimulating effect, it will be rather small. In view of the marginal gain on fractional $\mathrm{Ca}$ absorption which can possibly be obtained by optimizing the nutritional matrix, selecting $\mathrm{Ca}$ salts with a high bioavailability may be of particular relevance. In this respect an increase in fractional $\mathrm{Ca}$ absorption of 0.26 to 0.36 which can be achieved by replacing $\mathrm{CaCO}_{3}$ with calcium citrate-malate is illustrative (Peacock, 1991).

\section{Nutrient effects on development of neural functions and behaviour}

\subsection{Introduction}

Pregnancy and the first postnatal months are critical time periods for the growth, development and differentiation of the human nervous system. There is good evidence that availability of nutrients during these critical time periods affects brain growth and development and can have longterm programming effects on an individual's central nervous functions. In contrast to some other mammalian species, in man the peak growth rate of the brain ('brain growth spurt') occurs both pre- and postnatally, with continued relatively rapid growth well into the second year of life. Between the 24th week of gestation and the time of term birth, brain weight increases more than fivefold. The disproportionate speed of brain growth, compared with total body growth, is apparent from the fact that at age 2 years the weight of the human brain has already reached $80 \%$ of adult weight, while whole body weight at this age is less than $18 \%$ of adult weight. An adequate substrate supply is essential for a physiological brain composition and differentiation during this rapid perinatal growth.

\subsection{Physiology of neural development}

Development of neuronal tissues is characterized by the sequential occurrence of mitosis, cell migration, differentiation, synaptogenesis, apoptosis and synaptic reorganization. These consecutive steps begin during pregnancy at different gestational ages and occur over a certain time period in different brain areas; therefore, there is an overlap in time of the various brain development steps in different areas of the brain (Reisbick, 1996).

Mitosis of germinal cells located along the neural tube and the brain ventricles, which form neuronal and glia cells, begins in the sixth embryonic week, peaks in the second trimester and is almost complete by the end of the second trimester, even though a small number of cells may form during the last trimester of gestation (Jacobson, 1991; Rakic, 1995). Under the influence of hormones, cell adhesion molecules and other local factors, the created cells migrate to the brain nuclei and cortex and the ganglia of the peripheral nervous system (Jacobson, 1991; Kandel et al. 1991). Although largely occurring during pregnancy, nervous cell migration particularly in the superficial layers of the cerebral and cerebellar cortices continues to occur after term birth (Rakic, 1995). Cell differentiation into particular neurons may begin during migration but generally is only completed at its final destination (Kandel et al. 1995). The differentiation of neuronal cells is modulated by induction through surrounding cells, the kind of cell innervated, growth factors and hormones such as glucocorticoids, and nutrient intakes. For example, pre- and postnatal proteinenergy malnutrition has marked effects on brain cell differentiation (Cravioto \& Cravioto, 1996), and long-term depletion of the $n-3$ PUFA DHA induced altered brain cell levels of monoamines and monoamine receptors in rats. When neurons have migrated to their destination and reached their differentiation, they grow and form synaptic connections (Kandel et al. 1995). Most cell growth in the human cerebellar cortex occurs between 32 weeks of gestation and 11 months after term birth (Rakic, 1995). Synaptogenesis in primates peaks in the first 2-3 months of life (Rakic, 1995), and the number of synapses in the human visual cortex increases twofold between the ages of 2 and 8 months after birth, which is paralleled by a marked increase 
in the number of neurotransmitter receptors (Huttenlocher $e t$ al. 1982). The number of synapses formed is far greater than the number of synapses later found in adult brains. The early rapid synaptogenesis depends on an extensive formation of highly fluid cell membranes and, hence, on sufficient availability of substrates required for this membrane formation. Brain structure and function is also greatly influenced by apoptosis, since cell death affects between 20 and $80 \%$ of the neuronal cells formed during gestation before the time of birth (Rosenzweig et al. 1996), which appears to be regulated by genetically programmed apoptosis, protecting neurotrophic factors, synaptogenesis, hormones and eicosanoids. In the surviving cells, the synaptic connections are reduced and rearranged at a rapid rate initially, but continuing throughout the life of the organism in relation to stimulation and learning. This synaptic rearrangement appears to be regulated by many different modulators, including $\mathrm{Ca}$ channels, second messengers such as phosphatidyl inositol, protein kinases, membrane lipids and eicosanoid hormones (Reisbick, 1996; Wainwright, 1997).

\subsection{Nutrition and neural development}

In Europe and other developed countries, an associated secular increase both of adult height and adult intelligence quotients has been observed over the last few decades, and the hypothesis has been raised that both these effects are related to the early nutrient supply.

Several studies have documented that severe general malnutrition in infancy or early childhood, which is characterized by a combined deficiency of energy, protein and many other substrates, is associated with a marked reduction of cognitive ability (Cravioto \& Cravioto, 1996; Kretchmer et al. 1996). However, the adverse effects on neural development cannot be attributed entirely to nutrient depletion, but may also be modulated by other factors typically associated with severe childhood malnutrition, including infections, poverty, psychological depression and lack of adequate stimulation. Evidence of organic effects of malnutrition on brain growth and maturation was provided by the demonstration of cerebral atrophy and lasting organic brain damage (Ambrosius, 1966; Stoch et al. 1982; Houscham \& Devilliers, 1987) and by electrophysiological evidence of impaired information processing, such as altered auditory evoked brain stem potentials (Barnett et al. 1978; Bartel et al. 1986).

9.3.1. Protein. Randomized studies in premature infants demonstrated that a low protein intake during the early postnatal period resulted in poorer results of orientation, habituation and stability clusters when tested with the neonatal behaviour assessment scale (Bhatia et al. 1991), and in a markedly reduced mental and psychomotor development when assessed at an age of 18 months postterm with the Bayley scales of infant development (Morley \& Lucas, 1993).

9.3.2. Iodine. Today I deficiency is considered the most common cause of nongenetic inborn neurological damage on a worldwide basis, and causes cretinism with severe mental retardation (Stanbury, 1994). In I-deficient populations, an early I supply beginning before or at the time of conception can prevent neural damage of the infant, whereas a later start of I supply in the second or third trimester of pregnancy or after birth is associated with a smaller preventive effect (Xue-Yi et al. 1994).

9.3.3. Iron. $\mathrm{Fe}$ uptake into the brain is mediated by transferrin receptors on the endothelial surface of brain microvasculature, reaches its maximum during the period of rapid brain growth and peak myelinogenesis (Taylor \& Morgan, 1990) and continues throughout life. Analysis of $\mathrm{Fe}$ distribution in the human brain during childhood with magnetic resonance imaging showed the highest concentrations in the globus pallidus, caudate nucleus, putamen and substancia nigra, while the cortex and cerebellum had substantially lower contents. Fe serves as an essential cofactor in a variety of cellular and metabolic functions, including the synthesis of dopamine, serotonin, catecholamines and possibly $\gamma$-aminobutyric acid as well as myelin formation (Kretchmer et al. 1996), while Fe overload has toxic effects. In young rats deprived of $\mathrm{Fe}$ in early postnatal life, total brain Fe content was severely depleted to $27 \%$ of that of controls and was resistant to later restoration despite aggressive treatment (Dallman \& Spirito, 1977). Sustained early Fe deficiency in rats causes persistent behavioural and learning deficits, leading to the hypothesis that $\mathrm{Fe}$ sufficiency throughout the critical phases of early brain development is crucial to the achievement of normal brain $\mathrm{Fe}$ content, function and behaviour. Several studies in children have clearly documented that severe Fe depletion resulting in Fe-deficiency anaemia results in a poor attention span, poor performance in the Bayley mental development index, low intelligence scores, some degree of perceptual disturbance and altered affective behaviour (Lozoff \& Brittenham, 1986; Beard et al. 1993; Pollitt, 1993; Sheard, 1994; Kretchmer et al. 1996). Although children with Fe depletion without anaemia also showed behavioural abnormalities in some studies, these abnormalities appear to have been influenced by poor environmental conditions that were associated with the occurrence of Fe depletion (Lozoff et al. 1996). At this time there is no conclusive evidence that poor Fe status without anaemia has adverse effects on neural development in children.

9.3.4. Zinc. In animal experiments, $\mathrm{Zn}$ deprivation was shown to adversely affect brain growth, learning ability, memory and activity (Smart, 1974; Halas \& Sanstead, 1975, 1980; Peters, 1979). Low-birth-weight infants showed an improvement of motor development when supplemented with Zn (Friel et al. 1993). In a recent study in Indian children aged 6-35 months who were not malnourished, daily supplementation with $10 \mathrm{mg}$ elemental $\mathrm{Zn}$ (as $\mathrm{Zn}$ gluconate) for a period of 6 months resulted in a significant increase of observed activity (Sazawal et al. 1996).

9.3.5. Polyunsaturated fatty acids. Some $50-60 \%$ of the structural matter in the central nervous system is composed of lipids, which almost entirely serve structural functions in cell membranes and myelin. Much of the rapid lipid accretion during brain growth comprises lipids that can be synthesized de novo in the fetus and infant, e.g. cholesterol. In addition, the rapid brain growth occurring perinatally and the extensive synaptogenesis occurring during the first months of life require the incorporation of relatively large amounts of essential PUFA, primarily the highly unsaturated long-chain PUFA DHA and arachidonic 
acid (Koletzko, 1992). In experimental studies, the addition of DHA and arachidonic acid to fetal mouse brain cultures increased the number, diversity and complexity of synaptic contacts (Tixier-Vidal et al. 1986). In addition to cell growth and synaptogenesis, long-chain PUFA as well as eicosanoids formed from long-chain PUFA may influence neural cell apoptosis (Finstad et al. 1994; Wainwright, 1997). Experimental studies in rodents and in non-human primates indicated that the degree of long-chain PUFA incorporation into the developing brain influenced reflex development, memory, discrimination learning, retinal function and visual acuity (Neuringer, 1993; Wainwright, 1993), i.e. functions related to the efficacy of information processing.

The human fetal supply with preformed long-chain PUFA by a materno-fetal placental transfer (Koletzko \& Müller, 1990) may be influenced by the maternal dietary long-chain PUFA intake. Also, the postnatal long-chain PUFA supply in human milk is affected by maternal diet and can be altered by dietary supplements provided to lactating women (Harris et al. 1984; Koletzko et al. 1992). In contrast to human milk, most infant formulas do not contain preformed DHA and arachidonic acid. Although newborn infants have the ability to synthesize long-chain PUFA from EFA precursors, the rate of synthesis appears to be low (Demmelmair et al. 1995; Sauerwald et al. 1997) and long-chain PUFA levels in blood lipids (Decsi \& Koletzko, 1995) and brain (Farquharson et al. 1992; Makrides et al. 1994) of formula-fed infants are significantly lower than those found in breast-fed infants.

Some randomized intervention studies comparing diets without and with a supply of preformed long-chain PUFA both in premature infants (Uauy et al. 1990; Carlson \& Werkman, 1996) and in healthy term infants (Makrides et al. 1993, 1995; Agostoni et al. 1995) found indications of improved retinal and visual function and of cognitive development in infants receiving long-chain PUFA, while other studies found no appreciable advantage (Innis et al. 1996). Effects of supplementing additional long-chain PUFA during pregnancy or lactation on functional development of the infant have not been reported.

\subsection{Early nutrition and development of taste preferences}

Preferences of taste and smell are critical factors in selecting foods and drinks throughout life. There are some indications that sensory perception of tastes and flavours may be modulated by early exposure.

Observations of fetal swallowing following the ingestion of sweet- and bitter-tasting substances into the amniotic fluid suggest that the fetus is sensitive to sweet- and bittertasting substances (de Snoo, 1937; Liley, 1972). It has been concluded that both the olfactory apparatus and taste perception are fully developed in utero (Beauchamp et al. 1991). Molecules carrying flavours and aromas may cross the placenta, and it has been proposed that early sensory exposure may modulate the acquisition of later flavour preferences. In animal studies, such effects of intrauterine exposure to flavour-rich foods on postnatal food choices have been documented.

Premature infants tested between 33 and 40 weeks postconception and newborns during the first hours after birth show a clear and reproducible preference for sweet tastes (Beauchamp \& Mennella, 1980). In blinded controlled studies, the sucking behaviour of breast-fed infants is altered by supplementing their mothers with encapsulated garlic compared with placebo, and repeated consumption of garlic modifies the infantile response to this taste (Menella \& Beauchamp, 1993). Also the volatile flavours of vanilla and alcohol modulate infantile sucking behaviour (Beauchamp \& Mennella, 1980; Mennella \& Beauchamp, 1991). The question of to what extent food choices during childhood and adult life are modulated by pre- and postnatal experience is of major importance and needs to be further explored.

\subsection{Methodological aspects}

An optimization of the quality of nutrient intakes during pregnancy, lactation and infancy may well have the potential of improving developmental outcomes in the recipient infants. Since even small improvements of the population means by such potential effects are of major public health significance, they need to be carefully examined. If plausible hypotheses can be raised and supported by data from experimental models, epidemiological studies or pilot intervention trials, they should be subjected to rigorous testing with adequate scientific methodology in double-blind placebo-controlled randomized trials. While some electrophysiological measures of human neural function can be assessed with sufficient precision to justify interventions in small groups, behavioural methods tend to have a greater degree of variation and, therefore, effects on such outcome variables require large studies, particularly if one considers that dietary factors must be expected to have relatively small effects compared with genetic and other environmental influences. The results of such studies can be greatly influenced by the study design and factors such as the time points chosen for testing effects as well as the adequacy of the method chosen for testing the targeted effect. Large sample sizes may be required, for example, to show an effect of a dietary supplement, resulting in a comparably small mean difference of developmental scores due to the many other variables that influence such end-points. Therefore, the realization of adequate trials to test for long-term developmental effects of early food choices will usually require a large budget. In view of the major public health importance of the questions addressed by such trials, it appears justified that well-designed trials addressing relevant and pertinent questions are supported by public funds.

\section{Production of bioactive factors for inclusion into food products}

Interest in the production of human milk proteins, peptides, growth factors and other bioactive substances with the use of biotechnology and recombinant techniques is growing. The inclusion of such substances into dietary products may have beneficial physiological effects particularly in infancy and early childhood, for example defence against infectious agents, the optimization of nutrient uptake from the diet as well as the differentiation and growth of cells and tissues. Micro-organisms and transgenic animals can now be used 
for the production of bioactive proteins (Lönnerdal, 1996). However, the benefits and safety of each substance must be evaluated in adequate studies in cells, animal models and clinical studies before routinely adding them to products for infants to improve their nutrition, health or development. Proper manufacturing conditions must be developed for introducing such substances into foods. The importance of post-translational modifications must also be taken into account. Some proteins may require proper glycosylation or phosphorylation for physiological activity.

Several human milk proteins have been cloned and sequenced. The majority were cloned at the level of complementary DNA (cDNA). In a few cases the entire gene has been characterized. One of the first milk proteins which was cloned from a mammary gland library was $\alpha$ lactalbumin (Hall et al. 1987). Other human milk proteins that have been cloned include lysozyme, lactoferrin, human $\beta$-casein and $\kappa$-casein. For the production of human milk proteins and bioactive factors, several expression systems can be used, such as bacterial expression of recombinant proteins. The expression vector can be constructed so that the protein is made available in the supernatant fraction or in the bacteria. Bacterial expression will lead to the production of proteins which are not phosphorylated or glycosylated. If this property is needed for biological functions, yeast or fungi can be used as expression systems. Saccharomyces cerevisiae was used to produce human lactoferrin (Liang \& Richardson, 1993) and human $\beta$-caseins. Aspergillus nidulans and Aspergillus oryzae were also used to produce human lactoferrin (Ward et al. 1992a,b). Alternatively, living cells such as baby hamster kidney cell can be used to produce human lactoferrin (Ward et al. 1992a). As such expression systems will still provide proteins with different phosphorylation and glycosylation, physiological function may be altered. Tissue-specific expression of human milk proteins in transgenic animals should result in recombinant protein glycosylations and phosphorylation similar to the native human milk proteins.

The architecture of the transgene DNA that is introduced into the germline of animals by microinjection plays an important role in the level of expression of the transgene. DNA that is introduced by microinjection into the pronucleus is usually inserted randomly into the genome as head-to-tail concatemers. Because the eukaryotic genome is organized into topologically constrained domains, random integration can lead to position effects in which the transgene expression is influenced by the surrounding chromosomal sequences. Thus in many cases the level of transgene expression will vary over several logarithms, depending on the site of integration, and expression may be observed in $<50 \%$ of the positive transgenic mice. Because of the expense and time required to generate transgenic livestock, this presents a major problem (Stowell et al. 1991). To date, human lactoferrin (Rosen et al. 1996) and human lysozyme (Kim et al. 1994) have been expressed in transgenic mice with reasonable expression in the milk. Human lactoferrin was recently produced in transgenic cows (Maga et al. 1994). Whether the glycosylation pattern of human lactoferrin within the cow's mammary cells will alter the biological function remains to be elucidated.
Similar to the gene farming of human milk proteins and other important functional proteins in transgenic animals, such bioreactors are used to produce human hormones and growth factors. In transgenic rabbits, hGH was produced in milk in suitable amounts without being affected by the transgene expression (Limonta et al. 1995). Bovine growth hormone was also placed by a recombinant technique into the milk of transgenic mice (Thépot et al. 1995). In addition, human IGF1 was expressed in the milk of transgenic mice (Hadsell et al. 1996) and rabbits (Brem et al. 1994). Some oligosaccharides which may play an important role in promoting growth and differentiation of intestinal epithelial cells have successfully been expressed in the milk of transgenic mice (Prieto et al. 1995). The enormous potential of these methodologies for improving food products needs to be further explored.

\section{Commentary on biomarkers}

Drawing on experience from child health and development it is possible to use experience of inborn errors of metabolism to demonstrate the evolution and use of biomarkers to detect and predict a disease arising from an imbalance between systemic homeostasis and essential and non-essential dietary components. A good example is hyperphenylalaninaemia (HPA) which arises from an inborn error of metabolism of the essential amino acid phenylalanine (Scriver \& Clow, 1980; Güttler, 1984). First of all, however, it is helpful to consider some general aspects of the strategy of biomarkers.

Biomarkers can be defined as indicators of actual or possible changes of systemic, organ, tissue, cellular and sub-cellular structural and functional integrity which can be used, either singly or in batteries, to monitor health and exposure to compounds in populations and individuals: as such they are the essence of chemical pathology or clinical biochemistry. Thus although the term 'biomarker' might itself be relatively novel, the concept is far from being so: the use of biochemical biomarkers dates at least from the discriminatory use of the sweet taste of glycosuria to diagnose and name diabetes mellitus. This intolerance of glucose illustrates a disturbance of the usually tightly controlled internal milieu as conceived by Claude Bernard, and of the processes involved in maintaining this state, i.e. homeostasis. These mechanisms lie at the core of the regulatory adaptations which maintain a steady state in the face of changes in environment, including our interaction with desirable and non-desirable components of the diet, which, of course, is one of our most intimate interactions with the environment. Homeostasis is regulated by cellular and systemic mechanisms which, in turn, are dependent on gene-mediated responses. Genetic heterogeneity amongst people underlies the intrapopulation variability of the interaction between nurture and nature. These generalizations apply equally to exposure to abnormal compounds and to excessive or inadequate exposure to normal components in the diet or environment.

Homeostasis comprises several processes, some of which act synchronously, but many of which act in a specific sequence, each being triggered by the relative efficiency of the preceding process. Some of these mechanisms are 
specific for individual compounds. This applies to essential nutrients or generic groups of nutrients, but for non-nutrients and xenobiotics there appears to be a limited number of common protective mechanisms. In the chain arising from threatened or actual toxic exposure there would first be compensatory adaptations such as metabolic biotransformations (phase I: oxidation, hydrolysis, reduction; phase II: conjugations), excretion, and sequestration of compounds (for example in adipose tissue, bone, hair, skin); when these are inadequate biochemical and histopathological features follow with structural cellular damage and functional derangement. These lead to tissue damage with clinical manifestations (e.g. neurological and muscular toxicity, retinal toxicity, immunotoxicity, hepatotoxicity, nephrotoxicity, bone marrow damage, teratogenicity, cytotoxicity, cancer, methaemoglobinaemia, haemolysis) and overt disease states many of which are major health issues (e.g. cancers, cardiovascular disease, obesity, osteoporosis, adverse reactions to foods and food additives and contaminants, atopic disease, behavioural abnormalities, fetotoxic effects). This chain shows the series of genotypic (genetic), and phenotypic (biochemical and clinical) biomarkers.

The underlying assumption here is that all diet-related disease arises from an inappropriate interaction between diet and systemic homeostasis and that the fundamental basis of this imbalance lies in the relative imbalance of dietary exposure and the genetic controlled response. At this level the genome and its product would serve as an ideal biomarker: unfortunately the processes involved might not have been identified or might not be accessible to practical and ethical sampling techniques. Alternative and less immediate biomarkers have to be used. However, the more remote the biomarker is from the primary event the more it is attenuated and subject to confounding factors. It becomes less specific. On the other hand the more immediate it is to the basic interaction the more quantitatively related and predictive it becomes: biomarkers represent Garrod's concept that genetic factors determine the nature of chemical metabolism and human biochemical heterogeneity.

More immediate biomarkers are not only potentially more predictive, they might also provide more immediate outcomes which could be used to assess interventions in a reasonable timescale and, in turn, replace the temporally and aetiologically remote outcomes which are so often the foci of epidemiological studies of diet and health: for example the diseases mentioned earlier are probably both metabolically and temporally remote from their aetiology.

Insight into the metabolic processes involved in the particular issue being investigated can inform the choice of tissue or fluid to be sampled and the phenotypic marker to be measured. This applies also to genotypic biomarkers designed to assess adaptive phenomena but it is possible to measure some predictive genotypic markers in tissues other than those in which the gene product is expressed. Whatever the situation the selection of biomarker(s) should be dictated by the problem being considered rather than by the accessibility of tissue or fluid to be measured or the ease of an assay.

These general points are represented by the disease PKU which epitomizes the interaction between nature and nurture and the benefits which can be attained by an appropriate manipulation of the diet. PKU is a manifestation of HPA which results from the altered activity of the principally hepatic enzyme phenylalanine hydroxylase ( $E C$ 1.14.16.1; $\mathrm{PAH}$ ), functional defects of which arise from intrinsic defects in the apoenzyme or from defective synthesis of its cofactor (tetrahydrobiopterin) (Scriver \& Clow, 1980; Güttler, 1984; Scriver, 1991; Scriver et al. 1996; Güttler \& Guldberg, 1996). The condition was recognized in 1933 when a mother with a mentally retarded child sought help on the peculiar smell of her child's urine. She saw several doctors, one of whom even referred her to a psychiatrist for help with her delusion. In the end one physician, Dr Asbjorn Folling confirmed the peculiar smell. He attributed it to the presence of phenylpyruvic acid in the urine and he called the condition 'imbecillitas phenylpyruvica' thereby incorporating both the initial clinical and biochemical biomarkers into the condition's nomenclature (Güttler, 1984; Scriver, 1991). He developed the ' $\mathrm{FeCl}_{3}$ ' colorimetric test of urine to detect the excess metabolite and used it to screen mentally retarded children and adults for the condition (Scriver \& Clow, 1980). In 1950 Horst Bickel appreciated the implication of raised blood phenylalanine concentrations in PKU patients and explored the use of a phenylalanine-free mixture of amino acids to feed affected infants. It was found that blood phenylalanine levels fell and that the urine abnormality decreased. There was also some clinical and behavioural improvement, but the intervention was too late to affect the established developmental delay and mental damage. Nonetheless this progress in the phenotypic biomarkers demonstrated the potential clinical and economic benefits of screening and early diagnosis in the hope that early dietary intervention could prevent the neurological damage.

Early dietary management was effective, but many cases went undetected because the $\mathrm{FeCl}_{3}$ biomarker was relatively insensitive and non-specific (Scriver \& Clow, 1980). Phenylpyruvic acid is one of a number of normal metabolites of phenylalanine which are found in excessive amounts in the urine in PKU as a consequence of the increased activity of alternative pathways for the metabolism of phenylalanine. Other variables affected the production of these metabolites and it was appreciated that blood phenylalanine concentrations would be a better biomarker, but the analytical techniques (paper chromatography) available at that time were costly and time consuming. In the late $1950 \mathrm{~s}$ the abnormal gene product, i.e. defective PAH, was identified, but since this activity was in the liver this did not provide an effective biomarker. The finding of this functional defect reinforced the opinion that screening should be targeted at the HPA.

Guthrie solved the problem in 1961 by establishing a semiquantitative bioassay based on the inhibition of bacterial growth by high concentrations of phenylalanine. The test was done on blood drops collected on filter card from infants at 4-7 d of age by which time the babies would have fed and, in contrast to in utero, would have had the opportunity to challenge the activity of their endogenous PAH with a phenylalanine load. The biomarker for definitive diagnosis and monitoring of management was direct quantitative measurement of blood phenylalanine concentrations. This enabled an appreciation that these concentrations could correlate with the efficiency of management and with behavioural and other clinical outcomes. However, not all 
patients responded similarly or predictably. Amongst this heterogeneity was an atypical group with HPA which was, in the mid 1970s, found to be secondary to a defect in the synthesis of the tetrahydrobiopterin cofactor. Thus, in the midst of the phenotypic and molecular heterogeneity which was becoming increasingly obvious, it was realized that PKU or HPA was not the result of a single gene defect. The allele for PAH has since been found on chromosome 12q, and that for the affected stage in tetrahydrobiopterin synthesis is on chromosome 4 (Güttler \& Guldberg, 1996; Scriver et al. 1996).

HPA is, thus, evident as a complex entity with many clinical and metabolic phenotypes. Consistent with this heterogeneity and with the variation in dietary tolerance for phenylalanine, almost 300 mutations in the PAH gene have been identified. Some of these genetic mutations have been specifically correlated with the activity of their enzyme products and with the severity of the clinical disease (Scriver, 1991; Güttler \& Guldberg, 1996; Scriver et al. 1996).

In the context of biomarkers, HPA represents a continuum of genotypic, biochemical (PAH, tetrahydrobiopterin defect), metabolic (HPA), and clinical (the PKU syndrome) phenotypic biomarkers of an abnormal interaction between a dietary component and an individual's ability to achieve effective homeostasis at customary dietary exposure.

The genotypic biomarker may be used for definitive diagnosis and family screening and possibly for prognostication, but the metabolic biomarker is most useful for monitoring and tailoring the dietary reduction of phenylalanine. The urinary biomarker (PKU) is no longer of much use, and the clinical phenotypic biomarker is one of a medical tragedy.

PKU and HPA demonstrate the movement of biomarkers from remote and non-specific outcomes (many other conditions including other inborn errors of metabolism cause epilepsy and developmental delay) to more specific and informative outcomes, and ultimately to the basic genomic mutation offering the opportunity of appropriately designed diets. It is feasible that in due course a similar heterogeneity will be found in the metabolism of other nutrients, and that this will explain many of the conflicting phenomena found in epidemiological studies of the interaction between diet and health and in apparent heterogeneity of nutritional requirements. Such biomarkers should also provide more definitive indicators of response to interventions, thereby enabling shorter and more definitive epidemiological studies. Whether or not people would accept the corollary of this, namely specific diets tailored to their genotypic or surrogate metabolic characteristics, depends probably on the nature of the diets involved and on the people's motivation in the context of the much less dramatic and immediate effects of an inappropriate diet compared with that experienced with PKU. The integration of markers of susceptibility with appropriate follow up of long-term outcomes by epidemiological studies of characterized populations will demonstrate the relevance or otherwise of formal interventions.

\section{Conclusions}

Food supply and the metabolism of food ingredients in women during pregnancy and lactation and in their children have implications for long-term health and child development. Epidemiological evidence and studies performed in infants have highlighted the fact that maternal and intrauterine influences are of special importance during the development of the infant and child. Early nutrition modulates growth and functional development of the organism and appears to exert life-long programming effects that modulate health, disease and mortality risks in adulthood, neural function and behaviour, and quality of life.

The field of nutrient-gene interaction is in a phase of rapid expansion and development. There are several areas where dietary modulation of gene expression could exert beneficial effects, for example with respect to lipid metabolism and risk of cardiovascular disease. Applied research should further elucidate the interaction of nutrients and gene expression. The genes affected by specific nutrients, e.g. amino acids, must be characterized in animal models as well as the underlying cellular and molecular mechanisms. Since the vast majority of studies have been performed on animal models or animal cell lines, strategies must be defined to approach these questions in human subjects, for example by using human cell lines responding to nutrients. Once the mechanisms and relevance to man have been clarified, then development and testing of existing or new 'functional foods' could be performed both in animals and human subjects.

The relation between nutrients and differentiation needs to be further explored by in vivo models, studying food effects on cell differentiation and later performance. Concomitantly, the effects of nutrients on cell differentiation in in vitro studies should be strongly encouraged.

The course of pregnancy, childbirth and lactation as well as human milk composition and the short- and long-term outcome of the child may be influenced by the intake of foods and particularly micronutrients, e.g. PUFA, Fe, Zn and I. Folic acid supplementation from before conception through the first weeks of pregnancy was reported to markedly reduce the occurrence rates of severe embryonic malformations, including anencephaly and spina bifida. The potential of exerting beneficial effects for mother and child by modulating maternal nutrient supply should be further explored.

The evaluation of dietary effects on child growth requires epidemiological and field studies as well as evaluation of specific cell and tissue growth. Novel substrates, growth factors and conditionally essential nutrients (e.g. growth factors, amino acids, unsaturated fatty acids) may be potentially useful as ingredients in functional foods and need to be assessed carefully with respect to their potential effects on growth, maturation and development of specific cell types, tissues and organs under different physiological conditions. In particular, the potential modulation of later obesity by early food choices needs to be further explored.

Intestinal growth, maturation, intestinal adaptation and regulation and long-term function may be influenced by food ingredients. The roles of compounds such as dietary oligosaccharides, gangliosides, high-molecular-mass glycoproteins, bile salt-activated lipase, pre- and probiotics as to their physiological functions in the developing organism need to be further explored. The interaction of the appropriate genes of intestinal substrate transporters and their 
substrates in early childhood is not well understood and needs to be clarified.

There are indications for some beneficial effects of functional foods on the developing immune response in vitro and in vivo, for example induced by antioxidant vitamins, trace elements, fatty acids, arginine, nucleotides, and altered antigen content in infant foods. A general unresolved issue is related to the lack of reliable surrogate outcome markers when investigating the effects of nutrition on the developing immune response and possible long-term benefits.

Peak bone mass at the end of adolescence can be increased by dietary means, which is expected to be of long-term importance for the prevention of osteoporosis at older ages. Future studies should be directed to the combined effects of $\mathrm{Ca}$ and other constituents of growing bone, such as $\mathrm{P}, \mathrm{Mg}$ and $\mathrm{Zn}$, as well as vitamins $\mathrm{D}$ and $\mathrm{K}$, and trace elements $\mathrm{F}$ and $\mathrm{B}$. In addition to observational and intervention studies, in vitro and animal model studies might provide a basis for new concepts on the interaction and optimal relative proportions of the several macro- and micronutrients involved in bone growth and mineralization.

Pregnancy and the first postnatal months are critical time periods for the growth and development of the human nervous system, processes for which adequate substrate supplies are essential. Early diet may have long-term effects on the structure and function of the nervous system, sensory and cognitive abilities as well as behaviour. The potential beneficial effects of a balanced supply of nutrients such as I, $\mathrm{Fe}, \mathrm{Zn}$ and PUFA need to be explored in further detail.

The question of a possible relationship between early exposure to tastes and flavours and later food choice preferences may have a major impact on public health and needs to be further elucidated.

Bioactive factors such as human milk proteins, peptides, growth factors and other substances may be produced for use in food products with the use of biotechnology and recombinant techniques. The inclusion of such substances into dietary products may have beneficial physiological effects particularly in infancy and early childhood, for example defence against infectious agents, the optimization of nutrient uptake from the diet as well as the differentiation and growth of cells and tissues. The enormous potential of these methodologies for improving food products needs to be further explored.

\section{References}

Agostoni C, Trojan S, Bellu R, Riva E \& Giovannini M (1995) Neurodevelopmental quotient of healthy term infants at 4 months and feeding practice: the role of long-chain polyunsaturated fatty acids. Pediatric Research 38, 262-266.

Al MDM, van Houwelingen AC, Kester ADM, Hasaart THM, de Jong AEP \& Hornstra G (1995) Maternal essential fatty acid patterns during normal pregnancy and their relationship with the neonatal essential fatty acid status. British Journal of Nutrition $74,55-68$.

Allen LH (1986) Trace minerals and outcome of human pregnancy. Clinical Nutrition 5, 72-77.

Ambrosius KD (1966) Comportamiento del peso de algunos organos en niñoscon desnutición de tercer grado. Boletin Medico - Hospital Infantil de Mexico 28, 47.
Anderson B, Porras O, Hanson LA, Lagergård T \& Svanborg-Edén $C$ (1986) Inhibition of attachment of Streptococcus pneumoniae and Hemophilus influenzae by human milk and receptor oligosaccharides. Journal of Infectious Diseases 153, 232-237.

Anderson JJB (1996a) Introduction (symposium: nutritional advances in human bone metabolism). Journal of Nutrition 126, 1150S-1152S.

Anderson JJB (1996b) Calcium, phosporus and human body development. Journal of Nutrition 126, 1153S-1158S.

Andon MB, Lloyd T \& Matkovic V (1994) Supplementation trials with calcium citrate malate: evidence in favor of increasing the calcium RDA during childhood and adolescence. Journal of Nutrition 124, 1412S-1417S.

Antras-Ferry J, Robin P, Robin D \& Forest C (1995) Fatty acids and fibrates are potent inducers of transcription of the phosphoenolpyruvate carboxykinase gene in adipocytes. European Journal of Biochemistry 234, 390-396.

Baldwin HS (1996) Early embryonic vascular development. Cardiovascular Research 31, E34-E45.

Ballou LR, Laulederkind SJ, Rosloniec EF \& Raghow R (1996) Ceramide signalling and the immune response. Biochimica et Biophysica Acta 1301, 273-287.

Banks VF \& Beutler E (1988) Iron. In Modern Nutrition in Health and Disease, 7th ed., pp.193-226 [ME Shills and VR Young, editors]. Philadelphia, PA: Lea \& Febiger.

Barbul, A. (1990) Arginine and immune function. Nutrition 6, 53-58.

Barker DJP (1994) Mothers, Babies and Disease in Later Life. London: BMJ Publishing.

Barnett AA, Weis AP, Sotillo MV, Skurovich M \& Cravioto J (1978) Abnormal auditory evoked potentials in early human malnutrition. Science 201, 450-452.

Bartel PR, Robinson E, Conradie JM \& Prinsloo JG (1986) Brainstem auditory evoked potentials in severely malnourished children with kwashiorkor. Neuropediatrics 17, 178-182.

Beard JL, Connor JR \& Jones BC (1993) Iron in the brain. Nutrition Reviews 51, 157-170.

Beauchamp GK, Cowart BJ \& Schmidt HJ (1991) Development of chemosensory sensitivity and preference. In Smell and Taste in Health and Disease, pp. 405-416 [TV Getchell, RL Doty, LM Bartoshuk and JB Sow, editors]. New York, NY: Raven Press.

Beauchamp GK \& Mennella JA (1980) Early feeding and the acquisition of flavor preferences. American Journal of Clinical Nutrition 33, 2202.

Bendich A (1995) Immunology: functions to assess nutrient requirements. Journal of Nutritional Immunology 3, 47-56.

Bhatia J, Rassin DK, Cerreto MC \& Bee DE (1991) Effect of protein-energy ratio on growth and behaviour of premature infants: preliminary findings. Journal of Pediatrics 119, 103-110.

Bishop NJ, Dahlenburg SL, Fewtrell MS, Morley R \& Lucas A (1995) Early diet of preterm infants and bone mineralization at age five years. Acta Pediatricia 85, 230-236.

Boivin G, Dupuis J \& Meunier PJ (1993) Fluoride and osteoporosis. World Review of Nutrition and Dietetics 73, 80-103.

Bothwell TH, Charlton RW \& Cook JD (1979) Iron Metabolism in Man. Oxford: Blackwell.

Braga M, Vignali A, Gianotti L, Cestari A, Profili M \& Carlo VD (1996) Immune and nutritional effects of early enteral nutrition after major abdominal operations. European Journal of Surgery 162, 105-112.

Brem G, Hartl P, Besenfelder U, Wolf E, Zinovieva N \& Pfaller R (1994) Expression of synthetic cDNA sequences encoding human insulin-like growth factor-q (IGF1) in the mammary gland of transgenic rabbits. Gene 149, 351-355.

Bryan CF and Stone MJ (1993) In Nutrient Modulation of the Immune Response, pp.105-126 [S Cunningham-Ruddles, editor]. New York, NY: Marcel Dekker. 
Buddington RK, Chen JW \& Diamond JM (1991) Intestinal regulation of intestinal brush-border sugar and amino acid transport in carnivores. American Journal of Physiology 261, R793-R801.

Buddington RK \& Diamond JM (1989) Ontogenetic development of intestinal nutrient transporters. Annual Review of Physiology 51, 601-619.

Bueno JD, Torres M, Almendros A, Carmona R, Núñez MC, Ríos A \& Gil A (1994) Effect of dietary nucleotides on smallintestinal repair after diarrhoea. Histological and ultrastructural changes. Gut 35, 926-933.

Bung P, Stein C, Prinz R, Pietrzik K, Schlebusch H, Bauer O \& Krebs D (1993) Folsäureversorgung in der SchwangerschaftErgebnisse einer prospektiven Longitudinalstudie (Folic acid provision in pregnancy: results of a prospective longitudinal study). Geburtsh u Frauenheilk 53, 92-99.

Bung P, Prietl G, Willrodt A, Krebs D, Prinz-Langenohl R \& Pietrzik K (1995) Idiopathische Infertilität und Sterilität-spielt Folsäure eine Schlüsselrolle? (Idiopathic infertility and sterility: does folic acid play a key role?). Journal für Fertilität und Reproduktion 2, 21-24.

Burke BS, Harding VV \& Stuart HC (1943) Nutrition upon the condition of the infant at birth. Journal of Nutrition 26, 569.

Buts JP \& Nyakabasa M (1985) Role of dietary protein to adaptation at weaning in the development of the rat gastrointestinal tract. Pediatric Research 19, 857-862.

Butterworth CE \& Bendich A (1996) Folic acid and the prevention of birth defects. Annual Review of Nutrition 16, 73-97.

Buxton DB, Robertson SM \& Olson MS (1986) Stimulation of glycogenolysis by adenine nucleotides in the perfused rat liver. Biochemical Journal 237, 773-780.

Calvo MS \& Park YK (1996) Changing phosphorus content of the US diet: potential for adverse effects on bone. Journal of Nutrition 126, 1168S-1180S

Carlson SE, Cooke RJ, Rhodes PG, Werkman SH, Peeples JM \& Tolley EA (1991) Long term feeding of formulas high in linolenic acid and marine oil to very low birth weight infants: phospholipids fatty acids. Pediatric Researvh 30, 404-412.

Carlson SE, Cooke RJ, Werkman SH \& Peeples JM (1992) First year growth of preterm infants fed standard compared to marine oil $n-3$ supplemented formula. Lipids 27, 901-907.

Carlson SE \& Werkman SH (1996) A randomized trial of visual attention of preterm infants fed docosahexaenoic acid until two months. Lipids 31, 85-90.

Carlson SE, Werkman SH, Peeples JM, Cooke RJ \& Tolley EA (1993) Arachidonic acid status correlates with first year growth in preterm infants. Proceedings of the National Academy of Sciences USA 90, 1073-1077.

Carver JD (1994) Dietary nucleotides: cellular immune, intestinal and hepatic system effects. Journal of Nutrition 124, $144 \mathrm{~S}-148 \mathrm{~S}$.

Carver JD, Pimentel B, Cox W \& Barness L (1991) Dietary nucleotides effects upon immune function in infants. Pediatrics 88, 359-363.

Cerra FB, Lehmann S, Konstantinides N, Dzik J, Fish J, Konstantinides F, LiCari JJ \& Holman RT (1991) Improvement in immune function in ICU patients by enteral nutrition supplemented with arginine, RNA, and menhaden oil is independent of nitrogen balance. Nutrition 7, 193-199.

Chan GM, Hoffman K \& McMurry M (1995) Effects of dairy products on bone and body composition in pubertal girls. Journal of Pediatrics 126, 551-556.

Chandra RK (1991) Interactions between early nutrition and the immune system. Ciba Foundation Symposium 156, 77-89.

Chandra RK, Puri S \& Hamed A (1989a) Influence of maternal diet during lactation and use of formula feeds on development of atopic eczema in high risk infants. British Medical Journal 299,
228-230 (published erratum appears in British Medical Journal 299, 896).

Chandra RK, Puri S, Suraiya C \& Cheema PS (1986) Influence of maternal food antigen avoidance during pregnancy and lactation on incidence of atopic eczema in infants. Clinical Allergy 16, $563-569$.

Chandra RK, Singh G \& Shridhara B (1989b) Effect of feeding whey hydrolysate, soy and conventional cow milk formulas on incidence of atopic disease in high risk infants. Annals of Allergy 63, 102-106.

Chavance M, Herbeth B, Fournier C, Janot C \& Vernhes G (1989) Vitamin status, immunity and infections in an elderly population. European Journal of Clinical Nutrition 43, 827-835.

Cheung R, Karjalainen J, Vandermeulen J, Singal DP \& Dosch HM (1994) T cells from children with IDDM are sensitized to bovine serum albumin. Scandinavian Journal of Immunology $\mathbf{4 0}$, 623-628.

Chew BP (1995) Antioxidant vitamins affect food animal immunity and health. Journal of Nutrition 125, 1804S-1808S.

Chirico G, Marconi M, Colombo A, Chiara A, Rondini G \& Ugazio AG (1983) Deficiency of neutrophil phagocytosis in premature infants: effects of vitamin E supplementation. Acta Paediatrica Scandinavia 72, 521-524.

Cidlowski JA, King KL, Evans-Storms RB, Montague JW, Bortner CD \& Hughes FM (1996) The biochemistry and molecular biology of glucocorticoid-induced apoptosis in the immune system. Recent Progress in Hormone Research 51, 457-490.

Clarke SD (1994) Dietary polyunsaturated fatty acid regulation of gene transcription. Annual Review of Nutrition 14, 83-98.

Clarke SD \& Abraham S (1992) Gene expression: nutrient control of pre- and post-transcriptional events. FASEB Journal 6, 3146-3152.

Cohen A, Barankiewicz J \& Gelfand EW (1984) Roles of alternative synthetic and catabolic purine pathways in T lymphocyte differentiation. Proceedings of the National Academy of Sciences USA 81, 26-33.

Cole DE, Gundberg CM, Stirk LJ, Atkinson SA, Hanley DA, Ayer LM \& Baldwin LS (1987) Changing osteocalcin concentration during pregnancy and lactation: implications for maternal mineral metabolism. Journal of Clinical Endocrinology and Metabolism 65, 290.

Cosman D (1994) A family of ligands for the TNF receptor superfamily. Stem Cells 12, 440-455.

Coutsoudis A, Bobat RA, Coovadia HM, Kuhn L, Tsai WY \& Stein ZA (1995) The effects of vitamin A supplementation on the morbidity of children born to HIV-infected women. American Journal of Public Health 85, 1076-1081.

Coutsoudis A, Kiepiela P, Coovadia HM \& Broughton M (1992) Vitamin A supplementation enhances specific IgG antibody levels and total lymphocyte numbers while improving morbidity in measles. Pediatric Infectious Disease Journal 11, 203-209.

Cowell CT, Lu PW, Lloyd-Jones SA, Briody JN, Allen JR, Humphries IR, Reed E, Knight J, Howman-Giles R \& Gaskin $\mathrm{K}$ (1995) Volumetric bone mineral density - a potential role in paediatrics. Acta Paediatrica 411, Suppl., 12-16.

Crane R (1975) The physiology of intestinal absorption of sugars. In Physiological Effects of Food Carbohydrates, pp. 1-19 [A James and J Hodges, editors]. Washington, DC: American Chemical Society.

Cravioto A, Tello A, Villafán H, Ruiz J, Del Vedovo S \& Neeser JR (1991) Inhibition of localized adhesion of enteropathogenic Escherichia coli to Hep-2 cells by immunoglobulin and oligosaccharide fractions of human colostrum and breast milk. Journal of Infectious Diseases 163, 1247-1255.

Cravioto J \& Cravioto P (1996) Mental development and malnutrition. In Long-term Consequences of Early Feeding, pp. 35-56 
[J Boulton, Z Laron and J Rey, editors]. Philadelphia, PA: Lippincott-Raven.

Cynober L (1994) Can arginine and ornithine support gut functions? Gut 35, Suppl. 1, S42-S45.

Dahlqvist A \& Lindberg T (1965) Fetal development of the smallintestinal disaccharidase and alkaline phosphatase in the human. Biology of the Neonate 9, 24-32.

Dahlqvist A \& Lindberg T (1966) Development of the intestinal disaccharidase and alkaline phosphatase activities in the human fetus. Clinical Science 30, 517-528.

Dallman PR \& Spirito RA (1977) Brain iron in the rat: extremely slow turnover in normal rat may explain the long-lasting effects of early iron deficiency. Journal of Nutrition 107, 1075-1081.

Daly JM, Reynolds J, Sigal RK, Shou J \& Liberman MD (1990) Effect of dietary protein and amino acids on immune function. Critical Care Medicine 18, S86-S93.

Danielsen EM, Skovberg H, Norén O \& Sjöström H (1984) Biosynthesis of intestinal microvillar proteins. Intracellular processing of lactase-phlorizin hydrolase. Biochemical and Biophysical Research Communications 122, 82-90.

Danielsen EM, Skovbjerg H, Norén O \& Sjöström H (1981) Biosynthesis of intestinal proteins. Nature of precursor forms of microvillar enzymes from $\mathrm{Ca}^{2+}$-precipitated enterocyte membranes. FEBS Letters 132, 197-200.

Davidson NO, Hausman AML, Ifkovits CA, Buse JB, Gould GW, Burant CF \& Bell GI (1992) Human intestinal transporter expression and localization of GLUT 5. American Journal of Physiology 262, C795-C800.

Davis RL, Hargen SM, Yeomans FM \& Chow BF (1973) Long term effects of alterations of maternal diet in mice. Nutrition Reports International 7, 463-473.

De Luca LM (1991) Retinoids and their receptors in differentiation, embryogenesis and neoplasia. FASEB Journal $\mathbf{5}$, $2924-2933$.

de Snoo K (1937) Das trinkende Kind im Uterus (The drinking child in utero). Monatsschrift für Geburtshilfe und Gynäkologie 105, 88-97.

Decsi T \& Koletzko B (1995) Growth, fatty acid composition of plasma lipid classes, and plasma retinol and $\alpha$-tocopherol concentrations in full-term infants fed formula enriched with $\omega-6$ and $\omega-3$ long-chain polyunsaturated fatty acids. Acta Paediatrica 84, 725-732.

De-Lucchi C, Pita ML, Faus MJ, Molina JA, Uauy R \& Gil A (1987) Effects of dietary nucleotides on the fatty acid composition of erythrocyte membrane lipids in term infants. Journal of Pediatric Gastroenterology and Nutrition 6, 568-574.

Demirini S \& Tsang RC (1995) Calcium and phosphorus nutrition in infants. Journal of Pediatric Gastroenterology and Nutrition 21, 367-373.

Demmelmair H, von Schenck U, Behrendt E, Sauerwald T \& Koletzko B. (1995) Estimation of arachidonic acid synthesis in fullterm neonates using natural variation of ${ }^{13} \mathrm{C}$-abundance. Journal of Pediatric Gastroenterology and Nutrition 21, 31-36.

Deurenberg P (1992) Methods for determining fat mass and fat distribution. Acta Paediatrica Suppl. 383, 53-57.

Docherty K \& Clark AR (1994) Nutrient regulation of insulin gene expression. FASEB Journal 8, 20-27.

Dragunow M \& Preston K (1995) The role of inducible transcription factors in apoptotic nerve cell death. Brain Research Reviews 21, 1-28.

Dubois S, Dougherty C, DuQuetette M, Hanley JA \& Montgin JM (1991) Twin pregnancy: the impact of the Higgins Nutrition Intervention Program on maternal and neonatal outcomes. American Journal of Clinical Nutrition 53, 1397.

Duggin GG, Dale NE, Lyneham RC, Evans RA \& Tiller DJ (1974) Calcium balance in pregnancy. Lancet 2, 926-927.

Egge H, Dell A \& von Nicolai H (1983) Fucose containing oligosaccharides from human milk. Archives of Biochemistry and Biophysics 224, 235-253.

Endres $S$ (1996) $n-3$ Polyunsaturated fatty acids and human cytokine synthesis. Lipids 31, S239-S242.

Evans-Storms RB \& Cidlowski JA (1995) Regulation of apoptosis by steroid hormones. Journal of Steroid Biochemistry and Molecular Biology 53, 1-8.

Fälth-Magnusson K \& Kjellman NI (1992) Allergy prevention by maternal elimination diet during late pregnancy - a 5-year follow-up of a randomized study. Journal of Allergy and Clinical Immunology 89, 709-713.

Fälth-Magnusson K, Oman H \& Kjellman NI (1987) Maternal abstention from cow milk and egg in allergy risk pregnancies. Effect on antibody production in the mother and the newborn. Allergy 42, 64-73.

Farquharson J, Cockburn F, Patrick WA, Jamieson EC \& Logan RW (1992) Infant cerebral cortex phospholipid fatty-acid composition and diet. Lancet 340, 810-813.

Fernandes G, Venkatraman J, Khare A, Horbach GJ \& Friedrichs W (1990) Modulation of gene expression in autoimmune disease and aging by food restriction and dietary lipids. Proceedings of the Society for Experimental Biology and Medicine 193, 16-22.

Fievre S, Wieruszeski JM, Michalski JC, Lemoine J, Montreuil J \& Strecker G (1991) Primary structure of trisialylated oligosaccharide from human milk. Biochemical and Biophysical Research Communications 177, 720-724.

Finch JM \& Turner RJ (1996) Effects of selenium and vitamin E on the immune responses of domestic animals. Research in Veterinary Science 60, 97-106.

Finstad HS, Kolset SO, Holme JA, Wiger R, Farrants AK, Blomhoff R \& Drevon CA (1994) Effect of $n-3$ and $n-6$ fatty acids on proliferation and differentiation of promyelocytic leukemic HL-60 cells. Blood 84, 3799-3809.

Fleming TR \& DeMets DL (1996) Surrogate endpoints in clinical trials: are we being misled? Annals of Internal Medicine 125, 605-613.

Folkers K, Morita M \& McRee J Jr (1993) The activities of coenzyme Q10 and vitamin B6 for immune responses. Biochemical and Biophysical Research Communications 193, 88-92.

Fomon SJ \& Nelson SE (1994) Size and growth. In Nutrition of the Infant, pp. 36-83 [SJ Fomon, editor]. St Louis, MO: Mosby.

Fomon SJ (1991) Reference data for assessing growth of infants. Journal of Pediatrics 119, 415-416.

Food and Agriculture Organization/World Health Organization/ United Nations University (1985) Energy and Protein Requirements. WHO Technical Report Series no. 724. Geneva: WHO.

Forbes GB (1987) Human Body Composition, Growth, Aging, Nutrition and Activity. New York: Springer-Verlag.

Formica JV \& Regelson W (1995) Review of the biology of quercetin and related bioflavonoids. Food and Chemical Toxicology 33, 1061-1080.

Forni G, Cerruti Sola S, Giovarelli M, Santoni A, Martinetto P \& Vietti D (1986) Effect of prolonged administration of low doses of dietary retinoids on cell-mediated immunity and the growth of transplantable tumors in mice. Journal of the National Cancer Institute 76, 527-533.

Foufelle F, Girard J \& Ferré P (1996) Regulation of lipogenic enzyme expression by glucose in liver and adipose tissue: a review of the potential cellular and molecular mechanisms. Advances in Enzyme Regulation 36, 199-226.

Foufelle F, Gouhot B, Pégorier J-P, Perdereau D, Girard J \& Ferré P (1992) Glucose stimulation of lipogenic enzyme gene expression in white adipose tissue. Journal of Biological Chemistry 267, 20543-20546.

Friel JK, Andrews WL, Matthew JD, Long DR, Cornel AM, Cox M, McKim E \& Zerbe GO (1993) Zinc supplementation in very low birth weight infants. Journal of Pediatric Gastroenterology and Nutrition 17, 97-104. 
Fujisawa T, Riby J \& Kretchmer N (1991) Intestinal absorption of fructose in the rat. Gastroenterology 101, 360-367.

Garlick PJ \& McNurlan MA (1994) Protein metabolism in the cancer patient. Biochimie 76, 713-717.

Gaull GE, Rassin DK, Raiha NCR \& Heinonen K (1977) Milk protein quantity and quality in low-birth weight infants: III. Effects on sulfur amino acids in plasma and urine. Journal of Pediatrics 90, 348-355.

Gebhard KJ, Gridley DS, Stickney DR \& Shulz TD (1990) Enhancement of immune status by high levels of dietary vitamin B-6 without growth inhibition of human malignant melanoma in athymic nude mice. Nutrition and Cancer 14, 15-26.

Gerrard JW \& Shenassa M (1983) Sensitization to substances in breast milk: recognition, management and significance. Annals of Allergy 51, 300-302.

Gerstein HC (1994) Cow's milk exposure and type I diabetes mellitus. A critical overview of the clinical literature. Diabetes Care 17, 13-19.

Gerster H \& Moser U (1988) Is high-dose vitamin C intake associated with systemic conditioning? Nutrition Research 8 , $1327-1332$

Ghersa P, Huber P, Semenza G \& Wacker H (1986) Cell-free synthesis, membrane integration and glycosylation of prosucrase-isomaltase. Journal of Biological Chemistry 261, 7969-7974.

Ghigo E, Arvat E, Gianotti L, Nicolosi M, Valetto MR, Avagnina S, Bellitti D, Rolla M, Muller EE \& Camanni F (1994) Arginine but not pyridostigmine, a cholinesterase inhibitor, enhances the GHRH-induced GH rise in patients with anorexia nervosa. Biological Psychiatry 36, 689-695.

Gil A, Corral E, Martínez A \& Molina JA (1986a) Effects of dietary nucleotides on the microbial pattern of feces of at term newborn infants. Journal of Clinical Nutrition and Gastroenterology 1, 34-38.

Gil A \& Lozano E, De-Lucchi C, Maldonado J, Molina JA \& Pita $M$ (1988) Changes in the fatty acid profiles of plasma lipid fractions induced by dietary nucleotides in infants born at term. European Journal of Clinical Nutrition 42, 473-481.

Gil A, Pita M, Martínez A, Molina JA \& Sánchez-Medina F (1986b) Effect of dietary nucleotides on the plasma fatty acids in at-term neonates. Human Nutrition: Clinical Nutrition $\mathbf{4 0} \mathrm{C}$, 185-195.

Gil A \& Sánchez-Medina F (1981) Acid-soluble nucleotides of cow's, goat's and sheep's milk at different stages of lactation. Journal of Dairy Research 48, 35-44.

Gil A \& Sánchez-Medina F (1982) Acid-soluble nucleotides of human milk at different stages of lactation. Journal of Dairy Research 49, 301-307.

Gil A \& Uauy R (1989) Dietary nucleotides in infant nutrition. Journal of Clinical Nutrition and Gastroenterology 4, 145-153.

Gil A \& Uauy R (1995a) Nucleotides and related compounds in human and bovine milks. In Handbook of Milk Composition, pp. 436-464 [RG Jensen, editor]. San Diego, CA: Academic Press.

Gil A \& Uauy R (1995b) Nutritional and Biological Significance of Dietary Nucleotides and Nucleic Acids. Barcelona: Limpergraf.

Gilsanz V, Roe TF, Mora S, Costin G \& Goodman WG (1991) Changes in vertebral bone density in black girls and white girls during childhood and puberty. New England Journal of Medicine 325, 1597-1600.

Girard J, Ferré P, Pégorier JP \& Duée PH (1992) Adaptations of glucose and fatty acid metabolism during perinatal period and suckling-weaning transition. Physiological Reviews 72, 507-562.

Gray GM (1967) Malabsorption of carbohydrates. Federation Proceedings 26, 1415-1419.

Grimaldi PA, Knobel SM, Whitesell RR \& Abumrad NA (1992) Induction of $\mathrm{aP} 2$ gene expression by nonmetabolized long-chain fatty acids. Proceedings of the National Academy of Sciences USA 89, 10930-10934.

Gunnes M \& Lehman EH (1995) Dietary calcium, saturated fat, fiber and vitamin $\mathrm{C}$ as predictors of forearm cortical and trabecular bone density in healthy children and adolescents. Acta Paeditrica 84, 388-392.

Güttler F (1984) Phenylketonuria: 50 years since Follings discovery and still expanding our clinical and biochemical knowledge. Acta Paediatrica Scandinavia 73, 705-716.

Güttler F \& Guldberg P (1996) The influence of mutations of enzyme activity and phenylalanine tolerance in phenylalanine hydroxylase deficiency. European Journal of Pediatrics 155, Suppl. 1, S6-S10.

Hachey DL (1994) Benefits and risks of modifying maternal fat intake in pregnancy and lactation. American Journal of Clinical Nutrition 59, Suppl., 454S-464S.

Hadsell DL, Greenberg NM, Fligger JM, Baumrucker CR \& Rosen JM (1996) Targeted expression of des(1-3) human insulin-like growth factor I in transgenic mice influences mammary gland development and IGF-binding protein expression. Endocrino$\log y$ 137, 321-330.

Hakomori S \& Igarashi Y (1995) Functional role of glycosphingolipids in cell recognition and signaling. Journal of Biochemistry, Tokyo 118, 1091-1103.

Halas ES, Sanstead HH (1975) Some effects of prenatal zinc deficiency on behavior of the adult rat. Pediatric Research 9, 94-97.

Halas ES \& Sanstead HH (1980) Malnutrition and behavior: the performance versus learning problem revisited. Journal of Nutrition 110, 1858-1864.

Hale AJ, Smith CA, Sutherland LC, Stoneman VE, Longthorne VL, Culhane AC \& Williams GT (1996) Apoptosis: molecular regulation of cell death. European Journal of Biochemistry 236, $1-26$.

Halken S, Host A, Hansen LG \& Osterballe O (1993a) Preventive effect of feeding high-risk infants a casein hydrolysate formula or an ultrafiltrated whey hydrolysate formula. A prospective, randomized, comparative clinical study. Pediatric Allergy and Immunology 4, 173-181.

Halken S, Host A, Hansen LG \& Osterballe O (1993b) Safety of a new, ultrafiltrated whey hydrolysate formula in children with cow milk allergy: a clinical investigation. Pediatric Allergy and Immunology 4, 53-59.

Hall L, Emery DC, Davies MS, Parker D \& Craig RK (1987) Organization and sequence of the human $\alpha$-lactalbumin gene. Biochemical Journal 242, 735-742.

Hallberg L (1988) Iron balance in pregnancy. In Vitamins and Minerals in Pregnancy and Lactation. Nestle Nutrition Workshop Series, pp. 115-127 [H Berger, editor]. New York, NY: Raven Press.

Harris WS, Connor WE \& Lindsey S. (1984) Will dietary $\omega-3$ fatty acids change the composition of human milk? American Journal of Clinical Nutrition 40, 780.

Hauri HP (1986) Use of monoclonal antibodies to investigate the intracellular transport and biogenesis of intestinal brush border proteins. Biochemical Society Transactions 161, 161-163.

Hauri HP, Quaroni A \& Isselbacher KJ (1980) Monoclonal antibodies to sucrase-isomaltase: probes for the study of postnatal development and biogenesis of the intestinal microvillus membrane. Proceedings of the National Academy of Sciences USA 77, 6629-6633.

Hauri HP, Sterchi EE, Bienz D, Fransen JAW \& Marxer A (1986) Expression and intracellular transport of microvillus membrane hydrolases in human intestinal epithelial cell. Journal of Cellular Biology 101, 838-851.

Hauri HP, Wacker H, Rickli EE, Bigler-Meier B, Quaroni A \& Semenza G (1982) Biosynthesis of sucrase-isomaltase. 
Purification and $\mathrm{NH}_{2}$-terminal amino acid sequence of the rat sucrase-isomaltase precursor (pro-sucrase-isomaltase) from fetal intestinal transplants. Journal of Biological Chemistry 257, 4522-4528.

He Y, Chu SW \& Walker WA (1993) Nucleotide supplements alter proliferation and differentiation of cultured human $(\mathrm{CaCo}-2)$ and rat (IEC-6) intestinal epithelial cells. Journal of Nutrition 123, 1017-1027.

Hellerstein MK, Wu K, McGrath M, Faix D, George D, Shackleton CH, Horn W, Hoh R \& Neese RA (1996) Effects of dietary $n-3$ fatty acid supplementation in men with weight loss associated with the acquired immune deficiency syndrome: relation to indices of cytokine production. Journal of Acquired Immune Deficiency Syndromes: Human Retrovirology 11, 258-270.

Hemila H (1996) Vitamin C and common cold incidence: a review of studies with subjects under heavy physical stress. International Journal of Sports Medicine 17, 379-383.

Henderson RC \& Hayes PRL (1994) Bone mineralisation in children and adolescents with a milk allergy. Bone and Mineral 27, 1-12.

Hernández M \& Argente J (1992) Human Growth: Basic and Clinical Aspects. Amsterdam: Excerpta Medica.

Hernández-Muñoz R, Díaz-Muñoz M, Suárez J \& Chagoya de Sánchez V (1990) Adenosine partially prevents cirrhosis induced by carbon tetrachloride in rats. Hepatology $\mathbf{1 2}$, $242-248$.

Herskovics A, Quaroni A, Bugge B \& Kirsch K (1981) Partial characterization of the carbohydrate units of rat intestinal sucrase-isomaltase. Biochemical Journal 197, 511-514.

Houscham KC \& Devilliers JFK (1987) Computed tomography in severe protein-energy malnutrition. Archives of Disease in Childhood 62, 589-592.

Houtkooper LB, Going SB, Lohman TG, Roche AF \& Van Loan M (1992) Bioelectrical impedance estimation of fat free body mass in children and youth: a cross-validation study. Journal of Applied Physiology 72, 366-373.

Hughes DA, Wright AJA, Finglas PM, Peerless ACJ, Bailey AL, Astley SB, Pinder AC \& Southon S (1996) Beta-carotene supplementation enhances the expression of functionally associated molecules on human monocytes. Biochemical Society Transactions 24, 388S.

Hurle JM, Ros MA, Garcia-Martinez V, Macias D \& Ganan Y (1995) Cell death in the embryonic developing limb. Scanning Microscopy 9, 519-533.

Huttenlocher PR, de Courten C, Garey LJ \& van der Loos H (1982) Synaptogenesis in the human visual cortex-evidence for synapse elimination during normal development. Neuroscience Letters 33, 247-252.

Hytten FE \& Leitch I (1971) The Physiology of Human Pregnancy, 2nd ed. Oxford: Blackwell Scientific Publications.

Igarashi P (1994) Transcription factors and apoptosis in kidney development. Current Opinion in Nephrology and Hypertension 3, 308-317.

Innis SM, Nelson CM, Lwanga D, Rioux FM \& Waslen P (1996) Formula feeding without arachidonic acid and docosahexaenoic acid has no effect on preferential looking acuity or recognition memory in healthy full-term infants at 9 mo of age. American Journal of Clinical Nutrition 64, 40-46.

Institute of Medicine (1990) Nutrition During Pregnancy: Weight Gain and Nutrient Supplements. Washington, DC: National Academy Press.

Isolauri E, Juntunen M, Rautanen T, Sillanaukee P \& Koivula T (1991) A human Lactobacillus strain (Lactobacillus casei sp strain GG) promotes recovery from acute diarrhea in children. Pediatrics 88, 90-97.

Isolauri E, Kaila M, Mykkanen H, Ling WH \& Salminen S (1994) Oral bacteriotherapy for viral gastroenteritis. Digestive Diseases and Sciences 39, 2595-2600.
Jacobson M (1991) Developmental Neurobiology. New York: Plenum Press.

James TN (1993) Normal and abnormal consequences of apoptosis in the human heart: from postnatal morphogenesis to paroxysmal arrhythmias. Transactions - American Clinical and Climatological Association 105, 145-177.

Jirsova V, Koldovsky O, Heringova A, Hoskova J, Jirasek J \& Uher J (1965-66) The development of the functions of the small intestine of the human fetus. Biology of the Neonate 9, 44-49.

Johnston CC, Miller JZ, Slemenda CW, Reister TK, Hui S, Christian JC \& Peacock M (1992) Calcium supplementation and increase in bone mineral density in children. New England Journal of Medicine 327, 82-87.

Jørgensen HL, Schøller J, Sand JC, Bjuring M, Hassager C \& Christiansen C (1996) Relation of common allelic variation at vitamin $\mathrm{D}$ receptor locus to bone mineral density and postmenopausal bone loss: cross sectional and longitudinal population study. British Medical Journal 313, 586-590.

Kaila M, Isolauri E, Soppi E, Virtanen E, Laine S \& Arvilommi H (1992) Enhancement of the circulating antibody secreting cell response in human diarrhea by a human Lactobacillus strain. Pediatric Research 32, 141-144.

Kandel ER, Schwartz JH \& Jessell TM (1991) Principles of Neural Science. East Norwalk, CT: Appleton \& Lange.

Kandel ER, Schwartz JH \& Jessell TM (1995) Essentials of Neural Science. East Norwalk, CT: Appleton \& Lange.

Karasov WH, Pond RS III, Solberg DH \& Diamond JM (1983) Regulation of proline and glucose transport in mouse intestine by dietary substrate levels. Proceedings of the National Academy of Sciences USA 80, 7674-7678.

Kashfi K, Yang E, Chowdbury J, Chowdbury N \& Dannenberg A (1994) Regulation of UDPGT expression by phenolic antioxidants. Cancer Research 54, 5856-5859.

Kawata M (1995) Roles of steroid hormones and their receptors in structural organization in the nervous system. Neuroscience Research 24, 1-46.

Kember NF (1993) Cell kinetics and the control of bone growth. Acta Paeditrica Suppl. 391, 61-65.

Kemen M, Senkal M, Homann HH, Mumme A, Dauphin AK, Baier J, Windeler J, Neumann H \& Zumtobel V (1995) Early postoperative enteral nutrition with arginine- omega- 3 fatty acids and ribonucleic acid-supplemented diet versus placebo in cancer patients: An immunologic evaluation of $\operatorname{Impact}(R)$. Critical Care Medicine 23, 652-659.

Kerstetter JE (1995) Do dairy products improve bone density in adolescent girls? Nutrition Reviews 53, 328-332.

Keusch GT (1996) Symposium on vitamin A and immunity: salient points and directions for future research. Journal of Nutritional Immunology 4, 133-143.

Kilberg MS, Hutson RG \& Laine RO (1994) Amino acid-regulated gene expression in eukaryotic cells. FASEB Journal 18, 13-19.

Kilshaw PJ \& Cant AJ (1984) The passage of maternal dietary proteins into human breast milk. International Archives of Allergy and Applied Immunology 75, 8-15.

Kim SJ, Cho YK, Lee KW (1994) Expression of human lactoferrin in milk of transgenic mice using bovine $\beta$-casein/human lactoferrin cDNA fusion gene. Korean Society for Molecular Biology 4, 355-360.

Kiremidjian Schumacher L \& Stotzky G (1987) Selenium and immune responses. Environmental Research 42, 277-303.

Kitagawa H, Nakada H, Fukui S, Funakoshi I, Kawasaki T \& Yamashira I (1991) Novel oligosaccharides with the sialyl- Le structure in human milk. Biochemistry 30, 2869-2876.

Kitajima H, Sumida Y, Tanaka R, Yuki N, Takayama H \& Fujimura M (1997) Early administration of bifidobacterium breve to preterm infants: randomised controlled trial. Archives of Disease in Childhood 76, F101-F107. 
Knip M (1992) [Can type-1 diabetes in children be prevented?]. Nordisk Medicin, 107, 207-210.

Koldovsky O \& Strbak V (1995) Hormones and growth factors in human milk. In Handbook of Milk Composition, pp. 428-436 [RG Jensen, editor]. San Diego, CA: Academic Press.

Koldovsky O \& Thornburg W (1987) Hormones in human milk: a review. Journal of Pediatric Gastroenterology and Nutrition 6 , 172-196

Koletzko B (1992) Fats for brains. European Journal of Clinical Nutrition 46, Suppl. 1, S51-S62.

Koletzko B \& Braun M (1991) Arachidonic acid and early human growth: is there a relation? Annals of Nutrition and Metabolism 35, $128-131$.

Koletzko B \& Müller J (1990) Cis- and trans-isomeric fatty acids in plasma lipids of newborn infants and their mothers. Biology of the Neonate 57, 172-178.

Koletzko B, Thiel I \& Abiodun PO (1992) The fatty acid composition of human milk in Europe and Africa. Joumal of Pediatrics 120, S62-S70.

Kramer TR (1996) Relationship between vitamin A status and T-lymphocyte responsiveness. Journal of Nutritional Immunology 4, 77-85.

Krammer PH, Behrmann I, Daniel P, Dhein J \& Debatin KM (1994) Regulation of apoptosis in the immune system. Current Opinion in Immunology 6, 279-289.

Krenger W, Falzarano G, Delmonte J Jr, Snyder KM, Byon JC \& Ferrara JL (1996) Interferon-gamma suppresses T-cell proliferation to mitogen via the nitric oxide pathway during experimental acute graft-versus-host disease. Blood 88, 1113-1121.

Kretchmer N, Beard JL \& Carlson SE (1996) The role of nutrition in the development of normal cognition. American Journal of Clinical Nutrition 63, 997S-1001S.

Kroemer G, Petit P, Zamzami N, Vayssiere JL \& Mignotte B (1995) The biochemistry of programmed cell death. FASEB Journal 9, 1277-1287.

Kudsk KA, Minard G, Croce MA, Brown RO, Lowrey TS, Pritchard FE, Dickerson RN \& Fabian TC (1996) A randomized trial of isonitrogenous enteral diets after severe trauma. An immune-enhancing diet reduces septic complications. Annals of Surgery 531-540; discussion 540-543.

Kulkarni AD, Fanslow WC, Rudolph FB \&Van Buren CT (1992) Immunohemopoietic effects of dietary nucleotide restriction in mice. Transplantation 53, 467-472.

Kulkarni AD, Rudolph FB \& Van Buren CT (1994) The role of dietary sources of nucleotides in immune function: a review. Journal of Nutrition 124, 1442S-1446S.

Lacey JM \& Wilmore DW (1990) Is glutamine a conditionally essential amino acid? Nutrition Reviews 48, 297-309.

Laegrid A, Otnaess ABK \& Fugelsang J. (1986) Human and bovine milks: comparison of ganglioside compositions and enterotoxin inhibitory activity. Pediatric Research 20, 416-420.

Lanting CI, Fidler V, Huisman M, Touwen BCL \& Boersma ER (1994) Neurological differences between 9-year-old children fed breast-milk or formula-milk as babies. Lancet 344, 1319-1322.

Lechting A, Habicht JP, Delgado H, Klein RE, Yarbrough C \& Martorell R (1975) Effect of food supplementation during pregnancy on birth-weight. Pediatrics 56, 508.

Leclercq I, Horsmans Y, Desager JP, Pauwels S \& Geubel AP (1996) Influence of diet on liver volume and CYP activities in human non alcoholic fatty liver. Hepatology 24, 311A.

Lee WTK, Leung SSF, Wang SH, Xu YC, Zeng WP, Lau J, Oppenheimer SJ \& Cheng JC (1994) Double-blind controlled calcium supplementation and bone mineral accretion in children accustomed to a low-calcium diet. American Journal of Clinical Nutrition 60, 744-750.

LeLeiko NS, Bronstein AD, Baliga S \& Munro HN (1983) De novo purine nucleotide synthesis in the rat small and large intestine effect of dietary protein and purines. Journal of Pediatric Gastroenterology and Nutrition 2, 313-319.

LeLeiko NS, Martin BA, Walsh MJ, Kazlow P, Rabinowitz S \& Sterling K (1987) Tissue specific gene expression results from a purine and pyrimidine -free diet and 6-mercaptopurine in the rat small intestine and colon. Gastroenterology 93, 1014-1020.

LeLeiko NS, Walsh MJ \& Abraham S (1995) Gene expression in the intestine: the effect of dietary nucleotides. Advances in Pediatrics 42, 145-169.

Lentze MJ (1986) Die Ernährung von Frühgeborenen unter $1500 \mathrm{~g}$ enterale Voraussetzungen (Feeding of premature infants below $1500 \mathrm{~g}$ : enteral preconditions). Monatsschrift für Kinderheilkunde 134, 502-507.

Levy Marchal C, Karjalainen J, Dubois F, Karges W, Czernichow P \& Dosch HM (1995) Antibodies against bovine albumin and other diabetes markers in French children. Diabetes Care 18, 1089-1094.

Lewis DS, Bertrand HA, McMahan CA, McGill HC, Carey KD \& Masaro EJ (1986) Preweaning food intake influences the adiposity of young adult baboons. Journal of Clinical Investigation 78, 899-905.

Liang B, Lane L \& Watson RR (1995) Vitamin E stimulation of disease resistance and immune function. Expert Opinion on Investigational Drugs 4, 201-211.

Liang B \& Watson RR (1996) Vitamin E and immunomodulation for cancer and AIDS resistance. Expert Opinion on Investigational Drugs 5, 1221-1225.

Liang Q \& Richardson T (1993) Expression and characterization of human lactoferrin in yeast, Saccharomyces cerevisiae. Journal of Agriculture and Food Chemistry 41, 1800-1807.

Licata AA (1993) Monitoring calcium intake and absorption. World Review of Nutrition and Dietetics 73, 27-52.

Liley AW (1972) Disorders of the amniotic fluid. In Pathophysiology of Gestation: Fetal Placental Disorders, vol. 2 [NS Assali, editor]. New York, NY: Academic Press.

Lilja G, Dannaeus A, Foucard T, Graff LV, Johansson SG \& Oman $\mathrm{H}$ (1989) Effects of maternal diet during late pregnancy and lactation on the development of atopic diseases in infants up to 18 months of age - in-vivo results. Clinical and Experimental Allergy 19, 473-479.

Limonta JM, Castro FO, Martinez R, Puentes P, Ramos B, Aguilar A, Lleonart RL \& delaFuente J (1995) Transgenic rabbits as bioreactors for the production of human growth hormone. Journal of Biotechnology 40, 49-58.

Lindfors A \& Enocksson E (1988) Development of atopic disease after early administration of cow milk formula. Allergy 43, 11-16.

Llewellyn-Jones D (1965) Severe anaemia in pregnancy. Australian and New Zealand Journal of Obstetrics and Gynaecology 5, 191-197.

Lloyd T, Andon MB, Rollings N, Martel JK, Landis JR, Demers LM, Eggli DF, Kieselhorst K \& Kulin HE (1993) Calcium supplementation and bone mineral density in adolescent girls. Journal of the American Medical Association 270, 841-844.

Loche S, Carta D, Muntoni AC, Corda R \& Pintor C (1993) Oral administration of arginine enhances the growth hormone response to growth hormone releasing hormone in short children. Acta Paediatrica 82, 883-884.

Lodish H, Baltimore D, Berk A, Zipursky SL, Matsudaira P \& Darnell J (1995) Molecular Cell Biology. New York, NY Scientific American Books, WH Freeman.

Lönnerdal B (1996) Recombinant human milk proteins - an opportunity and a challenge. American Journal of Clinical Nutrition 63, 622S-626S.

López-Navarro AT, Gil A \& Sánchez-Pozo A (1995) Deprivation of dietary nucleotides results in a transient decrease in acid soluble nucleotides and RNA content in rat liver. Journal of Nutrition 125, 2090-2095. 
López-Navarro AT, Ortega MA, Peragon J, Bueno JD, Gil A \& Sanchez-Pozo A (1996) Deprivation of dietary nucleotides decreases protein synthesis in the liver and small intestine in rats. Gastroenterology 110, 1760-1769.

Lozoff B \& Brittenham GM (1986) Behavioural aspects of iron deficiency. Progress in Hematology 14, 23-53.

Lozoff B, Wolf AW \& Jiminez E (1996) Iron-deficiency anemia and infant development: effects of extended oral iron therapy. Journal of Pediatrics 129, 382-389.

Lucas A, Morley R, Cole TJ, Lister G \& Leeson-Payne C (1992) Breast milk and subsequent intelligence quotient in children born preterm. Lancet 339, 261-264.

Luke B \& Petrie RH (1980) Intrauterine growth: correlation of infant birth weight and maternal postpartum weight. American Journal of Clinical Nutrition 33, 2311.

Mackinnon AM \& Deller DJ (1973) Purine nucleotides biosynthesis in gastrointestinal mucosa. Biochimica et Biophysica Acta $319,1-4$.

Maga EA, Anderson GB, Mei CH \& Murray JD (1994) Expression of human lysozyme mRNA in the mammary gland of transgenic mice. Transgenic Research 3, 36-42.

Majamaa H \& Isolauri E (1997) Probiotics: a novel approach in the management of food allergy. Journal of Allergy and Clinical Immunology 99, 179-185.

Makrides M, Neumann MA, Byard RW, Simmer K \& Gibson RA (1994) Fatty acid composition of brain, retina, and erythrocytes in breast- and formula-fed infants. American Joumal of Clinical Nutrition 60, 189-194.

Makrides M, Neumann M, Simmer K, Pater J \& Gibson R (1995) Are long chain polyunsaturated fatty acids essential nutrients in infancy? Lancet 345, 1463-1468.

Makrides M, Simmer K, Goggin M \& Gibson RA (1993) Erythrocyte docosahexaenoic acid correlates with the visual response of healthy, term infants. Pediatric Research 34, 425-427.

Mandl J, Banhegy G, Kapalos M, Garzo T (1995) Increased oxidation and decreased conjugation of drugs in the liver caused by starvation, altered metabolism of certain aromatic compounds and acetone. Chemicobiological Interactions 96, 87-101.

Mantei N, Villa M, Enzler T, Wacker H, Boll W, James P, Hunziger W \& Semenza G (1988) Complete primary structure of human and rabbit lactase-phlorizin hydrolase: implications for biosynthesis, membrane anchoring and evolution of the enzyme. EMBO Journal 7, 2705-2713.

Marcinkiewicz J, Grabowska A \& Chain BM (1996) Is there a role for nitric oxide in regulation of T cell secretion of IL-2? Journal of Immunology 156, 4617-4621.

Mastrmatteo E \& Sullivan F (1994) Summary: international symposium on the health effects of boron and its compounds. Environmental Health Perspectives 102, Suppl. 7, 139-141.

Mathieu C, Waer M, Laureys J, Rutgeerts O \& Bouillon R (1994) Prevention of autoimmune diabetes in NOD mice by 1,25 dihydroxyvitamin D3. Diabetologia 37, 552-558.

Mayfield R, Yarbrough C \& Lechtig A (1991) Body composition of low-birth weight infants determined by using bioelectrical resistance and reactance. American Journal of Clinical Nutrition 54, 296-303.

Meikrantz W \& Schlegel R (1995) Apoptosis and the cell cycle. Journal of Cell Biochemistry 58, 160-174.

Melnik B, Plewig G \& Tschung T (1991) Are deficiencies of prostaglandin-E-mediated immunoregulation involved in increased IgE synthesis of atopic mononuclear cells in vitro? Allergy 46, 502-506.

Mennella JA \& Beauchamp GK (1991) The transfer of alcohol to human milk: effects on flavor and the infant's behavior. New England Journal of Medicine 325, 981-985.
Mennella JA \& Beauchamp GK (1993) The effects of repeated exposure to garlic-flavored milk on the nursling's behavior. Pediatric Research 34, 805-808.

Messer M \& Kerry KR (1967) Intestinal digestion of maltotriose in man. Biochimica et Biophysica Acta 132, 432-443.

Messina M \& Messina V (1996) Nutritional implications of dietary phytochemicals. Advances in Experimental Medicine and Biology 401, 207-212.

Millar MR, Bacon C, Smith SL, Walker V \& Hall MA (1993) Enteral feeding of premature infants with Lactobacillus GG. Archives of Disease in Childhood 69, 483-487.

Miller JB, Bull S, Miller J \& McVeagh P (1994) The oligosaccharide composition of human milk: temporal and individual variations in the monosaccharide components. Journal of Pediatric Gastroenterology and Nutrition 19, 371-376.

Miller LT \& Kerkvliet NI (1990) Effect of vitamin B6 on immunocompetence in the elderly. Annals of the New York Academy of Sciences 587, 49-54.

Milner. JA (1990) Trace minerals in the nutrition of children. Journal of Pediatrics 117, S147-S155.

Morillas J, Moltó L, Robles R, Gil A \& Sánchez-Pozo A (1994) Lipoprotein changes in small-for-gestational-age infants fed nucleotide-supplemented milk formula. Acta Paediatrica 83, $481-485$.

Morley R \& Lucas A (1993) Early diet and outcome in prematurely born children. Clinical Nutrition 12, Suppl., 6-11.

Naeye RL, Diener MM \& Dellinger WS (1989) Urban poverty: effects on prenatal nutritition. Science 166, 1026.

Nagata S (1997) Apoptosis by death factor. Cell 88, 355-365.

Naim HY, Roth J, Sterchi EE, Lentze MJ, Milla PJ, Schmitz J \& Hauri HP (1988) Sucrase-isomaltase deficiency in humans. Different mutations disrupt intracellular transport, processing and function of an intestinal brush border enzyme. Journal of Clinical Investigation 82, 667-679.

Naim HY, Niermann T, Kleinhans U, Hollenberg CP \& Strasser AWM (1991) Strikung structural and functional similarities suggest that intestinal sucrase-isomaltase, human lysosomal $\alpha$-glucosidase, and Schwanniomyces occidentalis glucoamylase are derived from common ancestral gene. FEBS Letters 294, $109-112$.

Naim HY, Sterchi EE \& Lentze MJ (1989) Structure, biosynthesis and glycosylation of human small intestinal maltase-glucoamylase. Journal of Biological Chemistry 263, 19709-19717.

National Research Council (1989) Recommended Dietary Allowances, 10th ed. Washington, DC: National Academy Press.

Navarro J, RuizBravo A, JimenezValera M \& Gil A (1996) Modulation of antibody-forming cell and mitogen-driven lymphoproliferative responses by dietary nucleotides in mice. Immunology Letters 53, 141-145.

Neggers YH, Cutter GR, Alvarez JO, Goldenberg RL, Acton R, Go RC \& Roseman JM (1991) The relationship between maternal serum zinc levels during pregnancy and birthweight. Early Human Development 25, 75-85.

Neuringer M (1993) The relationship of fatty acid composition to function in the retina and visual system. In Lipids, Learning and the Brain: Fats in Infant Formulas. Report of the 103rd Ross Conference on Pediatric Research, pp. 69-101 [J Dobbing, editor]. Columbus, $\mathrm{OH}$ : Ross Laboratories.

Newburg DS \& Neubauer SH (1995) Carbohydrates in milks: analysis, quantities and significance. In Handbook of Milk Composition, pp. 273-349 [RG Jensen, editor]. San Diego, CA: Academic Press.

Newburg DS, Pickering LK, McCluer RH \& Cleary TG (1990) Fucosylated oligosaccharides of human milk protect suckling mice from heat stable enterotoxin of Escherichia coli. Journal of Infections and Diseases 162, 1075-1080.

Newsholme EA \& Carrié AL (1994) Quantitative aspects of 
glucose and glutamine metabolism by intestinal cells. Gut $\mathbf{3 5}$, Suppl. 1, S13-S17.

Niv M, Levy W \& Greenstein NM (1963) Yogurt in the treatment of infantile diarrhoea. Clinical Pediatrics 2, 407-411.

Núñez MC, Ayudarte MV, Morales D, Suárez MD \& Gil A (1990) Effect of dietary nucleotides on intestinal repair in rats with experimental chronic diarrhea. Journal of Parenteral and Enteral Nutrition 14, 598-604.

Ogoshi S, Iwasa M, Kitagawa S, Ohmori Y, Mizobuchi S, Iwasa Y \& Tamiya T (1988) Effects of total parenteral nutrition with nucleoside and nucleotide mixture on $\mathrm{D}$-galactosamine-induced liver injury in rats. Journal of Parenteral and Enteral Nutrition 12, 53-57.

Ogoshi S, Iwasa M, Yonezawa T \& Tamiya T (1985) Effect of nucleotide and nucleoside mixture on rats given total parenteral nutrition after $70 \%$ hepatectomy. Journal of Parenteral and Enteral Nutrition 9, 339-342.

Ohyanagi H, Nishimatsu S, Kanbara Y, Usami M \& Saitoh Y (1989) Effects of nucleosides and a nucleotide on DNA and RNA syntheses by the salvage and de novo pathway in primary monolayer cultures of hepatocytes and hepatoma cells. Journal of Parenteral and Enteral Nutrition 13, 51-58.

Oldaeus G, Anjou K, Björksten B, Moran JR \& Kjellmann NIM (1997) Extensively and partially hydrolysed infant formulas for allergy prophylaxis. Archives of Disease in Childhood 77, $4-10$.

Olsen SF, Soerensen JD, Secher NJ, Hedegaard M, Henriksen TB, Hansen HS \& Grant A (1992) Randomized controlled trial of the effect of fish-oil supplementation on pregnancy duration. Lancet 339, 1003-1007.

Olsen SF, Hansen HS, Sorensen TI, Jensen B, Secher NJ, Sommer S \& Knudsen LB (1986) Intake of marine fat, rich in (n-3) polyunsaturated fatty acids, may increase birth-weight by prolonging gestation. Lancet 2, 367-369.

Onwude JL, Lilford RJ, Hjartardottir H, Staines A \& Tuffnell D (1995) A randomised double blind placebo controlled trial of fish oil in high risk pregnancy. British Joumal of Obstetrics and Gynaecology 102, 95-100.

Ortega MA, Núñez MC, Gil A \& Sánchez-Pozo A (1995) Dietary nucleotides accelerate intestinal recovery after food deprivation in old rats. Journal of Nutrition, 125, 1413-1418.

Osmond C, Barker DJP, Winter PD, Fall CHD \& Simmonds SJ (1993) Early growth and death from cardiovascular disease in women. British Medical Journal 307, 1519-1524.

Patton S, Gendler S \& Spicer AP (1995) The epithelial mucin, MUC1, of milk mammary gland and other tissues. Biochimica et Biophysica Acta 1241, 407-424.

Peacock M (1991) Calcium absorption efficiency and calcium requirements in children and adolescents. American Journal of Clinical Nutrition 54, 261S-265S

Penn ND, Purkins L, Kelleher J, Heatley RV, MascieTaylor BH \& Belfield PW (1991) The effect of dietary supplementation with vitamins $\mathrm{A}, \mathrm{C}$ and $\mathrm{E}$ on cell-mediated immune function in elderly long-stay patients: a randomized controlled trial. Age and Ageing 20, 169-174.

Perez RV \& Alexander JW (1988) Immune regulation by lipids. Transplantation Proceedings 20, 1162-1165.

Peters DP (1979) Effects of prenatal malnutrition on learning and motivation in rats. Physiology and Behaviour 22, 1067-1070.

Petralanda I, Yarzabal L \& Piessens WF (1988) Parasite antigens are present in breast milk of women infected with Onchocerca volvulus. American Journal of Tropical Medicine and Hygiene 38, 372-379.

Pfeffer SR \& Rothman JE (1987) Biosynthetic protein transport and sorting by the endoplasmic reticulum and Golgi. Annual Review of Biochemistry 56, 829-852.

Philips JA III (1995) Inherited defects in growth hormone synthesis and action. In The Metabolic and Molecular Bases of Inherited Disease, pp. 1965-1983 [CR Scriver, AL Beaudet, WS Sly and D Valle, editors]. New York, NY: McGraw-Hill.

Pietrzik K, Prinz R, Reusch K, Bung P, Mallmann P \& Chronides A (1992) Folate status and pregnancy outcome. Annals of the New York Academy of Sciences 669, 371-373.

Pita ML, Fernández MR, DeLucchi C, Medina A, MartínezValverde A, Uauy R \& Gil A (1988) Changes in fatty acids pattern of red blood cell phospholipids induced by type of milk. Dietary nucleotide supplementation and postnatal age in preterm infants. Journal of Pediatric Gastroenterology and Nutrition 7, 740-747.

Pizzini RP, Kumar S, Kulkami AD, Rudolph FB \& Van Buren CT (1990) Dietary nucleotides reverse malnutrition and starvationinduced immunosuppression. Archives of Surgery 125, 86-90.

Pocock NA, Eisman JA, Hopper JL, Yeates MG, Sambrook PN \& Eberl S (1987) Genetic determinants of bone mass in adults: a twin study. Journal of Clinical Investigation 80, 706-710.

Politt E (1993) Iron deficiency and cognitive function. Annual Review of Nutrition 13, 521-537.

Prasad AS (1995) Zinc: an overview. Nutrition 11, 93-99.

Prentice AM, Cole TJ, Foord FA, Lamb WH \& Whitehead RG (1987) Increased birth weight after prenatal supplementation of rural African women. American Joumal of Clinical Nutrition 46, 912-925.

Price JS, Oyajobi BO \& Russell RGG (1994) The cell biology of bone growth. European Journal of Clinical Nutrition 48, Suppl. 1, S131-S149.

Prieto PA, Mukerji P, Kelder B, Erney R, Gonzales D, Yun JS, Smith DF, Moremen KW, Nardelli C, Pierce M, Li Y, Chen X, Wagner T, Cummings R \& Kopchick JJ (1995) Remodeling of mouse milk glycoconjugates by transgenic expression of a human glycosyltransferase. Journal of Biological Chemistry 270, 29516-29519.

Quan R \& Gray GM (1993) Sucrase- $\alpha$-dextrinase in the rat. Journal of Clinical Investigation 91, 2785-2790.

Rakic $\mathrm{P}$ (1995) Corticogenesis in human and nonhuman primates. In The Cognitive Neurosciences, pp.127-145 [MS Gazzaniga, editor]. Cambridge MA: MIT Press.

Rall LC \& Meydani SN (1993) Vitamin B6 and immune competence. Nutrition Reviews 51, 217-225.

Ramam L, Rajalakshmi K, Krishnamachari KAVR \& Sastry KG (1978) Effect of calcium supplementation to undernourished mothers during pregnancy on the bone density of neonates. American Journal of Clinical Nutrition 21, 466-469.

Rasmussen KM (1992) The influence of maternal nutrition on lactation. Annual Review of Nutrition 12, 103-117.

Ravelli GP, Stein ZA \& Susser MW (1976) Obesity in young men after famine exposure in utero and early infancy. New England Journal of Medicine 295, 349-353.

Reisbick S (1996) Neural development. In Assessment of Infant Visual and Cognitive Function in Relation to Long-chain Poly. unsaturated Fatty Acids, pp.10-18 [S Carlson, M Neuringer and $S$ Reisbick, editors]. Basel: Editiones Roche.

Ribot C, Trémolieres F \& Pouilles JM (1995) Late consequences of a low peak bone mass. Acta Paediatrica Scandinavica 411, 31-35.

Riby J, Fujisawa T \& Kretchmer N (1993) Fructose absorption. American Journal of Clinical Nutrition 58, Suppl., 748S-753S.

Rigo J, Nyamugabo K, De Curtis M \& Senterre J (1996) Bone mineralization during the first year of life. In Recent Developments of Infant Nutrition, pp. 98-111 [JG Bindels, AC Goedhart and HKA Visser, editors]. Dordrecht, Boston and London: Kluwer Academic Publishers.

Ripa S \& Ripa R (1995) Zinc and immune function. Minerva Medica 86, 315-318.

Rodeberg DA, Chaet MS, Bass RC, Arkovitz MS \& Garcia VF 
(1995) Nitric oxide: an overview. American Journal of Surgery 170, 292-303.

Roberts JA, Hill GW \& Propelle AJ (1974) Maternal protein deprivation and toxemia of pregnancy studies in the rhesus monkey (Macacca mulatta). American Journal of Obstetrics and Gynecology 118, 14.

Rosales FJ \& Kjolhede C (1994) A single 210-mumol oral dose of retinol does not enhance the immune response in children with measles. Journal of Nutrition 124, 1604-1614 .

Rosen JM, Li S, Raught B \& Hadsell D (1996) The mammary gland as a bioractor: factor regulating the efficient expression of milk protein-based transgenes. American Journal of Clinical Nutrition 63, 627S-632S.

Rosenzweig MR, Leiman AL \& Breedlove SM (1996) Biological Psychology. Sunderland, MA: Sinauer Association.

Roskelley CD, Srebrow A \& Bissell MJ (1995) A hierarchy of ECM-mediated signalling regulates tissue-specific gene expression. Current Opinion in Cell Biology 7, 736-747.

Rudolph FB (1994) Symposium: dietary nucleotides: a recently demonstrated requirement for cellular development and immune function. Journal of Nutrition 124, 1431S-1432S.

Ruiz-Palacios GM, Cervantes LE, Newburg DS, López-Vidal Y \& Calva JJ (1992) In vitro models for studying campilobacter infections. In Campilobacter Jejuni. Current Status and Future Trends, pp.176-183 [I Nachamkin, MJ Blaser and LS Tomkins, editors]. Washington, DC: American Society of Microbiology.

Saavedra JM, Bauman NA, Oung I, Perman JA \& Yolken RH (1994) Feeding of Bifidobacterium bifidum and Streptococcus thermophilus to infants in hospital for prevention of diarrhoea and shedding of rotavirus. Lancet 344, 1046-1049.

Sabharwal H, Sjoblad S \& Lundblad A (1991) Sialylated oligosaccharides in human milk and feces of preterm, full-term and weaning infants. Journal of Pediatric Gastroenterology and Nutrition 12, 280-284

Sachs L (1996) The control of hematopoiesis and leukemia: from basic biology to the clinic. Proceedings of the National Academy of Sciences USA 93, 4742-4749.

Sánchez-Pozo A, Morillas J, Moltó L, Robles R \& Gil A (1994) Dietary nucleotides influence lipoprotein metabolism in newborn infants. Pediatric Research 35, 112-116.

Sánchez-Pozo A, Ramirez M, Gil A, Maldonado J, Van Biervliet JP \& Rosseneu M (1995) Dietary nucleotides enhance plasma lecithin cholesterol acyl transferase activity and apolipoprotein A-IV concentration in preterm newborn infants. Pediatric Research 37, 328-333.

Sanders EJ \& Wride MA (1995) Programmed cell death in development. International Review of Cytology 163, 105-173.

Sanderson IR \& He Y (1994) Nucleotide uptake and metabolism by intestinal epithelial cells. Journal of Nutrition 124, 131S-137S.

Sato G, Pardee A \& Sirbasku D (1982) Growth of cells in hormonally defined media. Cold Spring Harbor Conference on Cell Proliferation 9. New York: Cold Spring Harbor Laboratory.

Sauerwald TU, Hachey DL, Jensen CL \& Heird WC (1997) New insights into the metabolism of long-chain polyunsaturated fatty acids during infancy. European Journal of Medical Research 2, 88-92.

Savaiano DA \& Clifford AJ (1981) Adenine, the precursor of nucleic acids in intestinal cells, is unable to synthesize purines de novo. Journal of Nutrition 111, 1816-1822.

Savilahti E, Tainio VM, Salmenperä L, Siimes MA \& Perheentupa J (1987) Prolonged exclusive breast feeding and heredity as determinants in infantile atopy. Archives of Disease in Childhood 62, 269-273.

Sazawal S, Bentley M, Black RE, Dhingra P, George S \& Bhan MK (1996) Effect of zinc supplementation on observed activity in low socioeconomic Indian preschool children. Pediatrics 98, 1132-1137.
Sazawal S, Black RE, Bhan MK, Jalla S, Bhandari N, Sinha A \& Majumdar S (1996) Zinc supplementation reduces the incidence of persistent diarrhea and dysentery among low socioeconomic children in India. Journal of Nutrition, 126, 443-450.

Schiffrin EJ, Rochat F, Link Amster H, Aeschlimann JM \& Donnet Hughes A (1995) Immunomodulation of human blood cells following the ingestion of lactic acid bacteria. Joumal of Dairy Science 78, 491-497.

Scholl TO \& Hediger ML (1994) Anemia and iron-deficiency anemia: compilation of data on pregnancy outcome. American Journal of Clinical Nutrition 59, Suppl., 492S-501S.

Schoonjans K, Staels B \& Auwerx J (1996) Role of the peroxisome proliferator-activated receptor (PPAR) in mediating the effects of fibrates and fatty acids on gene expression. Journal of Lipid Research 37, 907-925.

Schroten H, Plogmann R, Hanisch FG, Hacker J, Nobis-Bosch R \& Wahn V (1993) Inhibition of adhesion of S-fimbriated E. coli to buccal epithelial cells by human skim milk is predominantly mediated by mucins and depends on the period of lactation. Acta Paediatrica 82, 6-11.

Schwartz GG (1992) Multiple sclerosis and prostate cancer: what do their similar geographies suggest? Neuroepidemiology 11, 244-254.

Scientific Committee for Food with the assistance of Aggett PJ, Arnal PJ, Arnal M, Bender D, Buss D, Christiansen C, Garabedian M, Grossklaus R, Hallberg L, Hermus R, Koletzko B, Pitt G, Schriver J \& Scott J (1993) Nutrient and Energy Intakes for the European Community. Reports of the Scientific Committee for Food (31st series). Luxembourg: Office of Official Publications of the European Communities.

Scriver CR (1991) Phenylketonuria - genotypes and phenotypes. New England Journal of Medicine 324, 1280-1281.

Scriver CR, Byck S, Prevost L \& Hoang L (1996) The phenylalanine hydroxylase locus: a marker for the history of phenylketonuria and human genetic diversity. $P A H$ Mutation Analysis Consortium. Ciba Foundation Symposium 197, 73-90.

Scriver CR \& Clow CL (1980) Phenylketonuria: epitome of human biochemical genetics. New England Journal of Medicine 303, 1336-1342.

Secher NJ \& Olsen SF (1990) Fish oil and preeclampsia. British Journal of Obstetrics and Gynaecology 97, 1077-1079.

Sei Y, Vitkovic L \& Yokoyama MM (1995) Cytokines in the central nervous system: regulatory roles in neuronal function, cell death and repair. Neuroimmunomodulation 2, 121-133.

Seidman E, LeLeiko N, Ament M, Berman W, Caplan D, Evans J, Kocoshis S, Lake A, Motil K \& Sutphen J (1991) Nutritional issues in pediatric inflammatory bowel disease. Journal of Pediatric Gastroenterology and Nutrition 12, 424-438.

Semba RD (1996) Linking vitamin A and childhood immunizations. Journal of Nutritional Immunology 4, 87-109.

Semba RD, Munasir Z, Beeler J, Akib A, Muhilal, Audet S \& Sommer A (1995) Reduced seroconversion to measles in infants given vitamin $\mathrm{A}$ with measles vaccination [see comments]. Lancet 345, 1330-1332.

Senkal M, Kemen M, Homann HH, Eickhoff U, Baier J \& Zumtobel V (1995) Modulation of postoperative immune response by enteral nutrition with a diet enriched with arginine, RNA, and omega-3 fatty acids in patients with upper gastrointestinal cancer. European Journal of Surgery, Acta Chirurgica $161,115-122$.

Shaw NJ \& Bishop NJ (1995) Mineral accretion in growing bones - a framework for the future? Archives of Disease in Childhood 72, $177-179$.

Sheard NF (1994) Iron deficiency and infant development. Nutrition Reviews 52, 137-140.

Sherman AR (1992) Zinc, copper, and iron nutriture and immunity. Journal of Nutrition 122, 604-609. 
Shiner M, Nichols VN, Barrish JP \& Nichols BL (1990) Pathogenesis of small-intestinal mucosal lesions in chronic diarrhea of infancy: II. An electron microscopic study. Journal of Pediatric Gastroenterology and Nutrition 11, 464-480.

Shor Posner G, Miguez Burbano MJ, Lu Y, Feaster D, Fletcher M, Sauberlich H \& Baum MK (1995) Elevated IgE level in relationship to nutritional status and immune parameters in early human immunodeficiency virus-1 disease. Journal of Allergy and Clinical Immunology 95, 886-892.

Sibai BM, Villar MA, Bray E (1989) Magnesium supplementation during pregnancy: a double blind randomized controlled clinical trial. American Journal of Obstetrics and Gynecology 161, 115.

Sigurs N, Hattevig G \& Kjellman B (1992) Maternal avoidance of eggs, cow's milk, and fish during lactation: effect on allergic manifestations, skin-prick tests, and specific IgE antibodies in children at age 4 years. Pediatrics 89, 735-739.

Sikorski R, Juszkiewicz T \& Paszkowski T (1990) Zinc status in women with premature rupture of membranes at term. Obstetrics and Gynecology 76, 675 .

Sjöström H, Norén O, Christiansen L, Wacker H \& Semenza G (1980) A fully active, two-active site, single-chain sucraseisomaltase from pig small intestine. Implications for the biosynthesis of a mammalian integral stalked membrane protein. Journal of Biological Chemistry 255, 11332-11338.

Sjöström H, Norén O, Danielsen EM \& Skovbjerg H (1983) Structure of microvillar enzymes in different phases of their life cycles. In Brush Border Membranes, Ciba Foundation Symposium 95, pp. 50-72 [R Porter and GM Collins, editors]. London: Pitman Books.

Slosman DO, Rizzoli R \& Bonjour J-Ph (1995) Bone absorptiometry: a critical appraisal of various methods. Acta Paediatrica 411, Suppl., 9-11.

Smart JL (1974) Activity and exploratory behavior of adult offspring of undernourished mother rats. Developmental Psychobiology 7, 315-321.

Spatling L \& Spatling G (1988) Magnesium supplementation in pregnancy: a double-blind study. British Journal of Obstetrics and Gynaecology 95, 120-125.

Speck R \& Lauterburg B (1991) Fish oil protects mice against acetaminophen hepatotoxicity in vivo. Hepatology 13, $557-561$

Spencer TD, Keen RW, Arden NK, Morrison NA, Major PJ, Nguyen TV, Kelly PJ, Baker JR, Sambrook PN \& Lanchbury JS (1995) Influence of vitamin D receptor genotype on bone mineral density in postmenopausal women: a twin study in Britain. British Medical Journal 310, 1357-1360.

Stabell C, Bale C, Pedro Da Silva AP \& Aaby P (1995) No evidence of fontanelle-bulging episodes after vitamin A supplementation of 6- and 9-month-old infants in Guinea Bissau. European Journal of Clinical Nutrition 49, 73-74.

Stanbury JB (editor) (1994) The Damaged Brain of Iodine Deficiency: Cognitive, Behavioral, Neuromotor, and Educative Aspects. Elmsford, NY: Cogniznat Communication.

Stansbridge EM, Walker V, Hall MA, Millar MR, Bacon C \& Chen $S$ (1993) Effects of feeding premature infants with Lactobacillus GG on gut fermentation. Archives of Disease in Childhood 69, $488-492$.

Steegers-Theunissen RPM, Boers GHJ, Trijbels FJM \& Eskes TKAB (1991) Neural tube defects and derangement of homocysteine metabolism. New England Journal of Medicine 324, 199-200.

Stephens S (1986) Development of secretory immunity in breast fed and bottle fed infants. Archives of Disease in Childhood 61, 263-269.

Stephens S, Brenner MK, Duffy SW, Lakhani PK, Kennedy CR \& Farrant J (1986a) The effect of breast-feeding on proliferation by infant lymphocytes in vitro. Pediatric Research 20, 227 231

Stephens S, Duffy SW \& Page C (1986b) A longitudinal study of gamma-interferon production by peripheral blood mononuclear cells from breast- and bottle-fed infants. Clinical and Experimental Immunology 65, 396-400.

Stoch MB, Smythe PM, Moodie AD \& Bradshaw O (1982) Psychosocial outcome and CT findings after gross undernourishment during infancy: a 20-year developmental study. Developmental Medicine and Child Neurology 24, 419-436.

Stowell KM, Rado TA, Funk WD \& Tweedie JW (1991) Expression of cloned human lactoferrin in baby hamster kidney cells. Biochemical Journal 276, 349-355.

Strbak V (1991) Hormones and bioactive substances in milk. Endocrine Regulation 25, 3-143.

Suarez A, Faus MJ \& Gil A (1996a) Dietary long-chain polyunsaturated fatty acids modify heart, kidney, and lung fatty acid composition in weanling rats. Lipids 31, 345-348.

Suarez A, Faus MJ \& Gil A (1996b) Dietary supplementation with long-chain polyunsaturated fatty acids increases susceptibility of weanling rat tissue lipids to in vitro lipid peroxidation. Journal of Nutritional Biochemistry 7, 252-260.

Suzuki H, Menegazzi M, Carcereri de Prati A, Mariotto S \& Armato U (1995) Nitric oxide in the liver: physiopathological roles. Advances in Neuroimmunology 5, 379-410.

Tanaka M, Lee K, Martínez-Augustin O, He Y, Sanderson IA \& Walker W (1996) Exogenous nucleotides alter the proliferation, differentiation and apoptosis of human small intestinal epithelium. Journal of Nutrition 126, 424-433.

Taylor EM \& Morgan EH (1990) Developmental changes in transferrin and iron uptake by the brain in the rat. Developmental Brain Research 55, 35-42.

Tengerdy RP (1990) The role of vitamin $E$ in immune response and disease resistance. Annals of the New York Academy of Sciences 587, 24-33.

Thépot D, Devinoy E, Fontaine ML, Stinnakre MG, Massoud M, Kann G \& Houdébine LM (1995) Rabbit whey acidic protein gene upstream region controls high-level expression of bovine growth hormone in the mammary gland of transgenic mice. Molecular Reproduction and Development 42, 261-267.

Thomasset M (1994) Vitamine $\mathrm{D}$ et système immunitaire (Vitamin D and immune system). Pathologie Biologie $\mathbf{4 2}$, $163-172$.

Tixier-Vidal A, Picart R, Loudes C \& Bauman AF (1986) Effects of polyunsaturated fatty acids and hormones on synaptogenesis in serum-free medium cultures of mouse fetal hypothalamic cells. Neuroscience 17, 115-132.

Torre PM, Ronnenberg AG, Hartman WJ \& Prior RL (1993) Oral arginine supplementation does not affect lymphocyte proliferation during endotoxin-induced inflammation in rats. Journal of Nutrition, 123, 481-488.

Trivedi P, Risteli J, Risteli L, Hindmarsh PC, Brook CG \& Mowat AP (1991) Serum concentration of the type I and III procollagen propeptides as biochemical markers of growth velocity in healthy infants and children and in children with growth disorders. Pediatric Research 30, 276-280.

Troncone R, Scarcella A, Donatiello A, Cannataro P, Tarabuson A \& Auricchio S (1987) Passage of gliadin into human breast milk. Acta Paediatrica Scandinavica 76, 453-456.

Uauy R, Birch DG, Birch EE, Tyson JE \& Hoffman DR (1990) Effect of dietary omega-3 fatty acids on retinal function of verylow-birth-weight neonates. Pediatric Research 28, 485-492.

Uauy R, Quan R \& Gil A (1994) Role of nucleotides in intestinal development and repair: implications for infant nutrition. Journal of Nutrition 124, 1436S-1441S.

Uauy R, Stringel G, Thomas R \& Quan R (1990) Effect of dietary 
nucleosides on growth and maturation of the developing gut in the rat. Journal of Pediatric Gastroenterology and Nutrition 4, 497-503.

Vaarala O, Klemetti P, Savilahti E, Reijonen H, Ilonen J \& Akerblom HK (1996) Cellular immune response to cow's milk beta-lactoglobulin in patients with newly diagnosed IDDM. Diabetes 45, 178-182.

Van Buren CT, Kulkarni AD, Fanslow WC \& Rudolph FB (1985) Dietary nucleotides: a requirement for helper/inducer $\mathrm{T}$ lymphocytes. Transplantation 40, 694-697.

Van Buren CT, Kulkarni AD, Schandle VB \& Rudolph FB (1983) The influence of dietary nucleotide on cell-mediated immunity. Transplantation 36, 350-352.

Vandenplas Y, Hauser B, Van Den Borre C, Clybouw C, Mahler T, Hachimildrissi S, Deraeve L, Malfroot A \& Dab I (1995) The long-term effect of a partial whey hydrolysate formula on the prophylaxis of atopic disease. European Journal of Pediatrics 154, 488-494.

Vandenplas Y, Hauser B, Van den Borre C, Sacre L \& Dab I (1992) Effect of a whey hydrolysate on the prophylaxis of atopic disease. Annals of Allergy 68, 419-424.

Vaulont S \& Kahn A (1994) Transcriptional control of metabolic regulation of genes by carbohydrates. FASEB Journal 8, 28 35 .

Vaux DL \& Strasser A (1996) The molecular biology of apoptosis. Proceedings of the National Academy of Sciences USA 93, 2239-2244.

Vermeer C, Gijsbers BL, Craciun AM, Groenen Van Dooren MM \& Knapen MH (1996) Effects of vitamin K on bone mass and bone metabolism. Journal of Nutrition 126, 1187S$1191 \mathrm{~S}$.

Villar J, Repke J, Belizan JM \& Pareja G (1987) Calcium supplementation reduces blood pressure during pregnancy: results of a randomized controlled clinical trial. Obstetrics and Gynecology 70, 317-322.

Virtanen SM, Räsänen L, Aro A, Lindström J, Sippola H, Lounamaa R, Toivanen L, Tuomilehto J \& Akerblom HK (1991) Infant feeding in Finnish children $<7 \mathrm{yr}$ of age with newly diagnosed IDDM. Diabetes Care 14, 415-417.

Viverge D, Grimmonprez L, Cassanas G, Bardet L \& Solere M (1990) Variations in oligosaccharides and lactose in human milk during the first week of lactation. Journal of Pediatric Gastroenterology and Nutrition 11, 361-364.

Wainwright PE (1993) Lipids and behaviour: the evidence from animal models. In Lipids, Learning and the Brain: Fats in Infant Formulas. Report of the $103^{\text {rd }}$ Ross Conference on Pediatric Research, pp. 69-101 [J Dobbing, editor]. Columbus OH: Ross Laboratories.

Wainwright PE (1997) Essential fatty acids and behavior: is there a role for the eicosanoids. In Handbook of Essential Fatty Acid Biology. Biochemistry, Physiology and Behavioral Neurobiology, pp. 299-341 [S Yehuda and DI Mostofsky, editors]. Totowa, NJ: Humana Press.

Walsh MJ, Sánchez-Pozo A \& LeLeiko NS (1990) A regulatory element is characterized by purine-mediated and cell type specific gene transcription. Molecular Cell Biology 10, 4356-4364.

Walsh MJ, Tsao KL \& LeLeiko NS (1992) Characterization of DNA-protein interactions within a distal regulatory element upstream of a mammalian housekeeping gene promoter. Journal of Biological Chemistry 267, 7026-7035.

Walsh CT, Sandstead HH, Prasad AS, Newberne PM \& Fraker PJ (1994) Zinc: health effects and research priorities for the 1990s. Environmental Health Perspectives 2, 5-46.

Wang X, Sato R, Brown MS, Hua X \& Goldstein JL (1994) SREBP-1, a membrane bound transcription factor released by sterol-regulated proteolysis. Cell 77, 53-62.
Ward PP, Lo JY, Duke M, May GS, Headon DR \& Conneely OM (1992b) Production of biologically active recombinant human lactoferrin in Aspergillus oryzae. BioTechnology 10, 784-789.

Ward PP, May GS, Headon DR \& Conneely OM (1992b) An inducible expression system for the production of human lactoferrin in Aspergillus nidulans. Gene 122, 219-223.

Warner JO (1980) Food allergy in fully breast fed infants. Clinical Allergy 10, 133-136.

Watanabe S, Sakai N, Yasui Y, Kimura Y, Kobayashi T, Mizutani T \& Okuyama H (1994) A high alpha-linolenate diet suppresses antigen-induced immunoglobulin $\mathrm{E}$ response and anaphylactic shock in mice. Journal of Nutrition 124, 15661573.

Watson JD, Hopkins NH, Roberts JW, Steitz JA \& Weiner AM (1987) Molecular Biology of the Gene, 4th ed. Menlo Park, CA: The Benjamin/Cummings Publishing Co.

Wells JL, James DK, Luxton R \& Pennock CA (1987) Maternal leukocyte zinc deficiency at start of third trimester as a predictor of fetal growth retardation. British Medical Journal 294, 1054.

Welply JK, Keene JL, Schmuke JJ \& Howard SC (1994) Selectins as potential targets of therapeutic intervention in inflammatory diseases. Biochimica et Biophysica Acta 1197, 215-226.

Welsh AO (1993) Uterine cell death during implantation and early placentation. Microscopy Research and Technique 25, 223-245.

Widdowson EM (1982) Importance of nutrition in development with special reference to feeding low-birth weight infants. In Meeting Nutritional Goals for Low Birth Weight Infants. Proceedings of the 2nd Ross Clinical Research Conference, pp. 4-11 [HS Sauls, WL Bachuber and LA Lewis, editors]. Columbus, $\mathrm{OH}$ : Ross Laboratories.

Williams C, Highley W, Ma EH, Lewis J, Tolbert B, Woullard D, Kirmani S \& Chung RA (1981) Protein, amino acid and caloric intakes of selected pregnant women. Journal of the American Dietetics Association 78, 28-35.

Winick M (1970) Fetal malnutrition. Clinical Obstetrics and Gynecology 13, 526 .

World Health Organization (1993) Global Prevalence of Iodine Deficiency Disorders. MDIS Working Paper no. 1. Geneva: WHO.

Worthington-Roberts B (1985) Nutritional deficiencies and excesses: impact on pregnancy, part 2. Journal of Perinatology $5,12$.

Wride MA \& Sanders EJ (1995) Potential roles for tumour necrosis factor alpha during embryonic development. Anatomy and Embryology, Berlin 191, 1-10.

Xue-Yi C, Xin-Min J, Zhi-Hong D, Rakeman MA, Ming-Li Z, O'Donnell K, Tai M, Amette K, DeLong N \& DeLong R (1994) Timing of vulnerability of the brain to iodine deficiency. New England Journal of Medicine 331, 1739-1744.

Yetiv JZ (1988) Clinical applications of fish oils [see comments]. Journal of the American Medical Association 260 , 665-670.

Zakeri Z \& Lockshin RA (1994) Physiological cell death during development and its relationship to aging. Annals of the New York Academy of Sciences 719, 212-229.

Zeiger RS \& Heller S (1995) The development and prediction of atopy in high-risk children: follow-up at age seven years in a prospective randomized study of combined maternal and infant food allergen avoidance. Journal of Allergy Clinical Immunology 95, 1179-1190.

Zeiger RS, Heller S, Mellon MH, Forsythe AB, O'Connor RD, Hamburger RN \& Schatz M (1989) Effect of combined maternal and infant food-allergen avoidance on development of atopy in early infancy: a randomized study [published 
erratum appears in Journal of Allergy and Clinical Immunology (1989) 84 (5 Pt 1), 677]. Journal of Allergy and Clinical Immunology 84, 72-89.

Zeiger RS, Heller S, Mellon MH, Halsey JF, Hamburger RN \&
Sampson HA (1992) Genetic and environmental factors affecting the development of atopy through age 4 in children of atopic parents: a prospective, randomized study of food allergen avoidance. Pediatric Allergy and Immunology 3, 110-127. 